Journal of the Scientific Agricultural Society of Finland Vol. 45: $121-2151973$

Maataloustieteellinen Aikakauskirja

\title{
SULPHUR STATUS IN FINNISH CULTIVATED SOILS
}

Selostus: Suomen viljelysmaiden rikkitila

J OHAN KORKMAN

Department of Agricultural Chemistry, University of Helsinki

ACADEMIC DISSERTATION

TO BE PRESENTED, WITH THE PERMISSION OF THE FACUlty of Agriculture and Forestry OF THE UNIVERSITY OF HELSINKI, FOR PUBLIC Criticism in AUditorium XII on May 16, 1973, AT 12 o'CLOCK 


\section{Preface}

This study was carried out at the Department of Agricultural Chemistry, University of Helsinki. I owe a debt of gratitude to my teacher, Professor Armi KaIla, Head of the Department, for the support she gave me in my work over a long period of time.

It is my pleasure to thank Professors Viljo PuUstjärvi and Helge Gyllenberg for checking my work and giving me valuable, constructive criticism.

The field experiments were established in cooperation with Dr. PAAvo Elonen and Dr. Osmo KARA in southern Finland and with VELI TuomikoskI, M. Sc., in northern Finland. I wish to thank these colleagues for their productive cooperation.

The translation of the Swedish manuscript into English was made by a working team consisting of Karl-Johan Ahlsved, B. Sc., Paul Erlewein and Martyn Summerhill. The Finnish summary was checked by Dr. ANTTI JAAккоL. I want to express my appreciation for their work.

In the practical laboratory work I was assisted in a praiseworthy manner by Miss OrLI TANSKa during the whole study.

I have received financial aid for this study from the Rikkihappo Oy:n tutkimussäätiō (Research Foundation of Rikkihappo L.td). During the period Sept. 1971 - Dec. 1972 I was exclusively making research work on the strength of these grants-in-aid. The translation was aided by the Svenska Vetenskapliga Centralrådet (Swedish Scientific Central Board in Finland). A travel grant from the Agronomien Yhdistys (Finnish Association of Agricultural Graduates) made it possible for me to visit research institutes in the Nordic Countries in 1969. Among all persons I met during my trip, I especially wish to thank Professor M. ØDELIEN at NLH, Norway, for his valuable advice.

Finally, I am grateful to the Scientific Agricultural Society of Finland for accepting my paper for inclusion in its series of publications.

Helsinki, March 1973

Johan Korkman 



\section{CONTENTS}

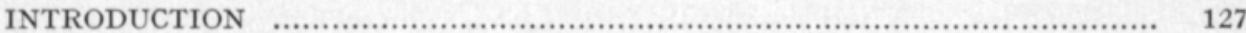

Sulphur research in plant husbandry and soil science …................................. 128

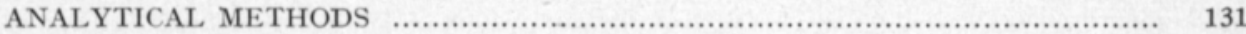

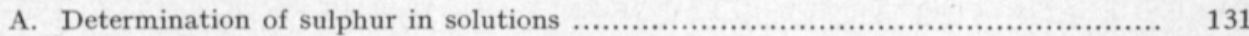

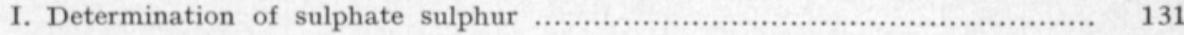

a. Gravimetric determination of sulphate sulphur …............................. 132

Procedure of analysis .............................................................. 132

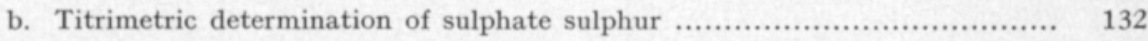

1. Procedure of analysis ........................................................... 133

2. Reliability of method …................................................ 133

c. Turbidimetric determination of sulphate sulphur ................................. 135

1. Procedure of analysis ........................................................ 135

2. Reliability of method ......................................................... 135

II. Determination of sulphide sulphur ……............................................ 136

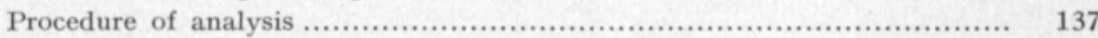

B. Analytical methods for soil and plant samples ......................................... 137

I. Pretreatment in laboratory ............................................................ 137

II. Determination of the total suphur in soil and plant samples ......................... 138

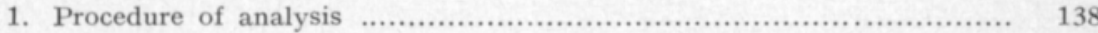

2. Reliability of method …...................................................... 140

III. Determination of elemental sulphur in soil …..................................... 142

1. Procedure of analysis ............................................................. 142

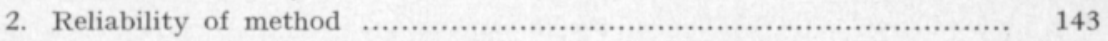

IV. Determination of various criteria of soil sulphur available to plants .............. 143

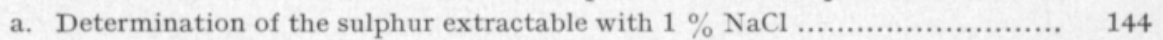

1. Procedure of analysis ............................................................ 144

2. Reliability of method ......................................................... 144

b. Determination of the sulphur extractable with $0.03 \mathrm{M} \mathrm{NaH}_{2} \mathrm{PO}_{4} \cdot 2 \mathrm{H}_{2} \mathrm{O}$ in a $2 \mathrm{~N}$

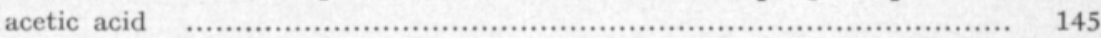

1. Procedure of analysis …........................................................ 145

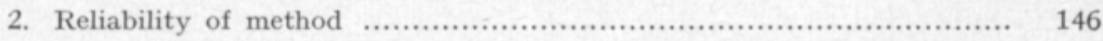

c. Determination of the sulphur extractable with ammonium acetate of

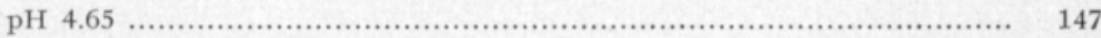

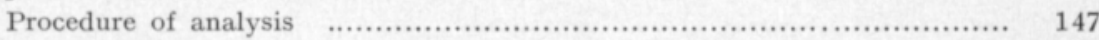

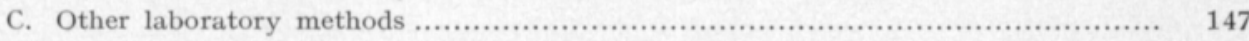

SULPHUR BALANCE OF THE SOIL …….......................................... 149

A. Sulphur emission into the atmosphere …............................................... 149

B. The absorption of atmospheric sulphur into the soil …............................. 152

C. The sulphur in the precipitation ............................................................. 153

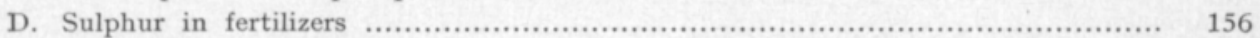

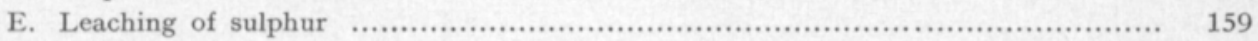

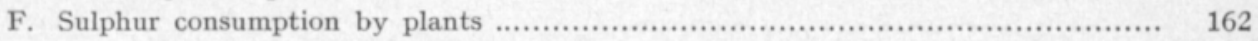




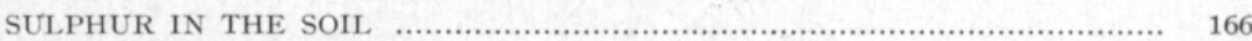

A. Chemical survey of the sulphur situation in cultivated soils in Finland ................... 167

I. Series of soil samples providing the basis of the survey ......................... 167

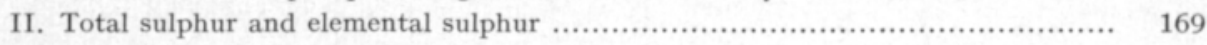

III. Chemical criteria for sulphur available to plants .............................. 173

a. Sulphur extractable with $\mathrm{NaCl}, \mathrm{NaH}_{2} \mathrm{PO}_{4}-\mathrm{CH}_{3} \mathrm{COOH}$ and $\mathrm{CH}_{3} \mathrm{COONH}_{4} \quad 173$

b. Mobilization and immobilization of extractable sulphur at incubation under

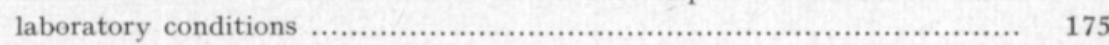

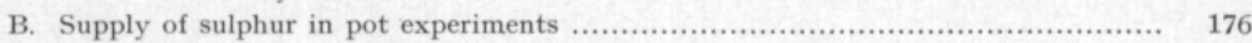

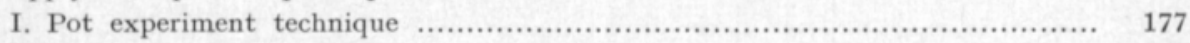

II. Yields and their dependency on the characteristics of the soil ................... 178

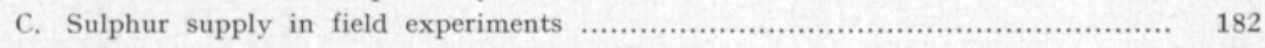

I. Experimental results from North Finland .................................... 182

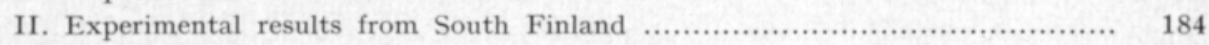

D. Comparison between field and pot experiments .................................. 188

DEPENDENCE OF THE AVAILABILITY OF SULPHUR TO THE PLANTS

UPON THE SUPPLY OF CERTAIN OTHER NUTRIENTS . . ......................... 190

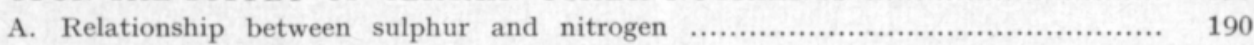

I. Physiological effect of ammonium nitrogen and nitrate nitrogen on the sulphur

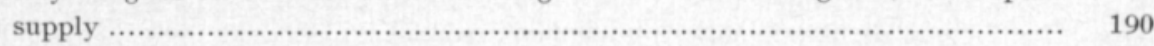

II. Dependence of yield upon the N/S ratio of the substrate ............................ 192

B. Pot experiment with sulphur and phosphorus as variables ............................. 197

C. Pot experiment with sulphur and molybdenum as variables .......................... 199

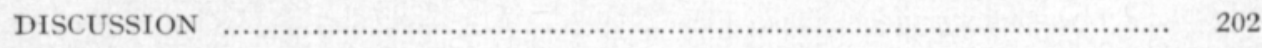

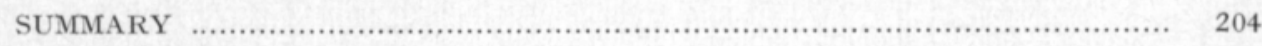

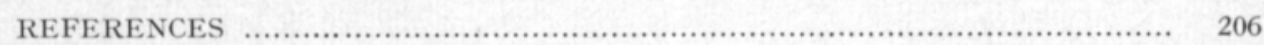

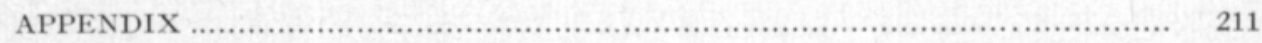

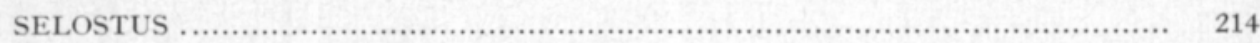




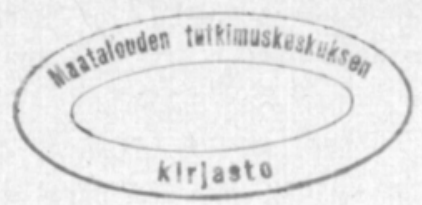

Korkman, J. 1973. Sulphur status in Finnish cultivated soils. J. Scient. Agric. ${ }^{-S o c}$. Finl, 45: 121-215.

Abstract. A method for determining total sulphur in plant material and soil samples using the induction furnace technique and subsequent turbidimetric determination of sulphate sulphur was discussed. A procedure for extracting sulphur from soil samples with ammonium acetate ( $\mathrm{pH} 4.65)$, the interference of the organic matter being reduced by oxidation of the extract with $\mathrm{H}_{2} \mathrm{O}_{2}$, was proposed.

Sulphur balance in Finnish cultivated soils was estimated by taking into account the average amounts of emitted ( $8 \mathrm{~kg} \mathrm{~S} / \mathrm{ha} / \mathrm{yr}$.), precipitated $(8 \mathrm{~kg} \mathrm{~S} / \mathrm{ha} / \mathrm{yr}$.) and leached $(8 \mathrm{~kg} \mathrm{~S} / \mathrm{ha} / \mathrm{yr}$.) sulphur. The actual situation in the cultivated soils seems thus to be depending, on an average, on the uptake by plants and the sulphur applied $(12 \mathrm{~kg} \mathrm{~S} / \mathrm{ha} / \mathrm{yr}$. in the early $1970 \mathrm{~s})$.

In 104 samples of cultivated soil, the content of total sulphur showed a slight correlation with the content of organic carbon. The amounts of sulphur extracted in various ways were not predictable by means of the soil characteristics used $\left(\mathrm{pH}_{\mathrm{CaCl}_{2}}\right.$, org. $\mathrm{C}$ and texture). Extracted sulphur did not correlate sufficiently with the development and sulphur uptake of plants.

Under field conditions in northern Finland, sulphur application produced a relatively distinct result in respect both to the ley yields on Carex peat, and their sulphur content. On mineral soils in southern Finland the yields were unaffected by supplementary fertilization with sulphur. In the pot experiments performed a fairly close relationship between sulphur and nitrogen was demonstrated.

\section{Introduction}

Sulphur is essential to plant development. The sulphur supply situation of cultivated plants in Finland is examined in the present work.

A thorough study of methods is necessary on account of the absence of analytic methods sufficiently tested in Finland, particularly in respect of soil analysis. However, the reported methods are of a provisional character insofar as they concern the sulphur in cultivated soil available to plants, and further investigations are required in order that the methods may provide results that are reliable and more easily interpreted.

The considerable supplement that plants and soil obtain from the atmosphere and from precipitation is a significant feature of the sulphur economy. Within the scope of the present work it will consequently be necessary to estimate the amount of sulphur supplied in this manner. Impoverishment of the sulphur 
supply in the soil through leaching also contributes towards making the sulphur situation in the soil more unstable than is the case with most other plant nutrients.

Sufficient information about the sulphur contents of cultivated soils in Finland did not exist, and an inventory was consequently made in the present study with the intention of providing a preliminary notion of the sulphur contents of these soils and the solubility of the sulphur. The importance to cultivated plants of this solubility is investigated by comparing the results of the chemical analysis with sulphur uptakes in pot experiments. The uptake of sulphur in ley and cereal was investigated in a few field experiments.

The need of an investigation of the type envisaged in this work arises out of an essential change in the fertilization practices which has taken place since the beginning of the 1960 s. During the whole of that period in which superphosphate was the dominant phosphorus fertilizer and also was used as the phosphorus component in the NPK fertilizers, soils received large amounts of sulphur in connection with the phosphorus fertilization, for superphosphate contains some 12 per cent of sulphur in the form of gypsum. The switch to NPK fertilizers based on phosphoric acid, with a consequent sharp decline in the use of sulphur and a concurrent sharp increase in fertilization with nitrogen, phosphorus and potassium, has caused a complete change in the situation in a few years. It is of interest at the present stage to discover how low the use of sulphur may be allowed to fall in relation to the use of other nutrients before the shortage of sulphur limits the yield.

\section{Sulphur research in plant husbandry and soil science}

The use of gypsum $\left(\mathrm{CaSO}_{4} \cdot 2 \mathrm{H}_{2} \mathrm{O}\right)$ as a fertilizer has very old traditions. Its use has apparently been long known in China, and Pliny (Honcamp 1931, p. 5) mentions that gypsum was a substance that the Romans employed for improvement of the soil. The first actual field experiment with results saved for posterity was one performed by MAYER at Kupferzel in Switzerland in 1768 (Alway 1940). Field experiments with gypsum were also carried out in the United States of America. Benjamin Franklin initiated a famous experiment in which, along a road leading to Washington, D.C., gypsum was spread out on a field so as to form the words "This has been plastered". Some time later passers-by could read this text clearly in the form of a rich growth. The agricultural chemists of that day did not quite know what the effect of gypsum depended upon (ØDELIEN 1957), and sulphur research was to experience a number of vicissitudes.

Sulphur was referred to as an indispensable plant nutrient as early as the middle of last century, by Justus von LIEBIG in his classical work on the use of chemistry in agriculture (1862, p. 86). Liebig's view was largely based upon results of plant analyses and observations on plant and animal physiology. Sulphur research experienced a period of success at the end of the 19th century and very beginning of the 20th century, when encouraging results were reported concerning experimental cultivations with a great number of plants of various 
species (Bogdanov 1899, Duley 1916, Ames and Boltz 1919). Sulphur fertilization appears to have produced a particularly great increment in yield in those cases in which organic residuals such as blood meal and cattle manure were coincidently applied to the soil (VERMOREL and DANTHONY 1913).

The use of sulphur fertilizers such as gypsum $\left(\mathrm{CaSO}_{4} \cdot 2 \mathrm{H}_{2} \mathrm{O}\right)$ and flowers of sulphur $\left(\mathrm{S}_{8}\right)$ experienced a sharp increase in commercial farming during that time. In Norway, for instance, 7.4 times as much sulphur as nitrogen was added to the soil with artificial fertilizers in 1908 (ØDELIEN 1970). It soon became obvious, however, that yields could not continually be increased with sulphur alone, without the simultaneous addition of other nutrients too (FIANNETTO 1912). The dominant position of superphosphate among the fertilizers made the secondary use of sulphur fairly great also.

By means of a pot experiment the Japanese DaIkuHaRa (1907) had already shown that the concentrations of sulphate sulphur which are required in the soil in order that plants might develop normally are rather small. In many experiments the yield increase produced with sulphur fertilization was low, and some research workers doubted whether it was expedient to employ sulphur at all (SöDERBAum 1919).

The indirect effects of the sulphur doses in the soil then began to attract attention. Sulphur seemed to increase the availability of phosphorus in the soil, at least in soils rich in lime (Lipman et al. 1916, Tottingham and Hart 1921, Chapman 1936). Sulphur addition increased the mineralization of nitrogen from organic material (ScotT and RoBERTSon 1926). There was an increase in the weathering of minerals, and potassium (SHEDD 1926) and also magnesium (Scott and Robertson 1926) were released. Micronutrients are frequently fixed in forms not easily available to plants when the soil is highly alkaline. It is consequently possible to correct a disturbed balance of micronutrients in soils rich in lime by adding substances with acid reaction such as flowers of sulphur. A certain flocculation of colloidal soil particles seemed to be of benefit to the soil structure (ScotT and RoBERTSON 1926).

Lyon and Bizzell (1918, pp. 72-78) devoted attention long ago to the relatively high mobility of the sulphate ion in the soil. By means of lysimeter experiments these research workers (Lyon and Bizzell 1936, pp. 21-22) found that in humid conditions leaching was a far bigger factor in the consumption of sulphur than was the uptake by plants. The vegetation and the lime situation were found to have a certain effect on the leaching propensity.

It was realized that a considerable fallout of sulphurous matter occurred along with precipitation (ERDMAn 1922, Johnson 1925, Wilson 1926, Vincent et al. 1935). The stated amounts of sulphate sulphur must be regarded as being relatively great even today. ERDMAN (1922) estimates the annual sulphur quantity in precipitation to have been about $17 \mathrm{~kg} / \mathrm{ha}$ in the Iowa countryside in the early years of the 1920 s. On average the fallout is probably not greater in the countryside today. Other data, too, indicate a rather intensive emission of sulphur dioxide into the atmosphere. A comparison with more recent results of analysis is difficult, however, on account of changes in laboratory and sampling techniques. Alway, Marsh and Methley (1937) warn against the risk of contamination which exists when use is made of ordinary galvanized rain gauges. 
It was also demonstrated that both plant and soil were able to absorb sulphur dioxide directly from the air (ALwAy et al. 1937).

Sulphur research today still proceeds from the fixed points referred to above. There has been a considerable development in the research equipment, in the purely analytical as well as the mathematical, but the basic problems of the sulphur economy of the plant and the sulphur balance of the soil remain the same. Although more than 1500 scientific articles dealing with sulphur from an agricultural viewpoint are mentioned in available bibliographies, the research input in this area is relatively speaking rather modest. The small and uncertain yield increments produced through sulphur fertilization in experiments during the 1920 s and 1930 s and later must have contributed to making interest rather lame. 


\section{Analytical methods}

The determination of sulphur in soil and plant material received most of the analytical interest in the present work. Every method in these cases has been the subject of some form of study of the method of analysis before being approved for use on an extensive scale. The other characteristics of the plant material and soil samples were generally determined in accordance with instructions in the literature and are consequently described in main outline only.

The determination of sulphur in soil and plants is often regarded as being laborious and difficult analytical work. There are two reasons for this state of things. First, the isolation and conversion of the sulphur fraction into a determinable form is usually time-consuming and may lead to losses of sulphur. Second, the determination of the converted and isolated fraction is laborious when conventional methods are employed. The analysis is often susceptible to disturbances when the determined concentrations are low.

\section{A. Determination of sulphur in solutions}

The sulphur can be determined in a great number of ways, many of which have been employed for different purposes. This is because none of the existing methods is definitely superior to the others in terms of sensitivity, reproducibility or facility. In the great majority of the current methods the sulphur is first converted into sulphate $\left(\mathrm{SO}_{4}{ }^{-}\right)$or sulphide $\left(\mathrm{S}^{-}\right)$form.

\section{Determination of sulphate sulphur}

Relatively large amounts of sulphate sulphur are often most reliably determined by gravimetry (BEATON et al. 1968). In practical analytical work sulphur quantities of approximately $\mathbf{1 - 5} \mathbf{~ m g}$ can be determined depending upon the sensitivity of the weighing scales used. Quantities below $1 \mathrm{mg}$ of $\mathrm{SO}_{4}-\mathrm{S}$ can be determined by turbidimeter, colorimeter or titration. For large amounts of sulphur there are a number of simple methods of determination such as indirect determination by atomic absorption or infrared spectroscopy.

In the present study the sulphate sulphur was determined 1) gravimetrically from fertilizer extract, 2) titrimetrically from soil extract, and 3) turbidimetrically in determination of total sulphur by combustion gas analysis and from certain soil extracts. 
A barium chloride solution is added to the solution in which the sulphate sulphur is to be determined, and barium sulphate is precipitated.

Only 2.2 and $4.1 \mathrm{mg}$ of barium sulphate are soluble per litre of water at $18^{\circ} \mathrm{C}$ and $100^{\circ} \mathrm{C}$ respectively (HANDBOOK OF CHEMISTRY AND PHYSICS 49th ed., $1968-1969)$. In solutions that are slightly acid the solubility of barium sulphate is somewhat higher (KolthofF and SANDELL 1950, p. 329), but in order to avoid the precipitation of barium phosphate, barium carbonate or barium hydroxide, however, the precipitation reaction should be carried out in acid conditions. Calcium and trivalent iron also precipitate easily together with barium sulphate, causing uncertainty and error in the analysis. Filtration, washing of the precipitate and weighting are causes of errors which, when the amounts of sulphur are low, have to be taken into account (FRENEY 1958).

Pure barium sulphate does not break up into barium oxide and sulphur trioxide until the temperature reaches $1400^{\circ} \mathrm{C}$, but in order to dry the precipitate and destroy the filter paper it is not usually desirable to raise the temperature beyond $800-900^{\circ} \mathrm{C}$, for a higher temperature than this may lead to partial decomposition if certain impurities are present.

Procedure of analysis (according to Kolthoff and SANDELl 1950, pp. 329-339)

Hydrochloric acid is added to a measured volume of the clear extract containing more than $1 \mathrm{mg}$ of $\mathrm{SO}_{4}-\mathrm{S}$ to give an $\mathrm{HCl}$ concentration of c. $0.05 \mathrm{~N}$. In order to obtain larger crystals in the precipitate, the solution is heated and a sufficient quantity of $\mathrm{BaCl}_{2}$ solution then added. The suspension is allowed to cool overnight, and the barium sulphate precipitate is recovered on a filter paper for fine precipitates. The precipitate is dried and the paper destroyed at $800^{\circ} \mathrm{C}$, the weighing being done at an accuracy of $0.1-0.01 \mathrm{mg}$.

b. Titrimetric determination of sulphate sulphur

For small quantities of sulphur occurring, for instance, in soil extracts, use is often made of titrimetric or colorimetric methods based upon precipitation of sulphate sulphur with barium chromate with a consequent determinable excess of dissolved chromate ions (Hirst and Greaves 1922, Cantino 1946, SAALBACH et al. 1962).

Barium chromate may partly coprecipitate with sulphate precipitation, which must be avoided in the gravimetric method but is of no account when the excess of free chromate ions is determined. Small quantities of calcium, magnesium, sodium, potassium, chloride, nitrate, carbonate or bicarbonate $(<25-$ $100 \mathrm{mg}$ per sample) do not interfere with the analysis (Cantino 1946). The phosphate ion may be precipitated before the addition of barium chromate in order that the precipitation of barium phosphate may be avoided. 
$200 \mathrm{ml}$ of the liquid is pipetted into a $250 \mathrm{ml}$ graduated flask. $5 \mathrm{ml}$ of iron chloride solution is added in order to reduce the risk of the barium being precipitated by the phosphate ions in the liquid, and the conditions are made alkaline through the addition of a few drops of concentrated $\mathrm{NH}_{4} \mathrm{OH}$. Iron (III)phosphate, which is sparingly soluble in a basic solution, is coprecipitated with iron(III)hydroxide and organic matter. The flask is kept in a water bath for an hour in order that the precipitation may be as complete as possible. The cooled bottle is then filled to the volume mark with water and the precipitate filtered off. The precipitation of sulphate with barium chromate must be carried out in an acid solution, but as the chromate solution is an acid one, a suitable quantity can be added directly to the alkaline filtrate. $200 \mathrm{ml}$ of the filtrate is put into a $250 \mathrm{ml}$ graduated flask and $25 \mathrm{ml}$ of the acid solution of barium chromate is added. The flask is allowed to stand for an hour but should be shaken by hand from time to time. Concentrated $\mathrm{NH}_{4} \mathrm{OH}$ is then added in drops until the solution turns alkaline, when the colour will change from orange to greenish yellow. The flask is then filled to the volume mark and is allowed to stand for $20-30$ minutes before the liquid is filtered through a small-pored filter paper (MN640d). The first $30 \mathrm{ml}$ of filtrate is poured off in order to reduce the risk that fine particles of barium chromate may enter into the titration, when the addition of acid would dissolve the chromate and cause a positive error. $200 \mathrm{ml}$ of the filtrate is put into a conical flask, and $0.5 \mathrm{~g}$ of potassium iodide and $5 \mathrm{ml}$ of hydrochloric acid $(25 \%)$ are added. The amount of iodine set free is titrated ten minutes later with thiosulphate until the added starch (1 ml) loses its blue colour.

The flask must be washed with $\mathrm{HCl}$ after each analysis to remove any adsorbed barium chromate.

\section{Reliability of method}

Performed in this manner the method is a warning example of how the results of an analysis are affected by factors other than those for which the analysis is intended. A known quantity of potassium sulphate $(0.64 \mathrm{mg} \mathrm{S})$ was added to extracts from $\mathbf{5}$ surface soils and $\mathbf{5}$ subsurface soils before the phosphate and hydroxide impurities were precipitated. The same amount of sulphur was also added to a pure extraction liquid, and potassium dihydrophosphate $(0.64 \mathrm{mg} \mathrm{P})$ was further added in one experiment in order to determine the interfering effect of the phosphate ion. Every extract was analysed in three replicates. The soil extracts were further analysed without the addition of sulphur, also in three replicates. When these values were subtracted from the results of the analyses obtained after the addition of sulphur, the difference constituted a measure of the recovered amount. This amount is shown in Table 1 as a percentage of the total added amount. In those cases in which sulphur was added to a pure extraction liquid with or without phosphate content, the total analysed quantity is given as a percentage of the added amount. 
Table 1. Sulphate sulphur as determined with the barium chromate method using titration with thiosulphate. The results are presented as the determined amount in per cent of the calculated.

$$
\mathrm{S}=0.64 \mathrm{mg} \mathrm{S} \text { as } \mathrm{K}_{2} \mathrm{SO}_{4} \quad \mathrm{P}=0.64 \mathrm{mg} \mathrm{P} \text { as } \mathrm{KH}_{2} \mathrm{PO}_{4}
$$

\begin{tabular}{|c|c|c|c|}
\hline & $\underset{\%}{\min }$ & $\underset{\%}{\max }$ & $\begin{array}{c}\text { average } \\
\%\end{array}$ \\
\hline 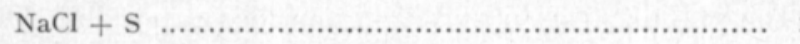 & 220 & 290 & 250 \\
\hline $\mathrm{NaCl}+\mathrm{S}+\mathrm{P}$ & 115 & 140 & 125 \\
\hline 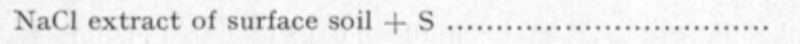 & 25 & 100 & 66 \\
\hline $\mathrm{NaCl}$ extract of subsoil $+\mathrm{S}$ & 115 & 190 & 155 \\
\hline
\end{tabular}

Carried out in the indicated manner, the method has a very strong tendency to give results that are too high (Table 1). This tendency is opposed by other factors in the extracts. The phosphorus content of the extracts may have some effect at this stage. The effect of the organic matter in the surface soils is probably not decisive, because the colouring of the extracts that is easily caused by the organic matter has been reduced by treatment with activated carbon, and the rest precipitated by treatment with $\mathrm{FeCl}_{3}$. This assumption is supported by the fact that the minimum value among the surface soils and the maximum value among the subsoils originate in the extracts of the peat soil which constituted the experimental series together with four mineral soils.

The explanation of the variation is assumed to be as follows. The method has a certain propensity to produce a positive error because some chromate in excess of the amount corresponding to the sulphate enters into the determination. This error is compensated for in the extracts of surface soils, even to too high a degree, through the effect of some unidentified factor which is present only to a lesser extent in the subsoil extracts. This factor might be the quantity of easily soluble phosphorus, which in these cultivated soils is probably higher in the surface layer than it is in the subsoil (cf. KaILA 1963). If this is the case, it means that some of the sulphate may have become coprecipitated with the phosphate during the treatment with trivalent iron. The observations showed, however, that some of the phosphate had not been precipitated during the treatment with iron chloride but it was precipitated in the form of ammonium phosphate during the treatment with alkali. There is a risk, then, that some of the excess chromate will accompany the precipitate.

As we have seen, the results of the analyses are of practically no relevance in absolute terms. The results would probably require correction in respect of some other factor in the soil extract, perhaps of easily soluble phosphorus. That a difference may just as well depend on a variation in the phosphorus content as on one in the sulphur content is very regrettable. 
Concentrations of sulphate sulphur between 1 and $100 \mathrm{mg}$ per litre can be determined turbidimetrically. When use is made of a sample of $20 \mathrm{ml}$, as was the case in the present work, it means that the determinable quantities of sulphur are those between 0.02 and $2 \mathrm{mg}$.

The method is based on the precipitation of barium sulphate, which in finely divided form can be retained in the suspension by means of a stabilizer such as gelatin (Dodgson 1961), glycerol (STEINBERgs 1953) or gum arabic (CHESNin and Yien 1951). The optic density is measured by colorimeter with the use of blue light. The greater the amount of barium sulphate precipitated, the more turbid will the suspension be and the smaller the transmission of light.

\section{Procedure of analysis}

In order to obtain results with good reproducibility it is of importance that the precipitation in the various analyses should take place under identical conditions. A great number of factors, such as the amount and the particle size of the crystals of barium chloride, the shaking period and the intensity of shaking, the temperature and the volume of the flask, have an effect upon the results. The procedure of analysis used in the present work was, in detail, as follows:

$20 \mathrm{ml}$ of the liquid to be analyzed was pipetted into a cylindrical flask of $100 \mathrm{ml} .20 \mathrm{ml}$ of an acetate buffer solution $(\mathrm{pH} \mathrm{4.8})$ and $2 \mathrm{ml}$ of gum arabic solution were added. After stirring, $1.0 \mathrm{~g}$ of barium chloride crystals were poured into the flask, whereupon the flask was immediately shaken in a "Desagan mechanical shaker set at its highest speed of revolution for a period of three minutes. The measurement of the transmission of the suspension was done by a "Lange $\mathrm{J}$ " colorimeter 20 minutes later, with a blue filter and a $50 \mathrm{ml}$ cuvette.

\section{Reliability of method}

When the control series was done in water, the curve became somewhat $\mathrm{S}$-shaped but fully acceptable in other respects. The time between the shaking and the measurement was not very critical, although a 20 minute period of waiting seemed to be the minimum. When the control series was done in a phosphate solution, the transmission became greatly altered depending on the length of time it stood. The turbidimetric method as such proved to be unreliable with soil extracts and phosphate solutions.

It is necessary that any interfering agents should be reduced in one way or another. A great improvement can be produced by performing a control series dissolved in the extraction liquid and allowing it to undergo the same pre-treatment with $\mathrm{H}_{2} \mathrm{O}_{2}$ as that undergone by the soil extracts. In the example shown in Table 2, soil extracts were produced by shaking $10 \mathrm{~g}$ of soil (23b) 
in $100 \mathrm{ml}$ of $\mathrm{KH}_{2} \mathrm{PO}_{4}$ solution containing $100 \mathrm{mg}$ of phosphorus per litre for 30 minutes. $25 \mathrm{ml}$ of the filtered extract was thereafter treated with $5 \mathrm{ml}$ of $15 \% \mathrm{H}_{2} \mathrm{O}_{2}$ for an hour on a hot water bath. $1 \mathrm{ml}$ of $20 \% \mathrm{HCl}$ was then added to the cooled extract and allowed to react for one hour, during which time the extracts became clear. The control series was treated in the same manner.

Table 2. Turbidimetrically determined recovery of sulphur added to a $\mathrm{KH}_{2} \mathrm{PO}_{4}(100 \mathrm{ppm} \mathrm{P})$ extract of a loamy clay. The extracts were treated with $\mathrm{H}_{2} \mathrm{O}_{2}$ and $\mathrm{HCl}$ prior to analysis.

\begin{tabular}{llcc}
\hline $\begin{array}{c}\text { Added } \\
\mathrm{mg} \mathrm{S}\end{array}$ & $\begin{array}{c}\text { Analyzed } \\
\mathrm{mg} \mathrm{S}\end{array}$ & $\begin{array}{c}\text { Difference } \\
\mathrm{mg} \mathrm{S}\end{array}$ \\
\hline 0 & 0.25 & - \\
& 0.04 & 0.29 & 0 \\
0.08 & 0.33 & 0 \\
0.12 & 0.38 & +0.01 \\
0.16 & 0.43 & +0.02 \\
0.20 & 0.48 & +0.03 \\
0.30 & 0.57 & +0.02 \\
0.50 & 0.76 & +0.01 \\
\hline
\end{tabular}

As appears from Table 2, quite acceptable results can be obtained by the oxidation method. The saving in labour involved in this pre-treatment in comparison, for instance, with the ion exchange technique (NyDAHL and GUSTAFsson 1953) is the reason for the selection of this method. Probably, it is primarily the interfering effect of the organic matter that is eliminated in this way. Unfortunately disturbances may still occur on account of other factors in the soil extracts.

\section{Determination of sulphide sulphur}

Determination of elemental sulphur and sulphide sulphur in the soil is most easily effected by analysis of the quantity of hydrogen sulphide, which can be drawn off under reducing and/or acid conditions. In some cases, when very small amounts of sulphur are concerned, there may also be cause first to reduce other sulphur compounds into a sulphide form and then to determine the hydrogen sulphide that develops (JoHnson and Nishita 1952). In the present work, however, sulphide determination was employed only for elemental sulphur in soil samples.

The method utilized herein has been described by BARRow (1968) and is based on titration of the hydrogen sulphide collected in an alkaline solution with mercury (II) ions and with dithizon as indicator. As long as the solution contains sulphide ions, the mercury (II) ions will not adhere to the dithizon molecule $\mathrm{C}_{6} \mathrm{H}_{5}-\mathrm{N}=\mathrm{N}-\mathrm{CS}-\mathrm{NH}-\mathrm{NH}-\mathrm{C}_{6} \mathrm{H}_{5}$. When all the $\mathrm{HgS}$ has been precipitated, the dithizon and $\mathrm{Hg}^{2+}$ will form a thio-enol complex of a bright red colour under the prevailing highly alkaline conditions. 
It is important that the titration is performed under reducing conditions for two reasons. Firstly, the sulphide sulphur may be oxidized if air should enter, and secondly, the indicator turns into diphenylthiocarbodiazon, which lacks complex-forming characteristics. To avoid this, hydroxylaminhydrochloride is added (Milton and WATERs 1949, p. 47) or the titration is performed in a nitrogen atmosphere (BARRow 1968).

Procedure of analysis

The hydrogen sulphide released in various ways from the reaction vessel is absorbed in $10 \mathrm{ml}$ of $1 \mathrm{~N} \mathrm{NaOH}$ which has been pipetted into a measuring cylinder of $50 \mathrm{ml}$. When all the sulphur is released, the delivery tube is disconnected from the rest of the apparatus and is left in the absorption liquid. $10 \mathrm{ml}$ of acetondithizon reagent (1 mg dithizon/100 ml glass-distilled acetone) is added in such a way that the tube will simultaneously be rinsed internally. The liquid is stirred by letting a weak stream of purified nitrogen gas bubble into the vessel, and titration with $0.001 \mathrm{~N} \mathrm{HgCl}_{2}$ is performed until the dirty yellow colour at the point of equivalence becomes a bright red. The change in colour is distinct, although when the amounts of sulphur are large (more than $0.3 \mathrm{mg} \mathrm{S}$ ) troubles may occur with a great precipitation of mercury sulphide.

$1 \mathrm{mMol} \mathrm{HgCl}_{2}$ is the equivalent of $1 \mathrm{mMol} \mathrm{S}$. As $0.5 \mathrm{ml}$ is reckoned to be the smallest volume that can be titrated with sufficient precision, $0.015 \mathrm{mg} \mathrm{S}$ in such conditions will be the lower limit for the sensitivity of the method, while the upper limit runs at $0.3-0.4 \mathrm{mg} \mathrm{S}$ for reasons stated above.

\section{B. Analytical methods for soil and plant samples}

\section{Pretreatment in laboratory}

The soil samples comprised some $15 \mathrm{~kg}$. They were spread out to dry at room temperature (c. $23^{\circ} \mathrm{C}$ ) in thin layers, and the samples were allowed to dry until there was a balance between the humidity of the laboratory atmosphere and that of the soil samples. The dried soil was divided up into two portions, the smaller portion of which was ground in a rotating crusher in which all particles of diameter greater than $2 \mathrm{~mm}$ were broken up. The ground samples were stored in cardboard boxes to be used at chemical analysis. The unground portion was used in pot experiments after being passed by hand through a sieve with square apertures of $0.25 \mathrm{~cm}^{2}$.

The plant samples were dried immediately upon being collected, in a "Horo" drying cabinet equipped with a fan. The drying temperature was $50^{\circ} \mathrm{C}$, and drying usually took approximately 24 hours. The period of drying, however, proved to be somewhat dependent on the amount of plant samples concurrently in the drying cabinet, and on the consistency of the material to be dried. After being dried the samples were milled in a "Culatti" hammer mill. In some cases, for instance for the wood and bark samples, a more powerful mill was required, however. A "Janke \& Kunkel" pulverizer was used in such cases. 


\section{Determination of the total sulphur in soil and plant samples}

The sulphur in the soil consists of many different components that vary a great deal from one another in characteristics. There are various forms of sulphur bound to organic matter, inorganic sulphur in difficultly soluble form, sorbed sulphate sulphur and, finally, sulphate sulphur dissolved in the soil solution (WIKLANDER 1957). It is obvious that extraordinarily effective methods will be necessary in a case such as this, in order that all these fractions may be converted into a dissolved form that is determinable in analysis. The total sulphur in the soil (as in plant samples) was determined in the present work through combustion in a closed system, in a flow of oxygen gas by means of an induction furnace. Induction furnaces are in quite common use nowadays, for they require a relatively small amount of work (JENSEN 1964, SEARLE 1968, LAVKULICH et al. 1970).

The induction furnace used in this work was manufactured by the "Laboratory Equipment Corporation" of Michigan, U.S.A., and was reliable in operation so far as its vital parts are concerned. With careless use, however, there is a risk of explosion in respect of the glass and quartz components.

In the furnace the sample is inserted into a high-frequency field within an induction coil. Magnetic materials are heated in this field through electromagnetic induction. Non-magnetic materials such as soil and plant samples do not heat up unless mixed with magnetic iron powder. In that event the sample is heated indirectly through the prior heating and melting of the iron. The manufacturer states that the temperature will rise to above $1600^{\circ} \mathrm{C}$.

Round the induction furnace itself auxiliary equipment is mounted for the purification of the gaseous oxygen and for the absorption of the combustion gases which are released from the induction chamber (Figure 1). The gaspurification section consists of there columns, one with concentrated sulphuric acid, followed by one with sascarit» and sdrierit" and one with a rotometer to measure the speed of flow of the gas. The absorption section consists of a glass tube wound inside a heating tape (HT 301, $100 \mathrm{~W}$ ), which keeps the temperature at the surface of the delivery tube at about $100^{\circ} \mathrm{C}$. The delivery tube is fixed with a short plastic pipe to a tube with the lower end fitted with a sinter (sinter density GO) that is inserted into the solution which is to absorb the sulphur released at combustion.

\section{Procedure of analysis}

$500 \mathrm{mg}$ of finely ground mineral soil $(200 \mathrm{mg}$ of organogenic soil or plant material) are weighed out in a crucible (Leco $528-35$ or $528-25$, which, however, has a greater tendency to deform at high temperatures). Approximately $1.5 \mathrm{~g}$ of powdered iron with a low content of sulphur (Leco 501-78) is added. After thorough mixing with the aid of a thin glass rod, the crucible is covered with a porous quartz cover (Leco 528-42).

The current is switched on roughly 15 minutes before use, in order that the temperature of the heating tape may rise sufficiently. The induction furnace 


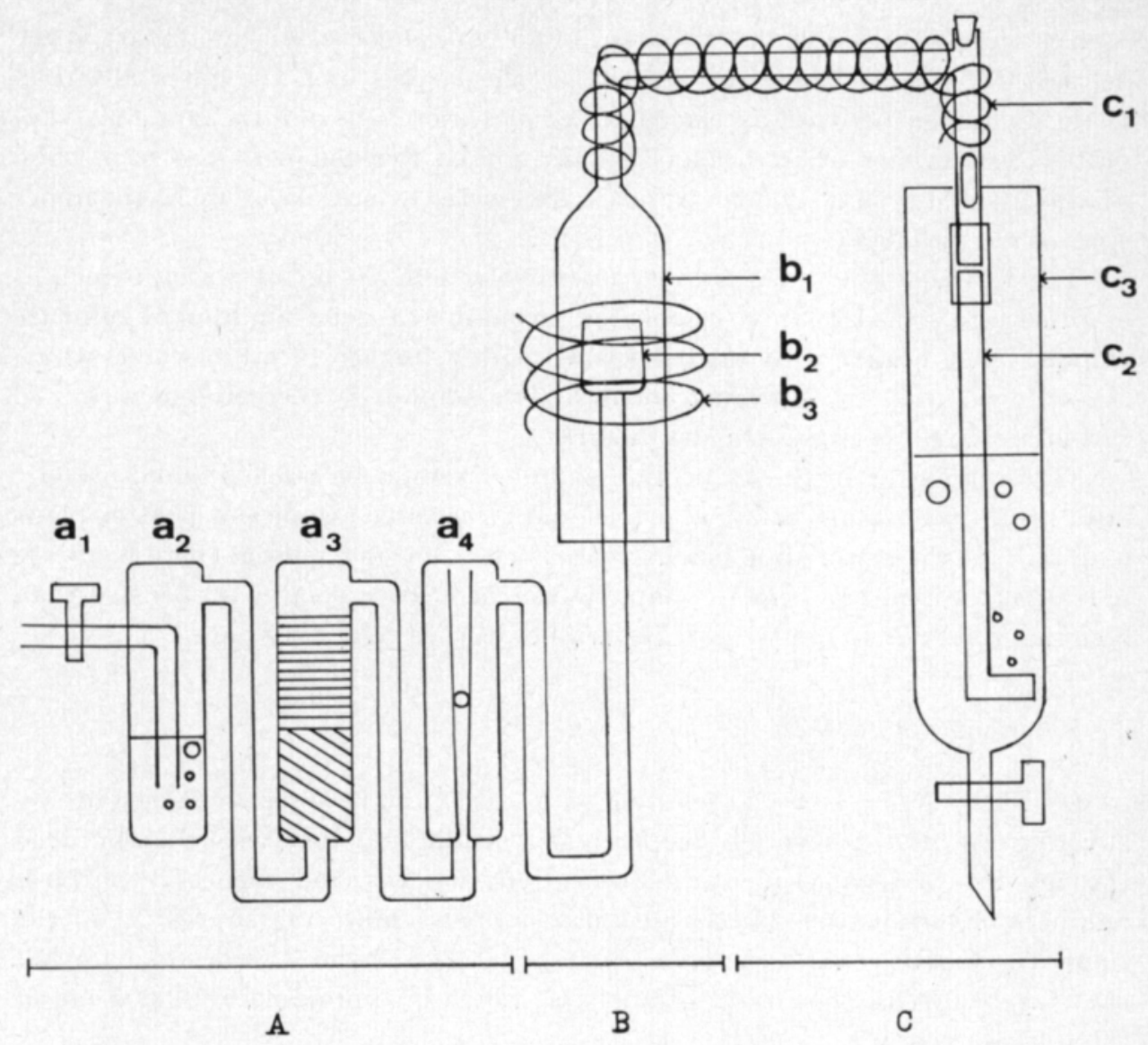

Figure 1. The most important parts of the induction furnace.

A. gas flow control and gas washing

$a_{1}$. needle valve

$a_{2}$. moisture trap with concentrated $\mathrm{H}_{2} \mathrm{SO}_{4}$

$\mathrm{a}_{3}$. column with ascarite and drierite

$\mathrm{a}_{4}$. rotometer

B. combustion

$b_{1}$. combustion tube (quartz)

$b_{2}$. crucible for the sample

$b_{3}$. induction coil

C. absorption of combustion gases

$c_{1}$. delivery tube with heating tape

$\mathrm{c}_{2}$. gas washing tube

$c_{3}$. vessel for absorption liquid

itself requires a mere 45 seconds of heating, and cannot be turned on until after that period.

The absorption liquid, $60 \mathrm{ml}$ of $2 \% \mathrm{H}_{2} \mathrm{O}_{2}$, is measured in the absorption chamber. The oxygen valve is opened, and the flow velocity is adjusted to 1 litre of $\mathrm{O}_{2}$ per minute.

The combustion is allowed to continue for 12 minutes. The absorption liquid 
$\mathrm{s}$ then removed and put into a beaker of $250 \mathrm{ml}$, and the unheated part of the delivery tube is washed with $2 \% \mathrm{H}_{2} \mathrm{O}_{2}$. The beaker with the gases absorbed in the hydrogen peroxide is placed on a hot water bath and the liquid is evaporated to dryness. The beakers should not be touched with the bare hand at this stage, for some condensation of excess $\mathrm{H}_{2} \mathrm{O}_{2}$ may occur up to the upper rims of the beakers.

The residues after evaporation are dissolved in $10 \mathrm{ml}$ of water, which is emptied into a flask that is suitable for turbidimetric determination of sulphate sulphur. The beaker is thereafter washed with a further $10 \mathrm{ml}$ of water, which is combined with the previous portion. The sulphur is thereafter determined turbidimetrically in the ordinary manner.

The sinter tube in the absorption chamber should be washed in $1 \mathrm{~N} \mathrm{NaOH}$ after some 10 burnings of mineral soils and after three samples of peat or plant material. If the sinter tube has become blocked for any reason, there is an obvious risk of explosion. Peat samples seem to have a greater propensity than plant samples not to ignite until the temperature is relatively high.

\section{Reliability of method}

a. The completeness of absorption was investigated by covering the first absorption chamber and conducting the gases that bubbled through into a second, identical absorption chamber and thence to a third. Sulphate determinations from all the chambers, however, showed that the sulphur quantities that may have entered chambers 2 and 3 were so small that they lay below the sensitivity of analysis, which is approximately $0.005 \mathrm{mg}$ of sulphur per sample.

b. The completeness of combustion was investigated partly by means of the burning of pure chemicals and partly by the burning of mixtures of soil and chemicals. Table 3 shows the results that were obtained in a series with different kinds of chemicals.

Table 3. Recovery of sulphur (\%) added as sulphanilic acid, sulphosalicylic acid and potassium aluminium sulphate in the dry combustion process.

\begin{tabular}{|c|c|c|c|c|}
\hline \multicolumn{2}{|r|}{ Analyzed amount } & \multicolumn{3}{|c|}{ Recovery } \\
\hline & & $\mathrm{C}_{6} \mathrm{H}_{4} \mathrm{NH}_{2} \mathrm{SO}_{3} \mathrm{H}$ & $\mathrm{C}_{7} \mathrm{H}_{6} \mathrm{O}_{6} \mathrm{~S} \cdot 2 \mathrm{H}_{2} \mathrm{O}$ & $\mathrm{KAl}\left(\mathrm{SO}_{4}\right)_{2} \cdot 12 \mathrm{H}_{2} \mathrm{O}$ \\
\hline & $\mathrm{mg}$ & $\%$ & $\%$ & $\%$ \\
\hline 2.5 & 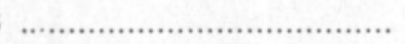 & 94 & 118 & 76 \\
\hline 5 & …ㄴ..1, & 74 & 105 & 69 \\
\hline 7.5 & 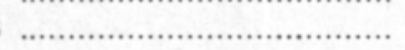 & 92 & 91 & 93 \\
\hline 10 . & 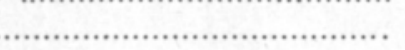 & 87 & 80 & 90 \\
\hline 15 . & . & 99 & 86 & 93 \\
\hline 20 . & 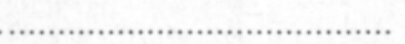 & 74 & 108 & 109 \\
\hline 30 . & 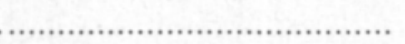 & 99 & 86 & 97 \\
\hline 40 . & 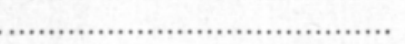 & 100 & 98 & 92 \\
\hline 50 . & (1) & 99 & 95 & 102 \\
\hline mear & $\left.\mathrm{n}^{1}\right)$ & $91 \pm 8$ & $96 \pm 9$ & $91 \pm 9$ \\
\hline
\end{tabular}

1) means $\pm s_{\overline{\mathbf{x}}} \cdot t_{0.05}$ 
Despite the great variation in Table 3, the method was approved primarily on account of the labour saving allowed. These results indicated a certain need for a correction factor with a value of approximately 1.1 if account is taken of the averages in Table 3. However, as there are values that are too high as well as values that are too low, the introduction of this factor is not warranted in the opinion of the author. The values that are given in various connections for the amount of total sulphur are uncorrected. It seems that the uncertainty would increase when the sulphur quantities get very small, but here too the error is both positive and negative, and a correction by quantity is consequently not possible.

As shown in Table 4, the situation is largely the same in those cases in which the known quantities of sulphur were blended into the soil samples.

Table 4. Recovery of sulphur added as potassium aluminium sulphate to a finesand soil (1a, $500 \mathrm{mg}$ ).

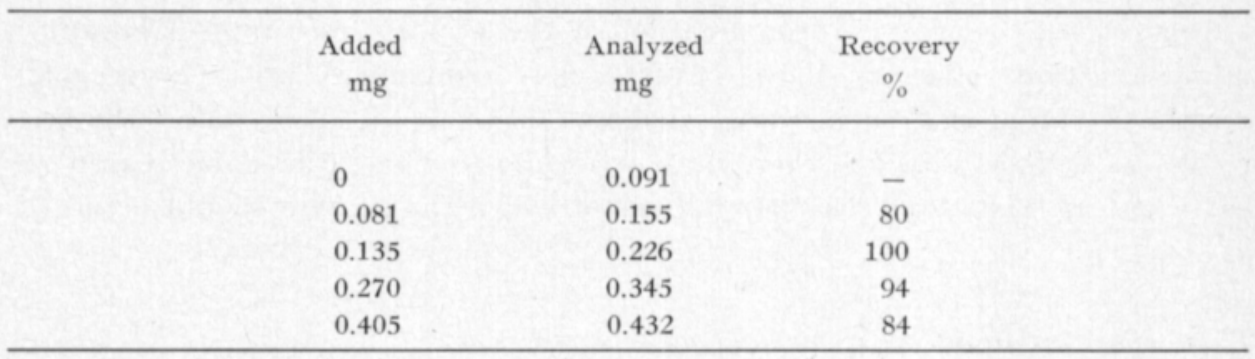

Investigations showed that there is no reason to make use of accellerators or "catalysts" other than iron powder. Tin was tried without success, among the accellerators and molybdenum trioxide and chromium trioxide among the catalysts (cf. SEARLE 1968). This is a step that is thought questionable by TABATABAI and BREMner (1970) too. The great variation that these researchers complain of in the induction combustion method conforms with the experience in the present work.

c. The completeness of dissolution after evaporation was investigated by thorough cleaning of the beakers used in routine analyses. The sulphur content of the liquid utilized for the cleaning was then determined. It proved, however, that the sulphur at this stage is very easily soluble, for even in those cases in which the evaporation pattern could be clearly discerned after the routine procedure, the sulphur determinations gave no reading.

d. The necessary number of parallel analyses and the calculation of the results were tested in 32 analyses of equivalent plant material. In chronological order the results of the analyses were as follows (in $\mathrm{mg} \mathrm{S} / \mathrm{g}$ plant material): $1.64,1.13,1.73,1.70,2.12,1.82,1.60,1.72,1.80,1.68,1.72$, $1.73,1.75,1.61,1.70,1.51,1.10,1.77,1.96,1.62,2.28,1.66,2.24,1.65,1.79$, $1.67,1.68,1.58,1.73,1.83,1.86$, and 1.76 . The arithmetic mean as well as the median of the material was $1.72 \mathrm{mg} \mathrm{S} / \mathrm{g}$ plant material. The moving averages and the medians for 3,5 and 15 parallel determinations were calculated on this material. 
Table 5. Coefficients of variation $\left(V=100 \frac{\mathrm{s}}{\overline{\mathrm{x}}} \%\right)$ for the concentration of sulphur calculated from 3, 5, and 15 analytical replicates.

\begin{tabular}{ccc}
\multicolumn{3}{c}{ replicates } \\
\hline 3 & 5 & 15 \\
$\%$ & $\%$ & $\%$ \\
\hline & & \\
7.25 & 5.93 & 1.71 \\
& 3.74 & 1.20 \\
\hline
\end{tabular}

As shown in Table 5, the variation of the medians is smaller than that of the arithmetic means for all the classes of replication. The reason is that on account of chance interference the method of analysis may produce results that have nothing at all in common with the other results. If, on some occasion, the combustion does not get started, the concentration of sulphur in the matter will appear to be very low. Contamination of the atmosphere of the laboratory, of the reaction vessels or of the cuvettes may temporarily produce very high results. In order that such totally unsuccessful analyses should affect the final results as little as possible, there may according to Table 5 be some reason to carry out at least three parallel analyses of which the median should be noted.

\section{Determination of elemental sulphur in soil}

Through examination of soil samples of high sulphur content, PUROKosKI (1958) was able to demonstrate the great tendency of sulphide sulphur to oxidize upon contact with the atmosphere. There simultaneously occurred an accumulation of elemental and sulphate sulphur. A year subsequent to the beginning of exposure to the air 15 per cent of the inorganic sulphur of the samples was still in elemental form, while practically the whole of the remainder was in the form of sulphate. The relative stability of the elemental sulphur may prompt an analysis of this sulphur fraction for practical purposes too. The elemental sulphur was analyzed in the present work from a few air-dried soil samples according to a method worked out by BARRow (1968).

\section{Procedure of analysis}

$50 \mathrm{~g}$ of soil is weighed out into an extraction flask and $100 \mathrm{ml}$ of chloroform is added. The flask is sealed with a plastic stopper or with a cork covered with plastic film, and is shaken for 30 minutes. $25 \mathrm{ml}$ of clear extract is pipetted into the reduction flask and is allowed to evaporate on a water bath. When the extract has evaporated, $2 \mathrm{ml}$ of acetone, $2 \mathrm{ml}$ of chloroform and c. $200 \mathrm{mg}$ of $\mathrm{Fe}$ powder are added.

The flask is connected to the reduction apparatus, the air is expelled from the apparatus together with the nitrogen gas, and a $50 \mathrm{ml}$ graduated flask 
with $10 \mathrm{ml}$ of $1 \mathrm{~N} \mathrm{NaOH}$ as absorption liquid is connected to the gas delivery tube. $10 \mathrm{ml}$ of $\mathrm{HCl}(1: 1)$ is poured into the reduction flask, and the flask is heated on an electric plate (set at $310^{\circ} \mathrm{C}$ in the present work) for 15 minutes.

The last part of the gas delivery tube is then disconnected and the tube is washed with $10 \mathrm{ml}$ of dithizon reagent which is pipetted into the graduated flask. Titration is carried out immediately in the graduated flask with $0.001 \mathrm{M}$ $\mathrm{HgCl}_{2}$. At the point of equivalence, which is easy to discern, the dirty yellow colour becomes a clear red.

\section{Reliability of method}

In a simple investigation of method, $3 \mathrm{mg}$ of $\mathrm{S}_{8}$ was mixed into a finesand sample (1b) and directly into the extraction liquid respectively before shaking (Table 6). All treatments had 3 replicates, and in the present modest material the reliability of the mean was \pm 6 per cent with a probability of 95 per cent when the variance for all treatments was assumed to be identical. In both cases the recovery of the added sulphur remained at c. 85 per cent. As BARrow (1968) very correctly pointed out when presenting the method, it will consequently be necessary to calibrate the $\mathrm{HgCl}_{2}$ solution against sulphur samples that have gone through the entire process of extraction and reduction.

Table 6. An example of the recovery of added elemental sulphur obtained with BARRow s (1968) method.

\begin{tabular}{|c|c|c|c|c|}
\hline & $\begin{array}{l}\text { Quantity of soil } \\
g \text { finesand (1a) }\end{array}$ & $\begin{array}{l}\text { Added } \\
\mathrm{mg} \mathrm{S}_{8}\end{array}$ & $\begin{array}{c}\text { Analyzed } \\
\text { mg S }\end{array}$ & $\begin{array}{c}\text { Recovery } \\
\%\end{array}$ \\
\hline 50 & (.................. & - & 0.08 & - \\
\hline 50 & 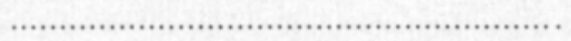 & 3.00 & 2.62 & 85 \\
\hline- & 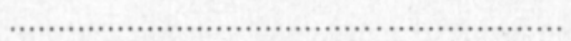 & 3.00 & 2.62 & 87 \\
\hline
\end{tabular}

BARROW (1970 b) himself reported an unsatisfactory extraction of elemental sulphur, which is held to be the result of the formation of a protective envelope of water around the sulphur, which makes it inaccessible to the organic solvent when the moisture of the soil sample is high.

\section{Determination of various criteria of soil sulphur available to plants}

Great efforts have been made to provide a chemical method of estimating the sulphur reserves of the soil which are available to plants. Criteria for these are then used indirectly to determine the need for a sulphur increment through fertilization. Methods for direct determination of the quantitative shortage have not been reported in respect of sulphur.

All the methods proceed from the extraction of a soil sample with a liquid free from sulphur which, on account of its ion exchange characteristics, of its 
acidity or alkalinity or its oxidation capacity, extracts a greater or smaller quantity of sulphur. The methods by which rather much of the nutrient is dissolved, frequently give too rough a picture of the possibility the plant has of taking up the substance from the soil; while weak extractants maycause technical difficulties in analysis and differences which are too small and unreliable between samples of different characteristics.

In order to determine the sulphur in the soil navailable to plants" use has been made of the following extractants at least: water (FRENEY 1958, SEIM et al. 1969), boiling water and successive treatment with $\mathrm{NaCl}$ and $\mathrm{H}_{2} \mathrm{O}_{2}$ (WILLiams and Steinbergs 1959, SaAlbach et al. 1962, Cooper 1968), $0.005 \mathrm{M}$ $\mathrm{MgCl}_{2}$ and $0.1 \mathrm{M} \mathrm{LiCl}$ (Roberts and Koehler 1968), $1 \% \mathrm{NaCl}$ (SaAlbach et al. 1962), $0.15 \%$ (Williams and Steinbergs 1959) and $0.02 \mathrm{~N} \mathrm{CaCl}_{2}$ (SaloNEN et al. 1965), $0.001 \mathrm{~N} \mathrm{HCl}$ (Lowe 1964), $\mathrm{KH}_{2} \mathrm{PO}_{4}$ (Ensminger 1954, Williams and Steinbergs 1964), $0.5 \mathrm{M}\left(\mathrm{K}_{2} \mathrm{HPO}_{4}+\mathrm{KH}_{2} \mathrm{PO}_{4}\right) \mathrm{pH} 7$ (Lowe 1964), $\mathrm{Ca}\left(\mathrm{H}_{2} \mathrm{PO}_{4}\right)_{2}$ (Rehm and CAldwell 1968, Serm et al. 1969), $0.5 \mathrm{M} \mathrm{NaHCO}_{3}$ pH 8.5 (Kilmer and Nearpass 1960), $\mathrm{CaCO}_{3}$ (Williams and Steinbergs 1964), $1.0 \mathrm{~N} \mathrm{NH}_{4}$-acetate (REHM and CALDWELL 1968), $1.0 \mathrm{~N} \mathrm{NH}_{4}$-acetate $\mathrm{pH}$ 7.0 (McClung et al. 1959), $0.5 \mathrm{~N} \mathrm{NH}_{4}$-acetate $+0.25 \mathrm{~N} \mathrm{H}$-acetate (SEIM et al. 1969), Morgan's solution $=$ Na-acetate $\mathrm{pH} 4.8$ (Chesnin and Yien 1951, Neller 1959) and $0.3 \mathrm{M} \mathrm{NaH}_{2} \mathrm{PO}_{4} \cdot 2 \mathrm{H}_{2} \mathrm{O}$ in $2 \mathrm{~N} \mathrm{H}$-acetate (COOPER 1968).

a. Determination of the sulphur extractable with $1 \% \mathrm{NaCl}$

1. Procedure of analysis (SAalbach et al. 1962)

$50 \mathrm{~g}$ of air-dried soil is weighed out in a 0.5 litre plastic flask. $250 \mathrm{ml}$ of $1 \%$ $\mathrm{NaCl}$ solution is added, and the flask is shaken in a mechanical shaker (in the, present study, of make DESAGA) for one hour. $3 \mathrm{~g}$ of active carbon is then added and the shaking is continued for a further $2-3$ minutes. After filtration, the sulphate sulphur is determined in accordance with the barium chromate method.

\section{Reliability of method}

The reproducibility for the sodium chloride extraction and the subsequent sulphate determination was investigated by performing extractions on 5 surface soils and 5 subsoil samples with three replicates of each (Table 7). The analytic average was calculated for the analyzed quantities, no account being taken of the fact that a smaller quantity of soil was analyzed for soil No. 3 than for the others.

No statistically significant differences occurred between the replicates of the analysis, which is an indication that the great variation $\left(\bar{x}^{ \pm} 9.5 \%\right.$ for $t_{0.05}$ ) is not necessarily due to inferior work in analysis, but rather to pure chance or to the low number of analyzed samples. 
Table 7. Analyzed amounts of sulphate sulphur in the case of three analytic replicates.

\begin{tabular}{|c|c|c|c|c|c|}
\hline $\begin{array}{c}\text { Sample } \\
\text { Nr }\end{array}$ & Soil type & $\begin{array}{c}\mathrm{I} \\
\mathrm{mg} \mathrm{S}\end{array}$ & $\begin{array}{c}\text { II } \\
\mathrm{mg} \mathrm{S}\end{array}$ & $\begin{array}{c}\text { III } \\
\text { mg S }\end{array}$ & $\begin{array}{c}\text { Average } \\
\text { mg S }\end{array}$ \\
\hline $1 \mathrm{a}$ & finesand ....... & 0.63 & 0.54 & 0.53 & 0.57 \\
\hline $1 \mathrm{~b}$ & 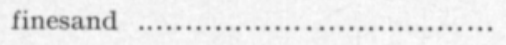 & 0.33 & 0.38 & 0.35 & 0.35 \\
\hline $2 a$ & loam & 0.75 & 0.74 & 0.61 & 0.70 \\
\hline $2 b$ & 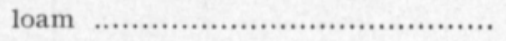 & 0.53 & 0.48 & 0.47 & 0.49 \\
\hline $3 a$ & 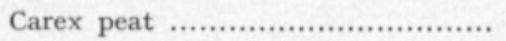 & 0.75 & 0.72 & 0.69 & 0.72 \\
\hline $3 \mathrm{~b}$ & 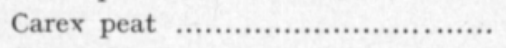 & 0.58 & 0.53 & 0.55 & 0.55 \\
\hline $4 a$ & 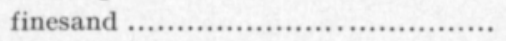 & 0.46 & 0.56 & 0.43 & 0.48 \\
\hline $4 b$ & 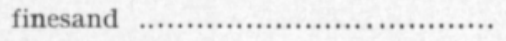 & 0.57 & 0.53 & 0.54 & 0.55 \\
\hline $5 a$ & finer finesand $\ldots \ldots \ldots \ldots \ldots \ldots \ldots \ldots \ldots \ldots \ldots \ldots \ldots \ldots$ & 0.90 & 1.04 & 1.03 & 0.99 \\
\hline $5 b$ & 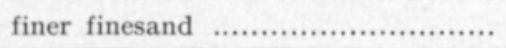 & 0.71 & 0.70 & 0.67 & 0.69 \\
\hline
\end{tabular}

b. Determination of the sulphur extractable with $0.03 \mathrm{M} \mathrm{NaH} \mathrm{P} \mathrm{O}_{4} \cdot 2 \mathrm{H}_{2} \mathrm{O}$ in a $2 \mathrm{~N}$ acetic acid

This extraction liquid was first used by BARDSLEy and LANCASTER (1960) to extract "soil sulphur" from heated samples. COOPER, however, made use later on (1968) of the same extractant for direct extraction from soil samples, and found a close connection between these results of analysis and observations of symptoms of sulphur deficiency in the field. The method differs from most others in the sense that extraction and filtration are followed by oxidation of dissolved organic compounds, which means that the determined fraction consists of dissolved sulphate sulphur, part of fixed sulphate sulphur (phosphate extraction) and an acid soluble part of the initially carbon-bound sulphur (acetic acid + oxidation with $\mathrm{H}_{2} \mathrm{O}_{2}$ ).

\section{Procedure of analysis}

$10 \mathrm{~g}$ of air-dried mineral soil or $3 \mathrm{~g}$ of peat soil is weighed out into a $100 \mathrm{ml}$ extraction flask, and $50 \mathrm{ml}$ of $0.03 \mathrm{M} \mathrm{NaH}_{2} \mathrm{PO}_{4} \cdot 2 \mathrm{H}_{2} \mathrm{O}+2 \mathrm{~N} \mathrm{CH}_{3} \mathrm{COOH}$ is added. After 30 minutes of shaking, the sample is filtered through dense paper. $25 \mathrm{ml}$ of the filtrate is taken to a $100 \mathrm{ml}$ beaker, and $5 \mathrm{ml}$ of $15 \% \mathrm{H}_{2} \mathrm{O}_{2}$ is added. The beaker is left on a hot water bath for one hour. The beaker is then taken off the bath, and $1 \mathrm{ml}$ of $20 \% \mathrm{HCl}$ is added and allowed to react for one hour, whereupon the solution should become perfectly clear.

The clear solution is poured into a $20 \mathrm{ml}$ graduated measuring glass, and the beaker is washed with small quantities of water which are then poured into the glass. Finally, the measuring glass is filled up to $20 \mathrm{ml}$. From the solution thus obtained, the sulphate sulphur is determined turbidimetrically but with the omission of the gum arabic additive. 
As the turbidimetric determination of sulphate is quite sensitive to small variations in $\mathrm{pH}$, etc., there is cause to investigate the extent to which the character of the extraction liquid and the other chemicals needed in the pretreatment of the soil samples affect the sulphate determination.

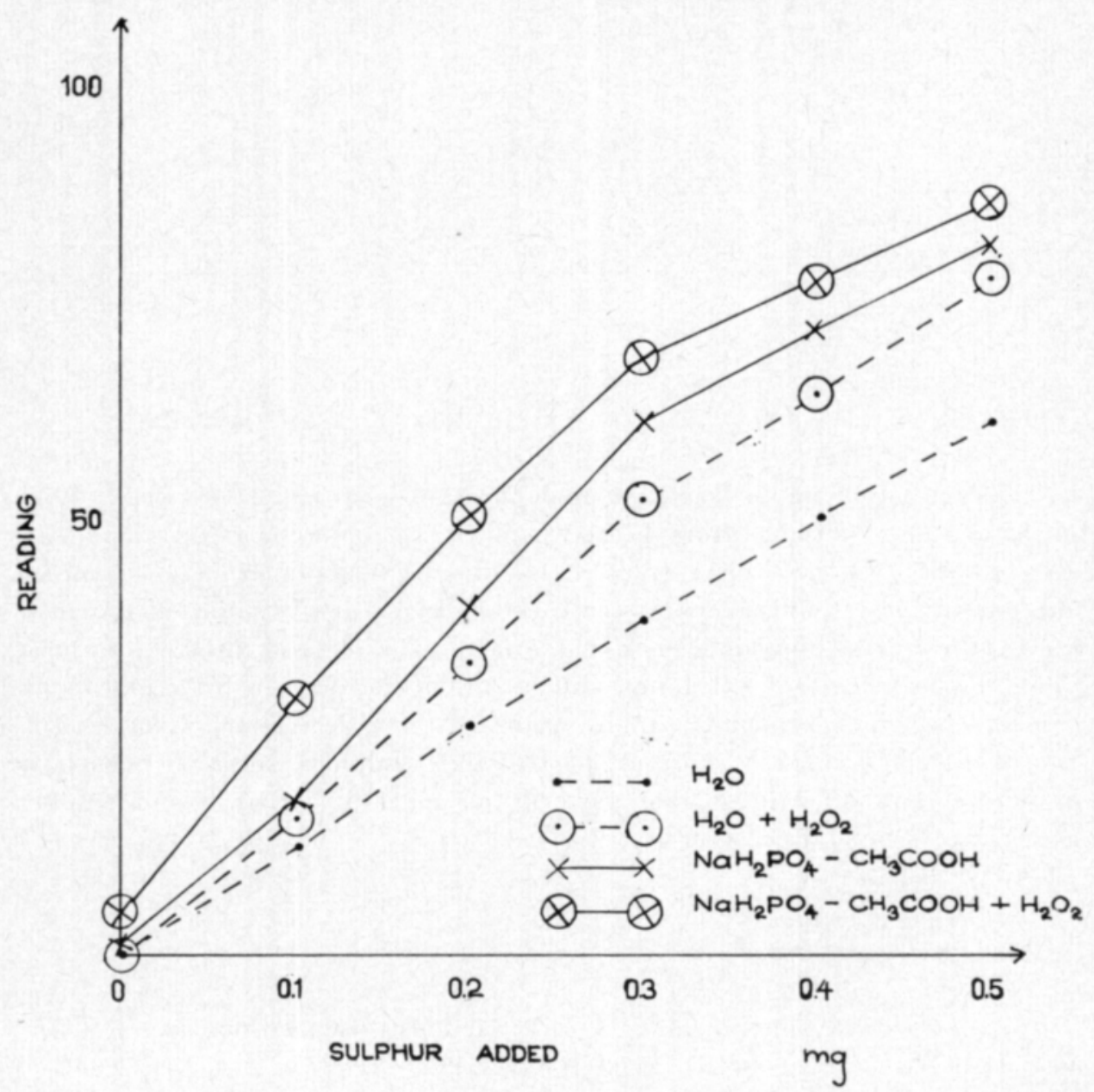

Figure 2. Interference of extractant and $\mathrm{H}_{2} \mathrm{O}_{2}$ treatment on the turbidimetric sulphate sulphur determination.

Standard solutions of sulphur with $0.1 \mathrm{mg}$ of $\mathrm{SO}_{4}-\mathrm{S} / \mathrm{ml}\left(0.4246 \mathrm{~g}\right.$ of $\left.\mathrm{CaSO}_{4} / \mathrm{l}\right)$ were prepared both in water and in $\mathrm{NaH}_{2} \mathrm{PO}_{4}$-acetic acid. With these solutions, standards were prepared containing $0.1,0.2,0.3,0.4$ and $0.5 \mathrm{mg}$ of $\mathrm{S}$ which were introduced in the course of analysis before and after the treatment with hydrogen peroxide. The results (Figure 2) show that it is necessary to use a standard series dissolved in $\mathrm{NaH}_{2} \mathrm{PO}_{4}$-acetic acid. Hydrogen peroxide treatment should also be done on the standard series, as this seems to raise the readings slightly, perhaps because of a small content of sulphur or through activation 
of impurities containing sulphur on the glassware. The reproducibility of the method is not among the best. All the soil samples in the present work were analyzed with three replicates, and the confidence interval of the average was as much as $\pm 22 \%$ at the 95 per cent level of confidence, provided that the variance was identical in the analyses in respect of all the soils.

c. Determination of the sulphur extractable with a m monium acetate of pH 4.65

In view of practical analytical work it was of interest to investigate the sulphur quantities extracted with ammonium acetate $\mathrm{pH} 4.65$, as this extractant is utilized to determine soil fertility in practical agriculture in Finland (VUORINEN and MäKITIE 1955).

Procedure of analysis

The procedure of analysis in this case is the same as that in extraction with $0.03 \mathrm{M} \mathrm{NaH}_{2} \mathrm{PO}_{4}$ in $2 \mathrm{~N} \mathrm{CH}_{3} \mathrm{COOH}$. According to accepted practice, however, the ratio between soil and liquid is measured in units of volume, usually $20 \mathrm{ml}$ of soil in $200 \mathrm{ml}$ of liquid. Shaking time is one hour.

The extraction liquid is a mixture of c. $62 \mathrm{ml}$ of concentrated acetic acid $(99-100 \%)$ and $45 \mathrm{ml}$ of $25 \%$ ammonia per litre. Control of the $\mathrm{pH}$ is necessary, and correction can be effected through the cautious addition of either component.

Gravimetric determination of the sulphate with or without hydrogen peroxide treatment of the extract did not give satisfactory results. The sulphate sulphur was consequently determined in this case, too, by turbidimetry after peroxide oxidation.

In detail, the analysis is carried out as follows. $50 \mathrm{ml}$ of extract is poured into a $100 \mathrm{ml}$ beaker, $10 \mathrm{ml}$ of $15 \% \mathrm{H}_{2} \mathrm{O}_{2}$ is added and the mixture is evaporated on a hot water bath. $1 \mathrm{ml}$ of $20 \% \mathrm{HCl}$ is added to the cooled evaporation residue and is allowed to react for one hour. The content of the beaker is then washed with small quantities of distilled water into a graduated measuring glass which, finally, is filled to the $20 \mathrm{ml}$ mark. This liquid is poured into the flask for turbidimetric determination of the sulphate sulphur which is carried out in the ordinary way but with the omission of the solution of gum arabic.

\section{Other laboratory methods}

The determination of nitrate nitrogen is done with an "Orion" nitrate specific electrode. In these tasks the measurements were made within the range of concentration of $1-100 \mathrm{mg}$ of $\mathrm{NO}_{3}-\mathrm{N} / \mathrm{l}$ extract. For the plant material the extraction ratio of 1: 125 between plant material and water was employed. The shaking period was 10 minutes and the solutions were filtered 
in all cases before determination. The nitrate content of the soil samples was determined in some cases from different extracts. No steps were taken to reduce the interfering $\mathrm{HCO}_{3}{ }^{-}$or $\mathrm{Cl}^{-}$. For a detailed study of the possibilities of the nitrate electrode, reference is made to Myers and Paul (1968), Paul and Carlson (1968), Mahendrappa (1969), Oien and Selmer-Olsen (1969), MACK and SANDERSON (1971).

Determination of the total nitrogen content of the plant $\mathrm{m}$ a t $\mathrm{t}$ e $\mathrm{r}$ was performed with the Kjeldahl method in concentrated sulphuric acid with copper sulphate as catalyst and potassium sulphate to raise the boiling point of the acid sufficiently.

The total nitrogen content of the soil samples was determined by means of a modification (BREMNER and SHAw 1958) of the Olsen method. It proved necessary to use quite small quantities of soil and large Kjeldahl flasks with the facility of great dilution before alkali addition at distillation, in order to avoid an all too violent neutralization reaction at that stage.

The total phosphorus in the plant matter was released from the organic compounds through heating in a furnace up to $550^{\circ} \mathrm{C}$. The ash was dissolved in $0.2 \mathrm{~N} \mathrm{HCl}$ and the phosphorus was determined with vanadate reagent (QUINLAN and DESESA 1955).

The total molybdenum in the plant material was determined from an ash extract in which the ash was dissolved in $6.5 \mathrm{~N} \mathrm{HCl}$ containing $0.5 \mathrm{~g}$ of $\mathrm{FeCl}_{3} \cdot 6 \mathrm{H}_{2} \mathrm{O} /$ litre. The molybdate was determined through rodanide dyeing by colorimeter after concentration through absorption into a small quantity of isoamyl alcohol carbon tetrachloride solution (JoHNson and ARKLEy 1954). For measurement, use was made of a Hitachi Perkin-Elmer UV-VIS spectrophotometer set at a wavelength of $470 \mathrm{~nm}$.

The content of organic carbon in the soil samples was determined through oxidation with potassium dichromate (GRAHAM 1948). The change in the colour of the chromate was measured with the colorimeter referred to in the previous paragraph and a wavelength of $645 \mathrm{~nm}$.

The $\mathrm{pH}$ of $\mathrm{th}$ e $\mathrm{s}$ oil $\mathrm{s}$ a mples was measurep in a 1: 2.5 soil -0.02 $\mathrm{N} \mathrm{CaCl}_{2}$ suspension. The measuring was carried out with a $»$ Beckman" potentiometer and a glass electrode.

The bulk density of the soil was calculated by means of weighing three parallel samples of $20 \mathrm{ml}$ of ground air-dried soil (ERviö 1971).

The $\mathrm{texture}$ of $\mathrm{the}$ s oil samples was determined by the pipette method with the pre-treatment recommended by Elonen (1971).

The a proxim ations for field capacity were determined in the laboratory from ground samples. In this method, the water is sucked artificially out of the soil samples for $\mathbf{1 5}$ minutes, by placing the soil samples in a $1 \mathrm{~cm}$ layer in a Büchner funnel attached to a suction flask. 


\section{Sulphur balance of the soil}

The sulphur situation of the soil and the access of sulphur to plants follow a slightly more complicated pattern than is the case with most other nutrients. This is mainly due to two factors. Firstly, the soil receives a considerable increment of sulphur from the atmosphere through precipitation which contains sulphur, and through absorption from the air. Secondly, plants are not exclusively dependent upon the sulphur supply in the soil, for they are able in some degree, at least, to satisfy their own needs through sulphur uptake directly from the atmosphere.

The importance of the sulphur in the atmosphere will be discussed more closely below, with respect to the sulphur emission into the atmosphere and the sulphur content in the precipitation. It is further necessary to study the processes that the soil sulphur may undergo. As in the case of most other nutrients, absorption by plants is only one part of the loss of nutrients, while the leaching with drainage and discharge water and the evaporation stand for the rest of the loss.

\section{A. Sulphur emission into the atmosphere}

On the input side of the sulphur balance of the soil, the fallout with the rain occupies a significant portion. It is consequently of interest to investigate the sources from which the sulphur in the atmosphere originates.In the combustion of fossil fuels and organic matter containing sulphur compounds, sulphur dioxide and sulphur trioxide of varying ratios are formed, depending on the combustion temperature, air supply and presence of soot with catalytic effect in the combustion chamber (TIKKANeN and YläsaARI 1972). However, the formation of sulphur dioxide seems to be dominant. It has not been definitively established to what extent and at what reaction speed the conversion takes place in the atmosphere from $\mathrm{SO}_{2}$ to $\mathrm{SO}_{3}$ and, subsequent to the absorption of water vapour, to $\mathrm{H}_{2} \mathrm{SO}_{4}$. At a very high temperature sulphur is emitted from inorganic substances, this occurring in natural conditions in volcanic areas. Reduced gaseous sulphur compounds may occur in environments low in oxygen, such as in mud on the beds of watercourses, in flooded areas and in peat soils (TAKAi and Asami 1962).

The sulphur content of the oils used as fuel for heating and power is more or less completely converted into gaseous form at combustion. The quantities 
of sulphur that enter the atmosphere in this way are rather big, as can be seen in Table 8. Refinery products slighter than diesel oil contain only very small amounts of sulphur and are consequently left out of Table 8 .

Table 8. Use of oil products in Finland and their sulphur contents. ${ }^{1}$ )

\begin{tabular}{|c|c|c|c|c|c|c|c|}
\hline & \multicolumn{3}{|c|}{$\begin{array}{l}\text { Total use } \\
1000 \text { tons }\end{array}$} & \multirow[t]{2}{*}{$\begin{array}{c}\text { Sulphur content } \\
\%\end{array}$} & \multicolumn{3}{|c|}{$\begin{array}{l}\text { Sulphur amount } \\
1000 \text { tons }\end{array}$} \\
\hline & 1970 & 1971 & 1972 & & 1970 & 1971 & 1972 \\
\hline Diesel oil .................. & 740 & 753 & 788 & $0.40-0.45$ & 3 & 3 & 3 \\
\hline Light oil .................. & 3300 & 3271 & 3478 & 0.60 & 20 & 20 & 21 \\
\hline \multirow[t]{2}{*}{ Heavy oil ................. } & 4300 & 4538 & 5110 & 2.5 & 108 & 113 & 128 \\
\hline & & & & To & al 131 & 136 & 152 \\
\hline
\end{tabular}

1) Laino, A. 1972. Neste Oy. Personal communication.

With even distribution over the 33.7 million hectares that make up the total area of Finland, the fallout per hectare originating in the combustion of oil would have been $3.9 \mathrm{~kg}$ of $\mathrm{S}$ in 1970 and $4.5 \mathrm{~kg}$ of $\mathrm{S}$ in 1972 . There is information, however, which indicates that a great deal of the sulphur reaches the ground quite close to the site of emission (Johansson 1959). The true distribution of the sulphur originating in the various combustion processes is dependent, in other words, upon the wind and precipitation conditions.

The utilization of coal and coke products is admittedly on the decline at the moment, but some types are still being used in large quantities in energy supply and industry (Table 9).

Table 9. Use of coal products in Finland and their sulphur contents, ${ }^{1}$ )

\begin{tabular}{|c|c|c|c|c|c|c|c|}
\hline & \multicolumn{3}{|c|}{$\begin{array}{l}\text { Total use } \\
1000 \text { tons }\end{array}$} & \multirow[t]{2}{*}{$\begin{array}{c}\text { Sulphur content } \\
\%\end{array}$} & \multicolumn{3}{|c|}{$\begin{array}{l}\text { Sulphur amount } \\
1000 \text { tons }\end{array}$} \\
\hline & 1970 & 1971 & 1972 & & 1970 & 1971 & 1972 \\
\hline Anthracite ................ & 118 & 96 & 104 & $0.95-2.0$ & 2 & 2 & 2 \\
\hline Pit coal ..................... & 267 & 235 & 122 & $0.60-1.8$ & 3 & 3 & 2 \\
\hline Slack ....................... & 2836 & 2575 & 2435 & $0.60-1.5$ & 30 & 27 & 26 \\
\hline Coke (imported) ........ & 792 & 665 & 659 & 1.0 & 8 & 7 & 7 \\
\hline \multirow[t]{2}{*}{ Crushed coke .............. } & 51 & 71 & 65 & 1.0 & 1 & 1 & 1 \\
\hline & & & & & 44 & 40 & 38 \\
\hline
\end{tabular}

1) Imported amounts from Customs Statistics 1972. Sulphur contents stated by the importing company GHH. 1972.

The sulphur quantities in Table 9 were calculated by multiplying the consumed amounts with the estimated average sulphur content for the various products. When an estimate is made of the quantities that entered the atmosphere, it must be remembered that a early average of 200,000 tons of the pit 
coal was used to produce 150,000 tons of coke as well as gas. The sulphur in the gas is recovered in the production process and consequently does not enter the atmosphere. At a low combustion temperature a proportion of the sulphur which is difficult to ascertain may, too, remain in the ashes or slag.

In the countryside use is still mainly made of wood for heating and cookin , while industry burns some wood, and some older buildings in population centres are also still heated by means of wood stoves. In order to get a rough picture of the sulphur quantities that may be emitted by the fuelwood, a few sulphur analyses of wood and bark samples were made. The results in Table 10, however, should be regarded merely as being guidelines, as only two samples of pine and spruce, one of birch and three of other deciduous trees (aspen, alder and rowan) were analyzed, with three replicates. The calculations were also complicated by the fact that the bark component contains considerably more sulphur than the wood component. In the analyzed samples the ratio between bark weight and wood weight was 1: 5.6 and this ratio was employed in the calculation of the sulphur contents given in Table 10 for the various types of fuelwood. The consumption of fuelwood indicated in cubic metres of solid measure is based on a preliminary estimate by the Forest Research Institute ${ }^{1}$ ), and for the conversion into weight units the coefficients mentioned in the forest calendar were applied. The estimated total consumption of fuelwood was thus estimated to 4.2 million tons in 1972 .

Table 10. Use of fuelwoods in Finland and their sulphur contents.

\begin{tabular}{|c|c|c|c|c|c|c|c|c|c|c|}
\hline & \multicolumn{6}{|c|}{ Total use } & \multirow{3}{*}{$\begin{array}{c}\text { Sulphur content } \\
\%\end{array}$} & \multirow{2}{*}{\multicolumn{3}{|c|}{$\begin{array}{l}\text { Sulphur amount } \\
1000 \text { tons }\end{array}$}} \\
\hline & \multicolumn{3}{|c|}{$\begin{array}{c}1000 \mathrm{~m}^{3} \\
\text { solid volume }\end{array}$} & \multicolumn{3}{|c|}{1000 tons } & & & & \\
\hline & 1970 & 1971 & 1972 & 1970 & 1971 & 1972 & & 1970 & 1971 & 1972 \\
\hline 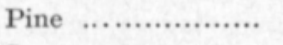 & 730 & 701 & 666 & 394 & 379 & 360 & 0.010 & 0.04 & 0.04 & 0.04 \\
\hline Spruce , .............. & 754 & 729 & 700 & 369 & 357 & 343 & 0.015 & 0.06 & 0.05 & 0.05 \\
\hline Birch ................. & 4950 & 4778 & 4572 & 3168 & 3058 & 2926 & 0.010 & 0.32 & 0.31 & 0.29 \\
\hline \multirow[t]{2}{*}{ Other hardwoords . } & 1255 & 1170 & 1142 & 628 & 585 & 571 & 0.011 & 0.07 & 0.06 & 0.06 \\
\hline & & & & & & & Total & 0.49 & 0.46 & 0.44 \\
\hline
\end{tabular}

At a low combustion temperature some of the sulphur may remain in an ungasified form in the ash. The sulphur in the fuelwood is thus a very insignificant source in raising the sulphur content of the atmosphere.

A large number of industrial processes cause emission of sulphurous compounds into the atmosphere. In its report (1973:6) the Committee for Air Conservation and Noise Abatement, estimated the emissions of sulphur into the atmosphere to be as shown in Table 11, the estimate being based on data provided by industry.

1) Hutrunen, T. 1973. Forest Research Institute, Helsinki. Personal communication. 
Table 11. Sulphur emission from industrial processes in Finland in 1970. Sulphur from oil and coal products omitted.

Emitted sulphur 1000 tons

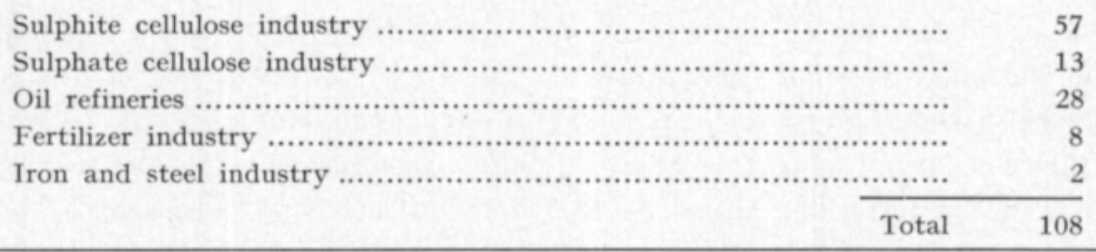

The great emission by the sulphite pulp industry is primarily a result of the fact that a very large portion of the sulphite waste liquor is burned. The sulphur emission from the oil refineries is likely to decrease somewhat in the next few years, as projected desulphurising plants are taken into use.

Gaseous sulphur compounds might be emitted from peatlands and flooded areas. Under extremely reduced conditions, when all the dissolved oxygen has been consumed, all the nitrate and nitrite nitrogen reduced, all four-valent manganese converted into two-valent form and all dissolved three-valent iron become two-valent, the sulphate sulphur $\left(\mathrm{S}^{6+}\right)$ begins to be reduced to sulphide sulphur $\left(\mathrm{S}^{2-}\right.$ ) (Koyama and Tomino 1970). $\mathrm{H}_{2} \mathrm{~S}$ is then first formed, and it is easily dissolved in the soil solution in large concentrations, especially when the temperature is low. The sulphide sulphur is then gradually precipitated in the form of various metal sulphides. The emission of free hydrogen sulphide is consequently slight (TAKIJIMA et al. 1962).

Methyl mercaptan $\left(\mathrm{CH}_{3} \mathrm{SH}\right)$ is formed at microbiological decomposition of the sulphur-bearing amino-acids methionine and cystine, but may under certain circumstances be formed from hydrogen sulphide and fermentation products from the decomposition of organic substances (TAKAI and Asami 1962).

In the atmosphere the reduced gaseous sulphur compounds are soon oxidized, and it is consequently impossible to distinguish these sulphur impurities in the atmosphere from those entering in a different fashion. It seems that nobody has ventured an estimation of the sulphur quantities in question, and the relative importance of these phenomena in the local or global sulphur balance. In as marshy a country as Finland it would be interesting to investigate such questions as well as the gas emission from peatlands in general, together with the importance thereof. ODÉN (1968, p. 12) suggests that there is a conversion of the sulphate sulphur in fertilizers into hydrogen sulphide in ordinary cultivated soils too - a question that may well deserve further study.

\section{B. The absorption of atmospheric sulphur into the soil}

The soil surface absorbs some sulphur from the air beyond the amounts that fall out with precipitation. Sulphur dioxide, a gas easily soluble in water, is pressed by the turbulence of the atmosphere against the soil surface and is 
dissolved into the soil moisture. A dry surface may thus be expected to absorb less sulphur than would a wet one, and a covered surface less than a bare one. It must certainly be the microclimate that ultimately determines what amount of sulphur is absorbed. JoHAnsson gives some estimates of this amount in his thesis of 1959. He demonstrates how the absorption of sulphur from the air in cultivated pots provides a greater sulphur increment than does precipitation. The directly absorbed amount was relatively highest when the amount of atmospheric sulphur was at its greatest, which may be an expression of the importance of the constant contact between the atmosphere and the soil surface, while the contact between raindrops or snowflakes in the precipitation and the very lowest layers of the atmosphere, in which sulphur pollution is at its most intensive, is naturally very brief and occasional.

Some of the sulphur that the plants absorb from the atmosphere may be carried to the roots and excreted into the soil, which may thus indirectly obtain an increment of sulphur from the atmosphere through the plant (deCormis 1968). In other words, it has not been unequivocally established whether a bare soil or an overgrown soil fixes more atmospheric sulphur.

\section{The sulphur in the precipitation}

The sulphur emission from various sources results in a certain sulphur content in the atmosphere. How high this content is, depends on the closeness to the source of emission (Johansson 1959), but also has a certain connection with the total emission in our entire continent (ODÉN), as some of the sulphur that has entered the atmosphere may be transported over long distances with the global movements of the higher atmospheric layers. A marked local increase in the deposition of sulphur can be traced only for a distance of a few kilometres from its source (Johansson 1959). On the other hand, the sulphur emissions in the industrial regions of Western Europe are held to influence the basic level of sulphur fallout even in the Nordic countries (ODÉN 1968).

The results reported in the present work are based upon analyses and sampling performed by the Institute of Marine Research in Helsinki. The processed material covers the period December 1, 1965 to November 30,1970 , i.e., a period of five years. The precipitation was collected for a month at a time at a total of 10 sampling sites in various parts of Finland. Representative samples of the precipitation of the month were sent to the Central Laboratory of the Institute of Marine Research for analysis. Unfortunately, the amount of sulphate sulphur is determined by means of precipitation of the sulphate with barium chromate and a colorimetric recording of the change in the colour of the chromate, and here, too, allowance must be made for a possible interference of phosphorus.

In the present work statistical processing was carried out on the previously unprocessed material consisting of the quantities of precipitation and the sulphur content in the precipitation. Of the total of 600 precipitation samples that were analyzed, the sulphur content of 15 had remained undetermined. The commonest reason for this omission was that the amount of rain during 
the period had been small $(0-19 \mathrm{~mm})$. On account of this the 15 samples were given the value of 0 for sulphur fallout in the calculations.

Table 12 shows the sulphur fallout during the successive twelve-month periods for the various sampling sites.

Table 12. Sulphur amounts in precipitation. Mean values for the five twelve-month periods between Dec. 1, 1965 and Nov. 30, 1970.

\begin{tabular}{|c|c|c|c|}
\hline & \multicolumn{2}{|c|}{ Position } & \multirow{2}{*}{$\begin{array}{l}\text { Sulphur in precipitation } \\
\qquad \mathrm{S} \mathrm{kg} / \text { ha per year }^{1} \text { ) }\end{array}$} \\
\hline & $\mathrm{N}$ & E & \\
\hline 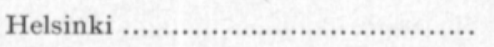 & $60^{\circ} 11^{\prime}$ & $24^{\circ} 58^{\prime}$ & $18,5^{\mathrm{c}}$ \\
\hline 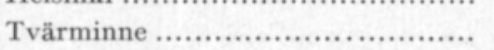 & $59^{\circ} 54^{\prime}$ & $23^{\circ} 12^{\prime}$ & $11.2^{\mathrm{b}}$ \\
\hline Sodankylä & $67^{\circ} 22^{\prime}$ & $26^{\circ} 39^{\prime}$ & $8,8^{\mathrm{ab}}$ \\
\hline Kuopio & $63^{\circ} 00^{\prime}$ & $27^{\circ} 44^{\prime}$ & $7.8^{\mathrm{ab}}$ \\
\hline Punkaharju & $61^{\circ} 48^{\prime}$ & $29^{\circ} 20^{\prime}$ & $7.0^{\mathrm{ab}}$ \\
\hline Jyväskylä ..................................... & $62^{\circ} 24^{\prime}$ & $25^{\circ} 40^{\prime}$ & $6.6^{\mathrm{ab}}$ \\
\hline Kuolio & $65^{\circ} 48^{\prime}$ & $28^{\circ} 35^{\prime}$ & $5.9^{\mathrm{a}}$ \\
\hline 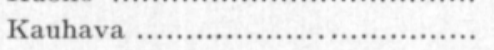 & $63^{\circ} 06^{\prime}$ & $23^{\circ} 03^{\prime}$ & $5.7^{\mathrm{a}}$ \\
\hline 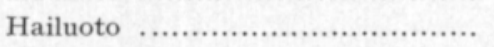 & $65^{\circ} 00^{\prime}$ & $24^{\circ} 45^{\prime}$ & $5.5^{\mathrm{a}}$ \\
\hline 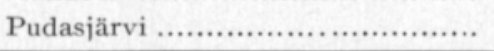 & $65^{\circ} 24^{\prime}$ & $26^{\circ} 55^{\prime}$ & $5.0^{\mathrm{a}}$ \\
\hline
\end{tabular}

1) Means followed by a common letter do not differ at $\mathrm{P}=0.05$.

The averages of Table 12 were treated with the Duncan (1955) test to ascertain any differences between the various periods and the various places. The indices show that Helsinki experienced a significant increase in sulphur fallout in comparison with the other sampling sites. In Helsinki it is the settlement of population and industry that have been responsible for the emission of sulphur into the atmosphere. Tvärminne research station on the peninsula of Hangö seems also to have had a slightly higher fallout of sulphate sulphur than some of the other sampling sites at least. It must certainly have been the sea foam drifting in over the coast that influenced the sulphur content of the precipitation there. A sulphur fallout of approximately $5 \mathrm{~kg}$ per hectare yearly seems to be expected in relatively sparsely settled non-industrialized parts, too, such as Pudasjärvi and Kuolio.

Treatment of the entire material reveals no significant differences between the various periods of twelve months. The total period of sampling is also too short to indicate any rising or declining trend. Nor could any significant differences among the months be obtained from the material when the total period was divided into months with the various years as replicates. This situation is to be expected in those cases in which no local sources of emission can be assumed to contribute to the fallout. By contrast, the local emission of sulphur is dependent on such things as the intensity of combustion during the respective period (Johansson 1969). For a closer study of any monthly variation, the results of analysis for Helsinki were processed (Table 13) in a separate statistical test.

The results did not unambiguously indicate that the fallout was highest during the winter months. The location of the town, on a headland in the Gulf 
Table 13. Monthly sulphur content in rainwater collected in Helsinki during the period Dec. 1, 1965 - Nov. 30, 1970.

Sulphur content $\mathrm{S} \mathrm{kg} / \mathrm{ha}^{\mathbf{1}}$ )

\begin{tabular}{|c|c|}
\hline y ................... & $1.3^{\mathrm{abc}}$ \\
\hline February .................. & $1.0^{\mathrm{ab}}$ \\
\hline March ................. & $1.2^{\mathrm{abc}}$ \\
\hline April ................... & $2.3^{\mathrm{c}}$ \\
\hline May ............... & $1.2^{\mathrm{abc}}$ \\
\hline June ............... & $0.8^{\mathrm{a}}$ \\
\hline July ............ & $1.8^{\mathrm{abc}}$ \\
\hline August ........... & $1.2^{\mathrm{abc}}$ \\
\hline September .... & $1.6^{\mathrm{abc}}$ \\
\hline October ............... & $2.2^{\mathrm{bc}}$ \\
\hline November & $2.0^{\mathrm{abc}}$ \\
\hline ecember. & $1.9^{\mathrm{abc}}$ \\
\hline
\end{tabular}

1) Means followed by a common letter do not differ at $\mathrm{P}=0.05$

of Finland, makes the atmospheric pollution generally slight. The fallout of sulphur with precipitation was markedly greater in April than in February and June and markedly greater in October than in June. Whether the absence of the expectedly great fallout for the coldest period, from December to March, is due to chance or might have something to do with other factors, was not settled within the scope of the present study. A factor worth investigating in the future might be the tendency of sulphur pollutions to become absorbed in rain and in snow respectively. In other words, investigations should be made on the question whether rainfall cleanses the atmosphere better than does the same amount of precipitation in the form of snow.

There is plenty of information in the literature about sulphur fallout in precipitation in various parts of the world. For a thorough study of these questions, reference in made to the excellent paper by Coleman (1966). It may be pointed out in a quite general sense that the fallout in industrialized zones may rise extremely high while the fallout in sparsely populated areas in Germany and Denmark seems to fluctuate around $10 \mathrm{~kg}$ of $\mathrm{S}$ per hectare per annum, in Sweden between 5 and $10 \mathrm{~kg}$ of $\mathrm{S}$ per hectare per annum and in the Swedish fells in the north some $2-3 \mathrm{~kg}$ of $\mathrm{S}$. The lowest recorded amounts (less than $1 \mathrm{~kg}$ of $\mathrm{S}$ per hectare per annum) are reported from Australia, New Zealand and Kenya.

The quantities of sulphur recorded for Finnish conditions in the present work fit the picture quite well. Encouraging, too, is the fact that sulphur quantities that are high in international terms were not recorded even in industrialized and densely settled areas. The calculated fallout is nevertheless on the high side rather than on the low side, if the discussion is strictly limited to the sulphur conveyed to the soil with the precipitation. This is due to the fact that solid particles containing sulphur may be deposited on the collecting vessel even during drought. Some of the very high readings for months of low 
precipitation seem to speak in favour of this assumption. As it is difficult to draw the mentioned distinction between the sulphur really dissolved in the precipitation and the solid particles of soot and dirt deposited on the collecting vessel and dissolved in the collected rainwater, it is probable that most if not all the values stated in the literature are recorded in the same way. This procedure is advantageous for the determination of the importance to cultivated plants of the sulphur content of the precipitation, because the solid particles can be as easily dissolved in the soil as in the reservoir of the water gauge.

\section{Sulphur in fertilizers}

A large proportion of the sulphur utilized by cultivated plants is that added to the soil by fertilizers. Although intentional fertilization with sulphur on a field scale has not been carried out to any great extent in Finland, sulphur has been added to the cultivated soil over the years in large amounts in the form of impurity and accompanying ion in nitrogen, phosphorus and potassium fertilizers. An estimate of the annual sulphur dose in the fertilizers was worked out in the present study from the import and sales statistics collated by the Market Research Department of the Pellervo Society and from results of analysis from Kemira Oy. In this estimate the deficiency in information concerning the sulphur content, especially before 1945 , is probably a greater source of error than that concerning the amounts employed.

The sulphur content is of little importance from a sales point of view, and it is consequently possible to offer a product for sale under a single trade-name and with identical contents of nitrogen, phosphorus and potassium but with highly varying contents of other agents such as sulphur. Where the older types of fertilizer are concerned, it was impossible to determine the variation. To give an example of the kind of variation that may be concerned, and to elucidate the cause of the difference between various production batches, a closer description is provided here only of one certain compound fertilizer $(15-8.8-12.5)$, which is the dominant type of fertilizer at this moment.

It is reckoned that during the first years of production the whole domestic output was of a type low in sulphur, of which it contained 0.4 per cent. Since 1968 , however, two different production processes have been in concurrent use for the manufacturing of the abovementioned compound fertilizer. The "DORR" process gives a product with approximately 2.1 per cent of sulphur, while the "PEC" process gives one with at least 0.4 per cent. A product containing 4.6 per cent of sulphur has been occasionally produced. The difference in sulphur content is the result of a varying use of ammonium sulphate in the production process. In Table 14 the sales during $1968-71$ are distributed according to sulphur content.

The type low in sulphur has thus been the commonest type on the market. The minimum sulphur content of fertilizer of this type should consequently always be stated as the most probable content on trade descriptions. In this connection it gives a misleading impression to state the sulphur content in the form of an average weighed according to the sales statistics, which has also been practiced. 
Table 14. Sale of a certain compound fertilizer (15-8.8-12.5) during the period 1968-71 divided according to the sulphur content of the product.

\begin{tabular}{|c|c|c|c|c|c|}
\hline \multirow{2}{*}{$\begin{array}{l}\text { Sulphur content } \\
\text { S\% }\end{array}$} & \multicolumn{5}{|c|}{$\begin{array}{c}\text { Sale } \\
1000 \text { tons }\end{array}$} \\
\hline & 1968 & 1969 & 1970 & 1971 & Total \\
\hline $0.4 \ldots \ldots \ldots \ldots \ldots$ & 148 & 196 & 228 & 198 & 770 \\
\hline 2.1 & 59 & 133 & 112 & 90 & 394 \\
\hline 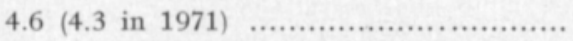 & 0 & 20 & 1 & 88 & 109 \\
\hline
\end{tabular}

In order to determine the variation in sulphur content within one and the same process, samples taken at various times from the same production unit were ordered from the Finnish producer. Four samples from the DORR process and four from the PEC process were received. After pulverization these samples were dissolved in $6.5 \mathrm{~N} \mathrm{HCl}$, and the dissolved sulphate sulphur was determined gravimetrically. The sulphur content in both processes slightly exceeded the declared minimum content: the product from the PEC process contained $0.44-$ 0.58 per cent of sulphur with an average of 0.52 per cent in the dry fertilizer, while that from the DORR process contained 2.6-2.9 per cent with an average of 2.8 per cent of sulphur in the dry fertilizer. These variations must be regarded as being surprisingly small.

However, the situation becomes more confusing when consideration is given to the fact that fertilizers are imported into Finland, too, and then sold in packings identical with those used for Finnish fertilizer. 10 samples of older types of compound fertilizer $(15-8.8-12.5$ (11.6)) were collected from a few farms. The question was one of remaining quantities from the period $1965-$ 71 the origin of which could not, unfortunately, be traced at the time. These samples were analyzed for their sulphur content in the same way as in the previous case. The sulphur content proved to lie between 0.65 and 5.9 per cent with a fairly even spread between these two extreme values. At least that fertilizer with the highest content of sulphur was probably imported.

The total use of sulphur in Finland from the year 1920 to June 1972, calculated on the grounds described above, is recorded in Figure 3. Throughout practically the whole of that period the dosage of sulphur was of the same order of magnitude as the dosages of nitrogen, phosphorus or potassium, which were inserted into the figure for the sake of comparison. During the years 195557 the cultivated soil was supplied with more sulphur than with any of the other mentioned nutrients. The transition from simple fertilizers to compound fertilizers and the introduction of fertilizers based on phosphoric acid instead of ones based on superphosphate have, however, caused a sharp decline in the use of sulphur in recent years. The sulphur dosage dropped by one half between 1965 and 1972, while the utilization of nitrogen almost doubled during that period. In the fertilization year of $1970-71$, nitrogen and sulphur were utilized in the ratio of $\mathrm{N}: \mathrm{S}=\mathbf{5 . 2}: \mathbf{1}$. During that time the cultivated acreage amounted to 2.55 million hectares, and the sulphur utilization amounted to $12.3 \mathrm{~kg}$ of $\mathrm{S}$ per hectare when account is taken of the fact that 1,131 tons of the total amount of 32,453 tons of $\mathrm{S}$ were employed in forest fertilization. 


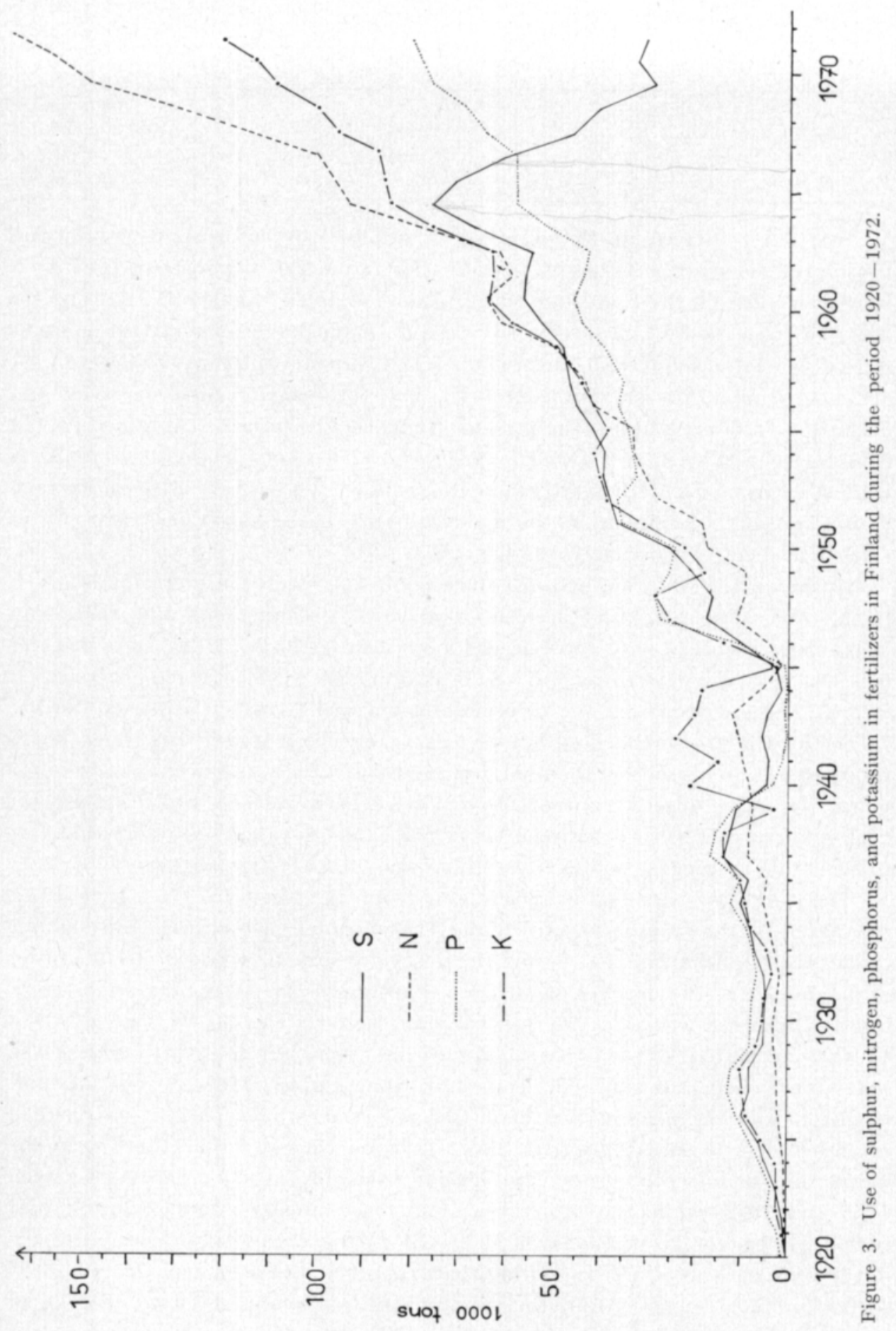




\section{E. Leaching of sulphur}

The leaching of sulphur compounds, primarily sulphate sulphur, has been the subject of intensive research. The movement of sulphur in the soil is dependent upon physical factors such as the total volume and distribution of the soil pores, which factors together characterize the hydraulic conductivity, and the amount of precipitation and its distribution. The soil structure and texture have an indirect influence through their effects on the porosity.

The texture affects the leaching also through the fact that there is greater chemical activity in the finest fractions. The fixation of sulphate to the soil particles is the stronger the lower the $\mathrm{pH}$ value (BARrow $1970 \mathrm{a}$ ). The dependence on the $\mathrm{pH}$ is held to be valid for both main types of sulphate-adsorbing material in the soil, i.e., for the positive charges of the clay minerals at the surfaces of fracture and for the iron and aluminium oxides (AYLMORE et al. 1967). In respect of the aluminium oxides, however, an adsorption maximum could be found at $\mathrm{pH} 4$ (CHAO et al. 1964).

The leaching conditions in Finland were estimated in the present work with the guidance of the results of analysis published by LAAKsonen $(1969,1970)$. It is an investigation of watercourses made by the Water Pollution Control Authority, which is performed in respect of all the most important watercourses in Finland. During 1962-68 sampling took place at above 160 different sites on average. Samples were extracted four times a year: in the beginning of March, in the middle of May and of August, and at the end of October. The estimated proportion of waste water is indicated for the various sampling sites (LAAKSONEN 1969). For the purposes of the present work it was necessary to exclude those samples in which a stated high sulphur content might be due to a large amount of waste and not to effective leaching. According to the data supplied by LAAKSONEN (1969) only 47 sampling sites were absolutely free of a wastewater load. In order to extend the number of sampling sites taken into account, if such is possible, the correlation between sulphur content and waste quantity was! tested in those cases in which the proportion of waste water was between 0.3 and 1 per thousand.

The total linear correlation coefficient between sulphur content and waste load for these 47 sampling sites was 0.02 , i.e. nonexistent, and these sampling sites were consequently included in the tests for leaching. The total number of sampling sites with no or with an insignificant load of waste was consequently 94.

The annual leaching of sulphur per hectare was calculated by taking into account the average content of sulphur, the average runoff and the size of runoff area. The relationship between the sulphur leaching per hectare (1) and the relative areas of cultivated land (2), peatland (3) and lake (4) in the run-off area was tested by means of linear correlation analysis. The coefficients of correlation

$$
\begin{aligned}
& r_{12}=0.43^{* * *} \\
& r_{13}=-0.16 \\
& r_{14}=0.29^{* *}
\end{aligned}
$$


show a positive although weak influence of the ratio of the area of cultivated land upon the leaching of sulphur. This can be assumed to be due to cultivation techniques, and also to a certain effect of settlement and of animal husbandry, the results of increased cultivated acreage. The acreage of peatland is unrelated to the leaching of sulphur. A weak negative tendency might suggest some fixation of sulphur in peat soil, but may also be due to other factors such as the location of the vast peatlands in the northern parts of Finland, where the sulphur fallout from the atmosphere is at its lowest. In sharp contrast to the result obtained by LAAKSONEN (1970) for the whole of the material, a separate processing of those watercourses that are not recipients of waste produces a weakly negative correlation between the sulphur and the lake acreage of the run-off area.

As shown in Figure 4, the differences between various parts of the country are great. The average leaching was calculated with account being taken of the total size of the run-off areas $\left(316,300 \mathrm{~km}^{2}\right)$ and the total leaching in the investigated areas $(218,000$ tons of $\mathrm{S}$ per annum), and an average was thus obtained of $6.9 \mathrm{~kg}$ per hectare per year. When the four northernmost watercourses were not taken into account as there were no collection stations for rainwater analyses, an average of $8.1 \mathrm{~kg}$ per hectare per year was obtained. The leaching that actually occurred from the land areas was calculated for that area in the following way. From the total area of $198.300 \mathrm{~km}^{2}$ the water area of $27,300 \mathrm{~km}^{2}$ was subtracted. The quantity of sulphur that fell with precipitation directly into the watercourses was obtained by multiplying the water area by the sulphur fallout per unit of area (0.836 tons of $\mathrm{S}$ per $\mathrm{km}^{2}$ per annum), which was taken from the investigation of precipitation. The sulphur quantity thus obtained was subtracted from the total amount of sulphur carried off $(160,000$ tons of $\mathrm{S}$ per annum). When the amount of sulphur thus obtained was distributed over the land area, the value of $8.0 \mathrm{~kg}$ of S per hectare per year was produced, a figure that will be employed in the discussion on the sulphur balance of the soil in the next section.

As can be seen, it is difficult to calculate an average for the whole country from the present material. The difficulty is increased on account of the inadequacy of information about a number of areas in southern and western Finland. The reason for this is that none of the sampling sites on the watercourses in these areas were sufficiently free of waste load to provide information on natural leaching from forest and field. The watercourses marked out in southern and south-western Finland in Figure 4 are probably also relatively more loaded with rural waste than are the watercourses in other more sparsely settled parts of the country.

The highest values for leaching come from areas with large stretches that were sedimented during the period of the Litorina Sea. It has been calculated that large amounts of sulphur run off every year especially in the western coastal region. The highest value, one of $91 \mathrm{~kg}$ of S per hectare per year, was obtained for the river Laihia. In his inventory of the sulphur-containing soils of the coastal regions PURokoski (1959) came to the conclusion that there are nearly 20,000 hectares of sulphate soils in that area. The leached quantities of sulphur decrease markedly farther to the north, and no similarity can be seen to the 


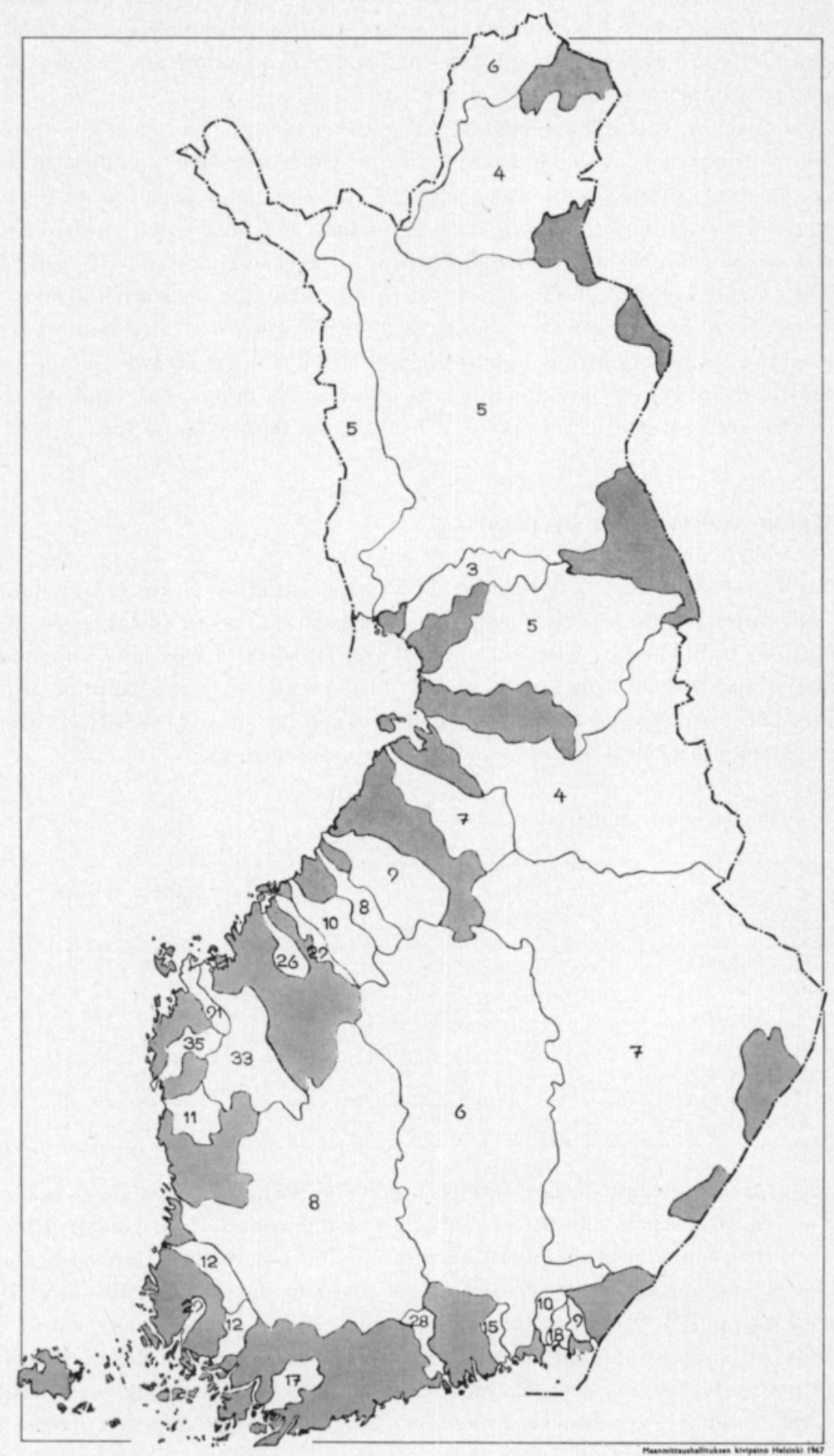

Figure 4. Calculated leaching of sulphur (kg S/ha/yr.). Dark areas are omitted because of waste water interference on the results obtained. 
vast sulphur-rich areas of which PURoKoski (1959) writes. It was unfortunately necessary to exclude a few interesting rivers of these regions, such as those of Lapua and Pyhäjoki, and the sulphur-rich areas in question may consequently be located primarily along these watercourses.

The values for leaching assessed in this manner are relatively low as compared with the estimates that have been made in Germany (BUCHNER 1958) and Norway (ØDELIEN 1965). In those studies, however, the question was partly concerned with lysimeter investigations in which leaching might be somewhat higher than normal on account of loosening of the soil, and partly with field observations on well-drained and well-fertilized cultivated soils with a relatively great run-off of drainage water. ØDELIEN (1965) unequivocally demonstrated that leaching is dependent on the intensity of sulphur fertilization. When forest, peatland and mountains are included in addition to cultivated land, as is the case in the present study, the average leaching is bound to be low.

\section{F. Sulphur consumption by plants}

It is relatively easy to determine how much sulphur is annually removed from cultivated lands together with the harvest. Table $\mathbf{1 5}$ is taken from the compilations published by Coleman (1966) and Beaton (1966). The information on grasses and clover appears to match fairly well with the sulphur uptake calculated according to the data published by SALONEN et al. (1965) from Finnish field experiments $(7-14 \mathrm{~kg}$ of $\mathrm{S}$ per hectare per annum).

Table 15. Sulphur content of certain crops.

\begin{tabular}{|c|c|c|}
\hline & $\begin{array}{c}\text { Yield } \\
\text { tons/ha }\end{array}$ & $\begin{array}{c}\text { Sulphur content } \\
\mathbf{k g} / \mathbf{h a}\end{array}$ \\
\hline Wheat ......................................... & 2.7 & $10-13$ \\
\hline Clovers ......................................... & 10 & $17-22$ \\
\hline Grasses ...................................... & 10 & $9-11$ \\
\hline 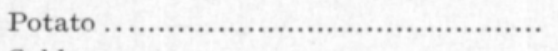 & $20-22$ & $8-11$ \\
\hline Cabbage ...................................... & 40 & $21-42$ \\
\hline Turnips …..................................... & 50 & $28-39$ \\
\hline 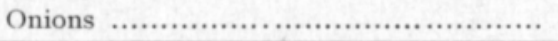 & 40 & $20-22$ \\
\hline
\end{tabular}

It is far more difficult to decide how much the plants actually have taken up from the soil in various conditions and how much comes from the air directly. That the importance of atmospheric sulphur should not be exaggerated is shown by the very numerous field experiments by which increased yields have been produced through fertilization with sulphur in many parts of the world and on widely different crops (BEATON 1966). In experimental conditions in which natural precipitation has been excluded and irrigation carried out with distilled water, the yield is very highly dependent on the sulphur deposits in the soil and on sulphur fertilization. This indicates that absorption of sulphur through the root system in the form of sulphate is the dominant process, at least for crops with rapid development and high but brief uptake of sulphur. 
The sulphur in the atmosphere may occur in solid form, as dust and particles of soot, or dissolved in microscopic droplets of liquid, or in the form of gas such as sulphur dioxide, hydrogen sulphide and other sulphurous gases. When, however, the proportion of sulphur dioxide is the highest, it is the uptake of that gas that has aroused the interest of the researcher. The uptake of hydrogen sulphide, mercaptans and other gaseous sulphur compounds through leaf and stem, however, is quite possible and actually likely.

A very high concentration of $\mathrm{SO}_{2}$ in the atmosphere may cause damage to plant tissues, with consequent necrosis and defoliation. An atmosphere with $0.5-1.5 \mathrm{mg}$ of $\mathrm{SO}_{2}$ per cubic metre seems to approach the harmful concentration (FALLER 1971 a). The concentration of sulphur dioxide is normally between 10 and 100 times as low as this; and at such levels the uptake by plants of $\mathrm{SO}_{2}$ from the air is an important increment in the sulphur supply (OLSEN 1957). In the experiment by OLSEN (1957) cotton plants with an unsatisfactory supply of sulphur in the substrate absorbed far more than half their sulphur content from the atmosphere. Even when there was a sufficient supply of sulphur in the substrate, almost 30 per cent of the total sulphur in the plant came from the atmosphere. In other experiments with the same isotope technique (JENSEN 1963) the proportion of total sulphur in barley, oats, lucerne (alfalfa), red clover, turnip and sugar beet which originated in the atmosphere varied between 13 and 36 per cent. The lowest percentages were obtained at an early stage of development and with a good supply of sulphate to the root system. No genuine differences can be discerned between various types of plant.

Plants take up sulphur from the atmosphere in direct proportion to the sulphur concentration (deCormis 1968). Under normal conditions, atmospheric sulphur does not suffice to meet the need of plants (OLSEN 1957), because a high $\mathrm{SO}_{2}$ content may damage the tissue before a concentration high enough for the sulphur balance is attained. Plants hardy to $\mathrm{SO}_{2}$, such as tobacco, are particularly able to utilize artificially increased sulphur dioxide as their only source of sulphur (FALLER $1971 \mathrm{~b}$ ).

It would seem that hardiness to sulphur dioxide would be related to the sulphur uptake of various plants. Cabbage and oil plants, in particular, which seem able to stand a great deal of $\mathrm{SO}_{2}$ in the atmosphere, also require large amounts of sulphur in order to develop.

\section{G. Sulphur balance of cultivated soils in Finland}

In put. As seen from the above, calculations have shown that the $\mathrm{f}$ a 11 o u t of sulphur in precipit a t i o $\mathrm{n}$ is roughly of the same magnitude as the emission from utilized fuels and industrial processes. In both these cases the quantities are in the region of $8 \mathrm{~kg}$ of $\mathrm{S}$ per hectare per year. A more important finding than the average fallout, however, is the fact that the nbasic level of the fallout of sulphur in the rural districts of relatively large parts of Finland appears to occur approximately in the amount of $5 \mathrm{~kg}$ of $\mathrm{S}$ per hectare per annum. 
Among the fertilizers the decisive role is played by the artificial fertilizers. It is calculated that the cultivated soil was supplied with approximately 12 times as much sulphur in artificial fertilizer $(12.3 \mathrm{~kg}$ of $\mathrm{S}$ per hectare per annum) as in farmyard manure (total of farmyard manure 2.5 million tons of dry matter of a sulphur content estimated at $1 \mathrm{~kg}$ per ton gives roughly $1 \mathrm{~kg}$ of $\mathrm{S}$ per hectare of cultivated soil per annum).

$\mathrm{T}$ a k e o t. The basic level of $1 \mathrm{e} \mathrm{a} \mathrm{ch}$ in $\mathrm{g}$, which was estimated above at $8 \mathrm{~kg}$ per hectare per annum, corresponds with the amount of sulphur in the precipitation. It is probable that far larger amounts will have to be calculated with, on account of applied sulphur, when land is more intensively cultivated. The leaching out of small annual doses may be at a low level during the growing season, but there is a risk of effective leaching of unutilized fertilizer sulphur in autumn and spring. The results of ØDELIEN (1965) from lysimeter investigations with radio-active sulphur indicate very strong leaching of applied sulphate sulphur from fallow land. The poor capacity of soils to fix sulphur makes it impossible to bring about a long-term increase in the sulphate sulphur content of the soil through the utilization of easily soluble sulphate compounds. An assessment of the total extent of leaching in various situations is made yet more difficult by the fact that some soils nevertheless possess a considerable capacity to bind sulphate sulphur (HogG 1966). This applies primarily to clay mineral of 1: 1 type, in which the positive charge and frequently, too, a contamination with colloidal iron and aluminium oxides possessing anion fixing properties, are greater than in 2: 1 minerals (HARWARD and REISENAUER 1966). The clay minerals in Finland would seem, however, to consist mostly of 2: 1 minerals of the illite type, and the sulphate fixation is in consequence probably rather weak.

The uptake of sulphur by plants depends on the type of plant. A cereal crop may, roughly speaking, be reckoned to take up $10 \mathrm{~kg}$ of S per hectare per annum; a ley crop between 15 and $20 \mathrm{~kg}$; and a root crop 20-30 $\mathrm{kg}$. The highest amount of sulphur is required by cultivated plants of the families Cruciferae and Liliaceae, in which sulphur is necessary not only for protein synthesis but also for the formation of various isothiocyan esters and organic sulphides, which give these plants their characteristic taste and smell.

It is very difficult to estimate the amounts of direct gas emission from the soil and direct absorption of sulphur by the soil. In an article (1962) FRENEY, BARROW and SPENCER, who are all authorities on sulphur, estimated the direct uptake at less than $0.1 \mathrm{~kg}$ of $\mathrm{S}$ per hectare annually and assumed that the emission of $\mathrm{H}_{2} \mathrm{~S}$ may be of importance only in waterlogged stretches and, for example, in shallow salt-water bays that are uncovered at low tide. The question is consequently one of factors of little importance to the total sulphur balance. JoHAnsson (1959) has put the direct absorption rather high, but fallout of solid sulphurous particles may have caused an abnormal in crease in the amount of sulphur in the soil in that case. The sulphur addition from pesticides, fungicides and insecticides is very small because the quantities used per unit of area are very low.

Under the outlined conditions, it is the sulphur in fertilizers that must equilibrate the uptake by plants of sulphur from the soil. Temporarily the 
weathering of mineral sulphur of the soil may also keep the sulphur supply at an acceptable level. In such cases fertilization with sulphur is likely to lead to increased leaching. It would seem that the sulphur reserves of the soil are often quite large, and that sulphur fertilization might be superfluous for long periods of time. A reliable estimate by chemical means of the sulphur situation of the soil would consequently be of importance in Finland as elsewhere. 


\section{Sulphur in the soil}

The most important sulphurous minerals of the soil are pyrite $\mathrm{FeS}_{2}$, pyrrhotite $\mathrm{FeS}_{-} \mathrm{Fe}_{5} \mathrm{~S}_{6}$, chalkopyrite $\mathrm{CuFeS}_{2}$, pentlandite $(\mathrm{Fe}, \mathrm{Ni})_{9} \mathrm{~S}_{8}$ and bornite $\mathrm{Cu}_{5} \mathrm{FeS}_{4}$. Of these, pyrrhotite, pentlandite and chalkopyrite mostly occur in basic rocks such as gabbro, while pyrite is common in acidic rocks. The sulphur content of the acidic rocks which are common in Finland is lower than that of the basic rocks, as can be seen in the following compilation out of the textbook by Rankama and Sahama (1964, pp. 743-755):

\begin{tabular}{|c|c|}
\hline & $\begin{array}{c}\mathrm{S} \\
\mathrm{g} \text { per ton }\end{array}$ \\
\hline Gabbro ................................ & 2000 \\
\hline Granite ......................... & 500 \\
\hline Alkali pyroxenite ................................ & 2000 \\
\hline Pyroxenite ......................................... & 3000 \\
\hline 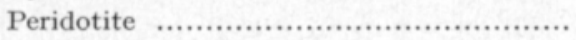 & 2500 \\
\hline
\end{tabular}

Weathered sulphide minerals and volcanic activity may, perhaps, when very long periods of time are in question, have been of extremely great importance to the global circulation of sulphur, but nowadays most of the nactiven sulphur in the soil occurs in an organic or in an inorganic form that is not mineral-fixed (NELSoN 1964), and it is consequently the availability in these that is of special interest.

The organic sulphur of the soil occurs in two main types (FrEnEY et al. $1970)$. They are a) organic sulphur bound directly to carbon, reducible to $\mathrm{S}^{2-}$ with Raney's nickel, and b) covalent bound sulphate sulphur, which can be reduced to hydrogen sulphide by hydriodic acid. The former group includes compounds of the same type as cysteine, cystine and methionine, while the latter group comprises sulphate esters.

The non-mineral-bound inorganic sulphur consists mostly of sulphate sulphur. In some analyzed soil samples from pastures in Australia the absorbed and easily soluble sulphate sulphurs together made up 6 per cent of the total sulphur, while the more reduced forms of the inorganic sulphur made up 1 per cent (FRENEY 1961). In oxygen-poor conditions, however, a relatively large part of this "active" inorganic sulphur may occur in the form of sulphide and elemental sulphur. In his thesis (1958) PURокоsкI showed how easily the sulphide compounds are oxidated when the soil is kept moistened but in good contact with the air. In a sulphide clay with approximately $9 \mathrm{~g}$ of $\mathrm{S}$ per $\mathrm{kg}$ of dry soil, 
a good 60 per cent was originally in sulphide form while 4 per cent occurred as $\mathrm{SO}_{4}-\mathrm{S}, 15$ per cent as $\mathrm{S}_{8}-\mathrm{S}$ and above 20 per cent as organic sulphur. One month later the sulphide form was almost totally absent, while the proportion of sulphate had increased to more than 40 per cent, that of the elementary sulphur to almost 35 per cent, sulphite sulphur occurred to an amount of $\mathbf{5}$ per cent of the total amount of sulphur, and the organic sulphur had remained constant.

The redisposition of the sulphur compounds of the soil into sulphate sulphur does not require any extreme conditions. A reduction of sulphate, however, does not occur except under highly reducing circumstances:

$$
\mathrm{SO}_{4}{ }^{2-}+\mathrm{H}_{2} \mathrm{O}+2 \mathrm{e}^{-}=\mathrm{SO}_{3}{ }^{2-}+2 \mathrm{OH}^{-} \text {(redox potential }=-0.92 \mathrm{~V} \text { ) }
$$
(DeVRIES 1968).

As the redox potential of the soil usually lies between -0.5 and +0.8 (JACKSON 1956, p. 652), the sulphate sulphur tends to become the dominant and practically only form of the non-mineral-bound inorganic sulphur in the soil.

\section{A. Chemical survey of the sulphur situation in cultivated soils in Finland}

\section{Series of soil samples providing the basis of the survey}

To get an idea of the sulphur situation in cultivated land in Finland, a series of soil samples was collected during the summer of 1969. The samples, taken from the two depths of $0-25 \mathrm{~cm}$ and $25-50 \mathrm{~cm}$, obtained from fields in cultivation, form a sparse network covering the southern and central parts of Finland (Figure 5). The sampling locality was determined in advance from the map, while the precise sampling site was selected with a view to obtaining the most representative sample possible of the dominant soil in the locality. Appendix 1 gives a few important general characteristics of the series of soil samples obtained in this manner. The total number of samples was 104 , of which 62 were surface soil and 42 subsoil, taken from 62 different localities.

The sampling localities $1-44$ were selected exclusively with a view to surveying the sulphur situation, while sampling localities $45-62$ were selected partly according to other criteria. 45a is a sample from a zero plot of a longterm experiment on fertilization and soil improvement at Leteensuo, an experimental station, later disbanded, of the Peat Cultivation Society. 46a is from an unfertilized plot of a field experiment of 1969 while $47 \mathrm{a}$ and $48 \mathrm{a}$ were taken primarily for use in pot experiments. $49 a-62 a$ are sulphur-unfertilized surface soil samples from field experiments with sulphur fertilization combined in most cases with field-scale irrigation. The quartz sand was used in pot experiments.

Of the soil samples, 21 are organogenic, 22 are clay soils, 18 silt and the rest coarse mineral soils. The weight per volume varies between 0.18 and $1.54 \mathrm{~kg}$ per litre of air-dried soil. The average for the peat soils is 0.32 , and for the mineral soils 1.06 , a fact worth bearing in mind when various extraction methods 


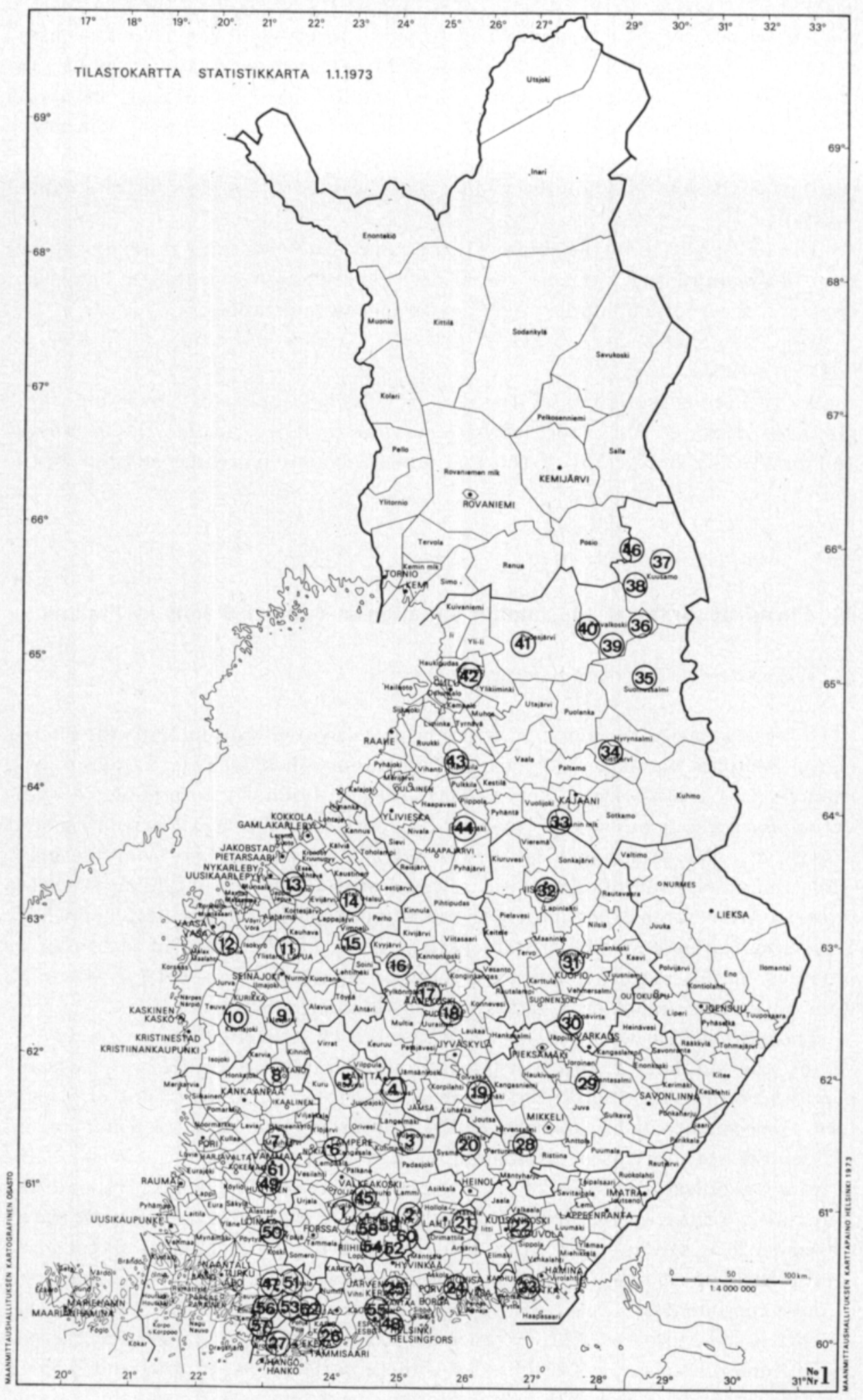

Figure 5. Map of the sampling localities. 
are being developed. The choice between an extraction ratio based on volume and one based on weight becomes difficult if identical criteria are desired for organogenic and mineral soils.

The $\mathrm{pH}$ of the samples varied between 3.3 and 6.4 with 80 per cent of all readings being between 4.0 and 5.4 and the median $\mathrm{pH}$ being 4.8. Such a distribution of $\mathrm{pH}$ values seems to be natural for Finnish conditions and probably fairly well represents the $\mathrm{pH}$ situation of the country as a whole.

The proportion of oxidizable carbon in the peat samples varies between 29.1 and 50.4 per cent. The latter extremely pure peat is a sample of subsoil. Generally, very many cultivated peatlands have a substantial depth of soil in which the carbon content increases with increasing depth. The situation on mineral soils is the reverse, of course, the subsoil containing on average a mere 1.0 per cent of organic carbon while the variation is great in the surface layer, an arithmetic mean thereof providing little information.

\section{Total sulphur and elemental sulphur}

Two criteria for soil sulphur are stated in the present work, i.e., total sulphur and elemental sulphur, which appear to be clearly defined chemically. The analyzed quantities of total sulphur are shown in Appendix 1. The primary results are brought together in Tables 16 and 17. Sample 57a was not included in the compilation because it was much too specific.

Table 16. Amounts of total sulphur grouped according to soil type and sampling depth. Values given in $\mathrm{mg} \mathrm{S} / \mathrm{kg}$ air-dry soil.

\begin{tabular}{|c|c|c|c|c|}
\hline & \multirow{2}{*}{$\begin{array}{l}\text { Number of } \\
\text { samples }\end{array}$} & \multicolumn{3}{|c|}{ Total sulphur } \\
\hline & & $\min$. & $\max$. & $\left.\operatorname{mean}^{1}\right)$ \\
\hline \multicolumn{5}{|l|}{ All samples } \\
\hline mould, peat ................................. & 21 & 530 & 2160 & $1180 \pm 220$ \\
\hline clay soils ..................................... & 22 & 120 & 1140 & $450 \pm 94$ \\
\hline silt, loam .................................... & 18 & 120 & 760 & $410 \pm 100$ \\
\hline finesand, sand ................................. & 42 & 130 & 700 & $310 \pm 43$ \\
\hline \multicolumn{5}{|l|}{ Surface samples } \\
\hline mould, peat ...................................... & 14 & 530 & 1810 & $1130 \pm 240$ \\
\hline 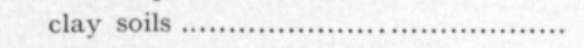 & 15 & 310 & 1140 & $480 \pm 110$ \\
\hline silt, loam .................................... & 10 & 330 & 760 & $520 \pm 120$ \\
\hline finesand, sand ................................. & 22 & 130 & 660 & $350 \pm 61$ \\
\hline \multicolumn{5}{|l|}{ Subsoil samples } \\
\hline mould, peat ............................... & 7 & 740 & 2160 & $1290 \pm 550$ \\
\hline clay soils ...................................... & 7 & 120 & 790 & $370 \pm 210$ \\
\hline 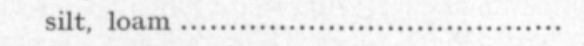 & 8 & 120 & 500 & $280 \pm 120$ \\
\hline finesand, sand ............................... & 20 & 140 & 700 & $270 \pm 60$ \\
\hline
\end{tabular}

1) means $\pm s_{\bar{x}} \cdot t_{0.05}$. 
For the purposes of a survey of the sulphur supply in the cultivated lands of Finland the results shown in Table 16 do not provide a clear picture of the probable occurrence of total sulphur in various soils and at various depths. The wide limits of confidence indicate that neither classification by type of soil nor classification by sampling depth will give a reliable picture of the sulphur situation. Yet it should be obvious that the organic and peat soils generally contain rather a lot of total sulphur per unit of weight.

In order to get an idea of the reasons for the variations, the results of analysis for total sulphur were compared with the general properties that had been determined in the series of soil samples (Appendix 1), the comparison being done by means of linear correlation analysis. The most important of the factors that could not be taken into account in this manner are probably the geological age and origin of the soil samples and the prevailing intensity of cultivation. Sedimentation during the Litorina period, with high sulphur content as a result, is assumed to be the case with at least three of the samples, in which the subsoil contained a surprisingly large amount of sulphur (samples 13b from Purmo, 23b from Karhula and 43b from Rantsila). Samples 13b and $43 \mathrm{~b}$ of these were taken several miles from the present coastline of the Gulf of Bothnia, which shows the immensity of the land elevation in those parts. Sample 57a, from Perniö, taken from a shoreline pasture more or less at the same level as the present surface of the sea, possesses a very high sulphur content originating from a rather recent time. This soil sample, which on account of its exceptionality was not included in the compilations, shows that the sulphur contents in the soils which are still being uncovered through land elevation may rise very high. The high sulphur content in soil sample $60 \mathrm{a}$, from Hausjärvi, is by contrast probably due to intensive cultivation. Any other explanation is, in any event, difficult to provide.

In the entire material the total sulphur shows a relatively close correlation with the amount of organic carbon $\left(\mathrm{r}=0.83^{* * *}\right)$. When the results of the samples were distributed among mineral and organic soils, however, there occurred a decrease in that part of the variation which could be explained in terms of differences in the contents of the organic matter. The results of the analyses on the mineral soils and the regression line for the relationship to the organic carbon are marked out in Figure 6. The soil samples discussed above have been ringed in. The content of total sulphur in the mineral soils shows a relatively close correlation with the organic carbon $\left(r=0.64^{* * *}\right)$. This correlation would become still closer if a few soil samples with marked character of sulphate soil were excluded from the material (the ringed-in points in Fig. 6). In the organic and peat soils the correlation between the total sulphur and the oxidizable carbon is low (Fig. 7).

No clear correlation between sulphur content and soil reaction could be demonstrated in the present material despite the fact that a few samples taken in the coastal regions seem to show in a dried condition a low $\mathrm{pH}$ value typical of sulphate soils and a relatively high content of sulphur (e.g. samples 13b and $23 \mathrm{~b})$.

The elemental sulphur (Table 17) appears to occur in soils in which the content of the total sulphur is high. The analyzed sulphur, however, may in this case 


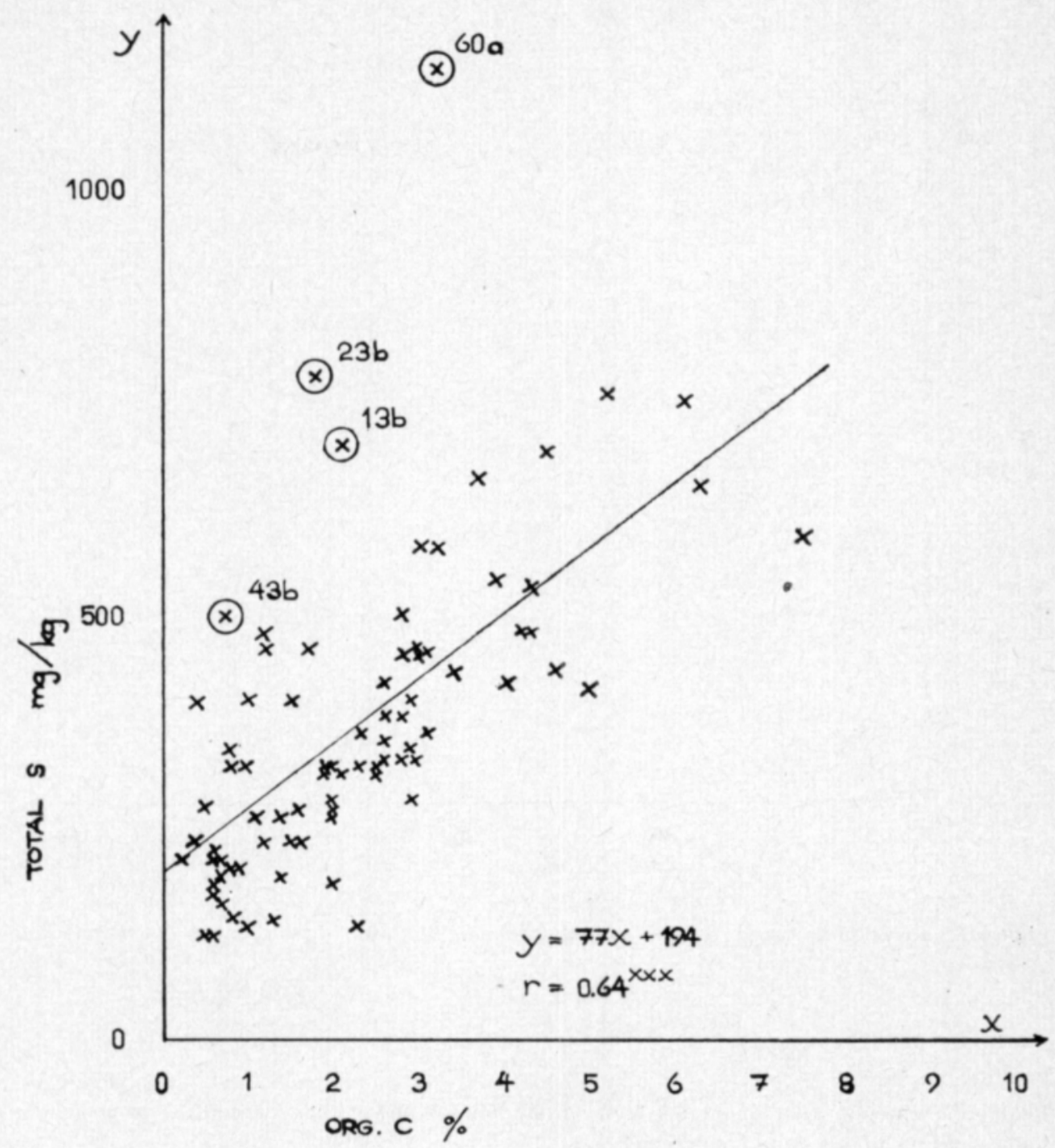

Figure 6. Relation between the contents of total sulphur and organic carbon in mineral soils.

be a pure laboratory product formed at the drying of the samples through interrupted sulphide oxidation. However, the conclusion drawn is that the elemental sulphur is not likely to be of any practical importance in surface soils in the field which are occasionally exposed to drying.

Scattered notes from a number of countries (Johansson 1959, SAALBACH et al. 1962, Jensen 1964, Lowe 1964, 1965, Searle 1968, Seim et al. 1969) show that the total sulphur situation in Finland does not diverge from that in other countries. 


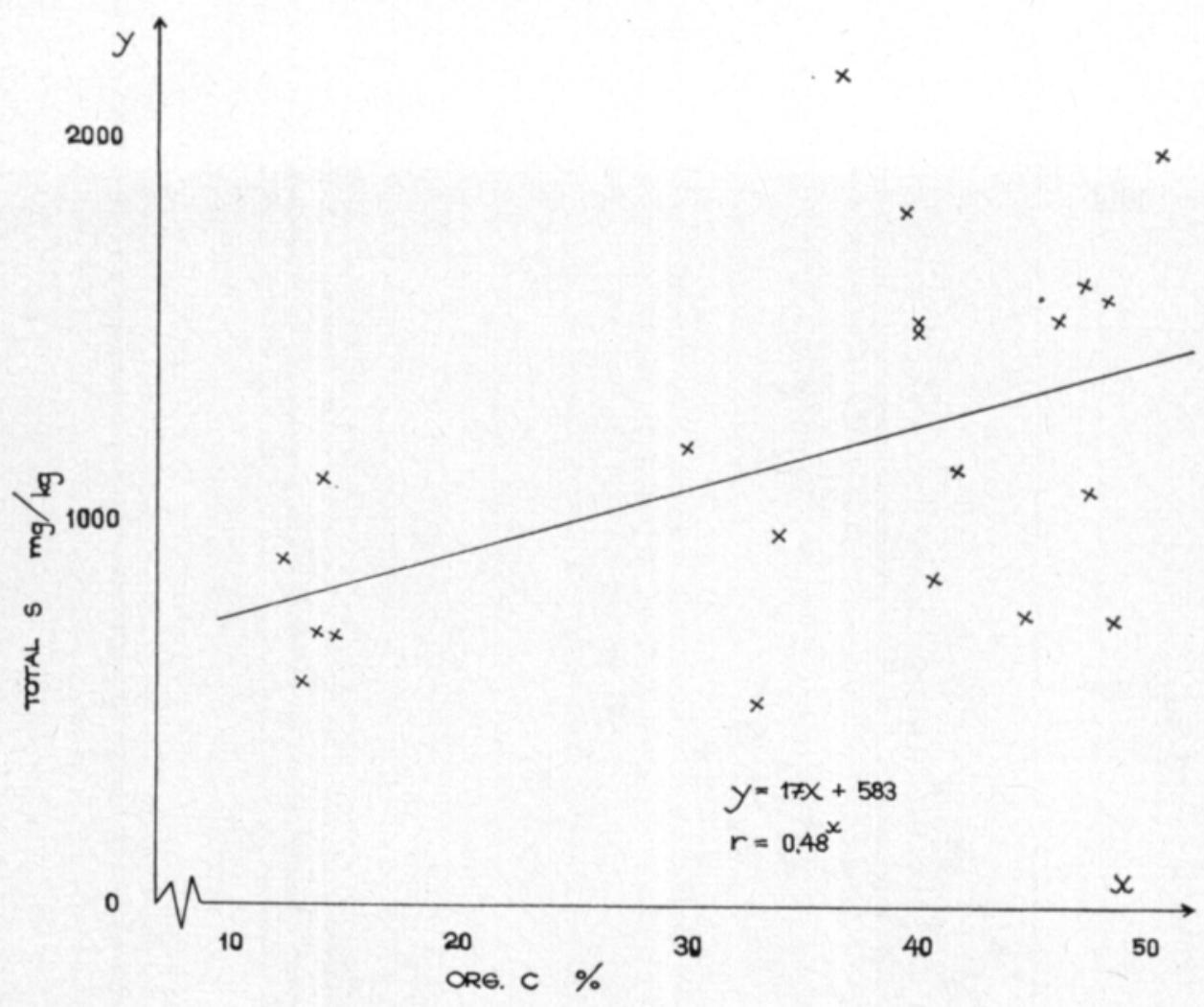

Figure 7. Relation between the contents of total sulphur and organic carbon in mould and peat soils.

Table 17. Amounts of elemental sulphur in subsoil samples grouped according to soil type Values given in $\mathrm{mg} \mathrm{S} / \mathrm{kg}$ air-dry soil.

\begin{tabular}{|c|c|c|c|c|}
\hline & \multirow{2}{*}{$\begin{array}{l}\text { Number of } \\
\text { samples }\end{array}$} & \multicolumn{3}{|c|}{ Elemental sulphur } \\
\hline & & $\min$. & $\max$. & $\overline{\left.\operatorname{mean}^{1}\right)}$ \\
\hline Mould, peat ........................... & 5 & 0.3 & 5.4 & $1.9 \pm 2.8$ \\
\hline Clay soils ............................ & 7 & 0.3 & 7.6 & $1.7 \pm 2.4$ \\
\hline Silt, loam ............................. & 8 & 0.2 & 1.1 & $0.7 \pm 0.3$ \\
\hline Finesand, sand ...................... & 20 & 0.2 & 2.1 & $0.6 \pm 0.3$ \\
\hline
\end{tabular}

1) means $\pm s_{\overline{\mathbf{x}}} \cdot t_{0.05}$. 


\section{Chemical criteria for sulphur available to plants}

a. Sulphur extractable with NaCl, $\mathrm{NaH}_{2} \mathrm{PO}_{4}-\mathrm{CH}_{3} \mathrm{COOH}$ and $\mathrm{CH}_{3} \mathrm{COON} \mathrm{H}_{4}$

The extracted sulphur fractions shown in Table 18 indicate, as does the total sulphur, a great variation; and a classification by type of soil and depth of sampling hardly facilitates the interpretation of the results. Of these extraction liquids the $\mathrm{NaH}_{2} \mathrm{PO}_{4}-\mathrm{CH}_{3} \mathrm{COOH}$ solution ("PA») has usually been able to extract the largest quantities of sulphur, and the acid ammonium acetate solution the smallest, also when the bulk density is taken into account. Extrac-

Table 18. Amounts of NaCl-, $\mathrm{NaH}_{2} \mathrm{PO}_{4}-\mathrm{CH}_{3} \mathrm{COOH}-$, and $\mathrm{NH}_{4}$ Ac-extractable sulphur grouped according to soil type and sampling depth. Values for the former two extractants given in $\mathrm{mg}$ $\mathrm{S} / \mathrm{kg}$ air-dry soil and for the last-mentioned extractant in $\mathrm{mg} \mathrm{S} / \mathrm{l}$ air-dry soil.

\begin{tabular}{|c|c|c|c|c|c|c|c|c|c|c|}
\hline & \multirow{2}{*}{$\begin{array}{l}\text { No. of } \\
\text { samples }\end{array}$} & \multicolumn{3}{|c|}{$\mathrm{NaCl}$-extractable } & \multicolumn{3}{|c|}{$\mathrm{NaH}_{2} \mathrm{PO}_{4}-\mathrm{CH}_{3} \mathrm{COOH}$-extr. } & \multicolumn{3}{|c|}{$\mathrm{CH}_{3} \mathrm{COONH}_{4}$-extr. } \\
\hline & & $\min$. & $\max$. & $\operatorname{mean}^{1}$ ) & $\min$. & $\max$. & $\operatorname{mean}^{1}$ ) & $\min$ & $\max$ & mean $^{1}$ ) \\
\hline \multicolumn{11}{|l|}{ All samples } \\
\hline mould, peat & 21 & 19 & 180 & $82 \pm 24$ & 40 & 350 & $150 \pm 36$ & 2 & 24 & $7 \pm 3$ \\
\hline clay soils ...... & 22 & 13 & 120 & $36 \pm 10$ & 14 & 110 & $47 \pm 10$ & 0 & 180 & $18 \pm 17$ \\
\hline silt, loam .... & 18 & 18 & 180 & $64 \pm 24$ & 15 & 240 & $76 \pm 37$ & 0 & 250 & $34 \pm 36$ \\
\hline finesand, sand & d 42 & 14 & 120 & $37 \pm 7$ & 17 & 160 & $62 \pm 10$ & 1 & 57 & $10 \pm 4$ \\
\hline \multicolumn{11}{|l|}{ Surface samples } \\
\hline mould, peat & 14 & 24 & 180 & $90 \pm 35$ & 64 & 350 & $160 \pm 51$ & 2 & 24 & $8 \pm 5$ \\
\hline clay soils ...... & 15 & 19 & 53 & $32 \pm 7$ & 31 & 74 & $49 \pm 8$ & 0 & 22 & $8 \pm 3$ \\
\hline silt, loam .... & 10 & 18 & 180 & $74 \pm 39$ & 36 & 240 & $91 \pm 54$ & 1 & 250 & $35 \pm 54$ \\
\hline finesand, sand & d 22 & 14 & 77 & $38 \pm 9$ & 28 & 120 & $59 \pm 11$ & 1 & 41 & $7 \pm 4$ \\
\hline \multicolumn{11}{|l|}{ Subsoil samples } \\
\hline mould, peat & 7 & 19 & 130 & $69 \pm 38$ & 40 & 160 & $110 \pm 36$ & 2 & 12 & $5 \pm 4$ \\
\hline clay soils ...... & 7 & 13 & 120 & $46 \pm 35$ & 14 & 110 & $43 \pm 31$ & 2 & 180 & $39 \pm 59$ \\
\hline silt, loam .... & - 8 & 18 & 110 & $51 \pm 26$ & 15 & 230 & $58 \pm 59$ & 0 & 210 & $33 \pm 60$ \\
\hline finesand, sand & d 20 & 14 & 120 & $41 \pm 12$ & 17 & 160 & $66 \pm 19$ & 1 & 57 & $13 \pm 7$ \\
\hline
\end{tabular}

1) means $\pm s_{\bar{x}} \cdot t_{0.05}$.

tion by means of these solutions differs in principle from extraction with sodium chloride in that the two former, on account of the hydrogen peroxide treatment of the extracts, also takes off the most easily extractable organic sulphur while the extraction with $\mathrm{NaCl}$ is merely aimed at ascertaining the amount of soluble sulphate sulphur. It consequently appears strange, initially, that sodium chloride should have given higher results than extraction with $\mathrm{PA}$ in some cases. This is probably because the 1 per cent $\mathrm{NaCl}$ solution, despite the low fixation propensity of the chloride ion, was more effectively able to release fixed sulphate sulphur than was the weak phosphate solution employed in the PA method. 
The NaCl-soluble sulphate sulphur showed a certain correlation with the total sulphur $\left(\mathrm{r}=0.82^{* * *}\right)$ and, on average, made up 9.5 per cent of the latter. The correlation with the organic carbon of the soil samples $\left(r=0.54^{* * *}\right)$ is completely eliminated when the effect of the total sulphur is reduced. This material gives no opportunity of ascertaining whether the sulphate thus extracted was bound in a higher degree with the organic matter or with the mineral particles.

That the question is one of a chemically diffuse sulphur fraction which is extracted in the PA method is shown in the loose relationship with the total sulphur $\left(r=0.63^{* * *}\right)$. The results were affected by the content of organic carbon $\left(\mathrm{r}=0.60^{* * *}\right)$, as in the $\mathrm{NaCl}$ method, indirectly through an increase in the content of total sulphur.

The ammonium acetate extraction is interesting insofar as it could easily be introduced as a routine method, for the same extractant is already being used for the determination of easily soluble phosphorus, potassium and calcium in the routine analyses performed to determine the need for fertilization in commercial farming in Finland. It is important to observe that this method, in contrast to the previous methods, has an extraction ratio between soil and liquid that is based on units of volume. When studying the data on bulk density in Appendix 1, it will be noticed that in this way a 3-7 times greater weight of mineral soil than of the peat soils will be analyzed. The amount of sulphur extracted by the ammonium acetate method was quite independent of the content of organic matter. In the present study this is regarded as being an advantage, as nothing suggests that the organic matter is of any primary importance to the sulphur supply of plants.

Sulphur soluble in ammonium acetate constitutes too small a fraction analytically. Most of the results lie between 2 and $10 \mathrm{mg}$ of S per litre of soil, and the differences are easily covered by small variations in the techniques of analysis and in sampling. The low values are also sensitive to agents that may interfere with the determination of the sulphur. The method seems to give the most reliable results for soils that contain relatively large amounts of sulphur. The extraction seemed to be particularly sensitive to the sulphur in the soils of sulphate-soil type. In samples $23 \mathrm{~b}, 43 \mathrm{a}$ and $43 \mathrm{~b}$ more sulphur was extracted with ammonium acetate than with either of the other methods, when account is taken of the bulk density.

SAAlbach, Kessen and Judel (1962) state slightly lower values for extraction with $\mathrm{NaCl}$ than those obtained in the present study, which is probably due to the higher content of organic matter in the Finnish soils. As shown in the study of method, the difference may also be due to quite different factors, such as a higher content of easily soluble phosphorus in the German soils. The values stated by COOPER (1968) for extraction with $\mathrm{NaH}_{2} \mathrm{PO}_{4}$-acetic acid in New Zealand also seem low. As the carbon content of the soils in question is not stated, it can only be assumed that they were rather poor in humus. It also seems that the soil samples were mainly taken in areas known to be low in sulphur. 
b. Mobilization and immobilization of extractable sulphur at incubation under laboratory conditions

In order that a single extraction may provide an idea of the chances of plants to take up a nutrient from a specific soil during the growing period under conditions that are satisfactory in other respects, the method of extraction should fulfil the following criteria:

1. The extracted fraction must be absorbable in entirety or in determinable proportion.

2. The quantity of substance mobilized during the growing season must be closely correlated with the original extracted quantities, or there should be no mobilization at all.

3. The absorbable non-extractable and non-mobilizing quantity of substance must stand in determinable relationship with the extracted quantity or must be entirely absent.

It is consequently only in those cases in which the wintensity factorn in point 1 stands in known relationship with the "capacity factorn in points 2 and 3 that a single extraction value may provide acceptable information. The part of the nutrient deposit in the soil mentioned under point 3 is the fraction which, analytically regarded, is the one most difficult to define. Consequently, the choice is often made of extraction media that are relatively effective in order that the absorbable non-extracted fraction should be of as little importance as possible. In those cases in which an immobilization reaction takes place instead of mobilization, it must suffice to ascertain whether there is a close relationship between the value of analysis before immobilization and that after immobilization.

In order to investigate how the methods used to extract soluble sulphur relate to point 2 above, an investigation was performed in the laboratory in the following way. $200 \mathrm{ml}$ of soil was placed in each of a number of $400 \mathrm{ml}$ beakers and moistened to field capacity. The beakers were stored for 20 days in a dark room at a temperature of $+20^{\circ} \mathrm{C}$. In order to avoid too great a dryingup in the dry air of the laboratory (relative humidity c. $50 \%$ ) the samples were re-moistened every third day. The number of incubated samples was 97 . Samples 3b, 29a, 30b, 31a, 34a, 38a and 48a had to be excluded, as the amount of soil in stock was insufficient.

The mobilization that occurred during the period of incubation was determined in terms of the difference between the extraction results for soil kept humid for 20 days and those for soil kept dry all the time. Extraction with ammonium acetate was performed on all the soil samples, while 19 of the soils (3a, 7a, 7b, 13a, 13b, 17a, 17b, 23a, 23b, 27a, 27b, 33a, 33b, 37a, 37b, 43a, $43 \mathrm{~b}, 47 \mathrm{a}$ and 53a) were selected for extraction with $1 \% \mathrm{NaCl}$ and $0.03 \mathrm{M}$ $\mathrm{NaH}_{2} \mathrm{PO}_{4}$ in $2 \mathrm{~N}$ acetic acid. The incubated samples were dried before analysis. The change during the period ${ }^{1}$ ) of incubation proved to be rather small

1) The primary results can be seen in the Department of Agricultural Chemistry, University of Helsinki. 
where the extraction with $\mathrm{NaCl}$ was concerned. The highest mobilization and the highest immobilization were $10 \mathrm{mg}$ of $\mathrm{S}$ per $\mathrm{kg}$ of soil. On average $2 \mathrm{mg}$ of $\mathrm{S}$ per $\mathrm{kg}$ of soil was mobilized in the present material, in which the average for sulphur extracted with $\mathrm{NaCl}$ was $67 \mathrm{mg}$ of $\mathrm{S}$ per $\mathrm{kg}$. The amount of mobilization or of immobilization did not stand in any close relationship with the original extracted amounts.

The extraction with $\mathrm{NaH}_{2} \mathrm{PO}_{4}$ tended to produce lower values after incubation than without incubation. The immobilization in all the organic and peat soils was high both absolutely and relatively. A certain equalization of the values of analysis seemed to occur during the incubation. This might have been the result of changes occurring during extended storage of the soil samples, even in dry conditions. On average a good 20 per cent of the extractable sulphur in the peat soils but only 3 per cent of that in the other soils were immobilized during the 20 days on which the samples were kept moist. In view of the practical importance of the method of extraction, it was in any event of interest that the values of analysis before incubation correlated closely with those after incubation $(\mathrm{r}=0.97 * * *)$.

The extraction with acid ammonium acetate showed no definite correlation between mobilization and original value of analysis. On average the result of the analysis increased after incubation by one third, but there were great variations in either direction.

Thus none of the methods of extraction met the criterion under point 2 according to which the mobilization should stand in a known relationship with the original extracted quantity of substance. As the question of the availability to plants of the extracted amount of sulphur could not be unequivocally analyzed, either, the choice of extraction method, for instance extraction with acid ammonium acetate, must be regarded as being a provisional one pending further results of research on the chemical status of sulphur in the soil and the ability of plants to absorb various sulphur compounds (cf. Jones et al. 1972).

\section{B. Supply of sulphur in pot experiments}

The only thing that justifies a method of extraction is the attempt to simulate the nutrient-solving effect of the substances excreted by the plant roots, the ion exchange occurring between plant roots and soil particles and the mobilization processes occurring in the soil on account of biological and chemical activity. The results of the chemical analyses were compared in the present study with the development and sulphur absorption of the plants in pot and field experiments in order to ascertain the reliability of the information provided by the various extraction procedures about the sulphur situation of the soil samples. 
Pot experiments were carried out in greenhouse and in pot-experiment garden at premises of the University of Helsinki at Viikki. The area lies in the geographic centre of the urban district of Helsinki but is not surrounded by any particularly dense or air-polluting built-up sections. As all the experiments were performed under roof, the sulphur content of rainwater was eliminated while absorption directly from the atmosphere might naturally occur. The pot-experiment garden, for instance, only had netted walls, and the change of air must have been very effective there at least. The greenhouse department had automatic aeration in the roof and manual aeration in the walls. The temperature was adjusted to $20^{\circ} \mathrm{C}$ by thermostat, but during sunny summer days this normal temperature was regularly exceeded by $5-10^{\circ} \mathrm{C}$.

The vessels, which could hold 0.5 litres of soil, lacked drainage, and leaching from these pots was thus out of the question. In order to facilitate the exchange of gases between the atmosphere and the bottom layer in the airproof plastic pots, a plastic tube of suitable stiffness and width was bent in such a way that both ends were above the soil while the tube in the soil made a loop towards the bottom of the pot. In that part of the tube which was to run towards the bottom a number of large holes were cut to allow the exchange of gases and liquids. This tube made it possible to water the pots from the surface as well as from the bottom. It may be a good idea not to have to expose the surface to the flow of water, especially when the plants are small and the stems weak.

Irrigation was done with water that had been pressed through an ionexchange column and then allowed to warm up in a large fibreglass basin under the glass roof. The requisite amount of water was determined through weighing. The field capacity for all the soils had been determined in advance in the laboratory. It was the field capacity thus obtained that was the primary object of the irrigation. During the most intensive growing period the pots were irrigated daily.

Fertilization was administered by means of a single application at the establishment of the experiments. Table 19 shows the basic quantities of the various nutrients and the compounds used.

The experiment was started on April 20, 1970 with 87 test soils (soils 1a-48a with the exception of $8 \mathrm{~b}, 19 \mathrm{~b}$ and $21 \mathrm{~b}$ ). All the soils received basic quantities of all nutrients except sulphur. As the amount of soil available for the experiment was limited, only four pots of each soil could be included. Two of these pots were fertilized with sulphur $\left(\mathrm{Na}_{2} \mathrm{SO}_{4}\right)$ while two were left without. Each pot was sown with twelve kernels of Otra barley. They were cut just before coming into ear, on June 22, 1970. 14 soil samples (soils $49 \mathrm{a}-62 \mathrm{a}$ and $21 \mathrm{~b}$ ) were subsequently added, and these were cultivated together with the repeats of the older series in an identical experiment between January 20 and March 3, 1971.

The stalks were cut right at ground level and were then dried and weighed. At the later cutting, on March 3, 1971, two persons independently assessed the effect of the sulphur fertilization according to a scale of $0-4$. The differences in colour, which would not have been taken into account if only weighing had been performed, were thus recorded. 
Table 19. Normal, amounts of nutrients in the pot experiments, and compounds applied in fertilizing and liming.

\begin{tabular}{|c|c|c|}
\hline & $\mathrm{mg} / 1$ soil & chemical compound \\
\hline N & 215 & $\mathrm{Ca}\left(\mathrm{NO}_{3}\right)_{2} \cdot 4 \mathrm{H}_{2} \mathrm{O}$ \\
\hline к & 125 & $\mathrm{KCl}$ \\
\hline $\mathrm{P}$ & 20 & $\mathrm{Ca}\left(\mathrm{H}_{2} \mathrm{PO}_{4}\right)_{2} \cdot \mathrm{H}_{2} \mathrm{O}$ \\
\hline $\mathrm{Mg}$ & 25 & $\mathrm{MgCl}_{2} \cdot 6 \mathrm{H}_{2} \mathrm{O}$ \\
\hline s & 20 & $\mathrm{Na}_{2} \mathrm{SO}_{4}$ \\
\hline Mn & 10 & $\mathrm{MnCl}_{2}$ \\
\hline $\mathrm{Cu}$ & 2 & $\mathrm{CuCl}_{2} \cdot 2 \mathrm{H}_{2} \mathrm{O}$ \\
\hline 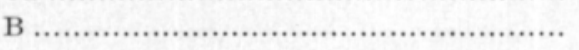 & 1 & $\mathrm{H}_{3} \mathrm{BO}_{3}$ \\
\hline 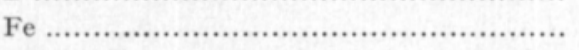 & 0.5 & Fe-EDTA \\
\hline 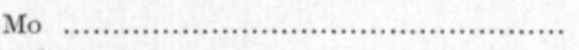 & 0.3 & $\mathrm{Na}_{2} \mathrm{MoO}_{4} \cdot 2 \mathrm{H}_{2} \mathrm{O}$ \\
\hline $\left.\mathrm{Zn}^{1}\right)$ & 0.7 & Zn-EDTA \\
\hline $\left.\mathrm{CaCO}_{3}{ }^{1}\right)$ & 895 & $\mathrm{CaCO}_{3}$ \\
\hline
\end{tabular}

1) Only in sand cultures.

\section{Yields and their dependency on the characteristics of the soil}

The yield from the various soil samples varied a great deal on account of the diversified physical conditions of the soils. The weight of the dried yield in the first cultivation, without fertilization with sulphur, varied between 0.29 and $9.11 \mathrm{~g}$ per pot. The highest yields, with sulphur fertilization, were about $14 \mathrm{~g}$ per pot. Appendix $2^{1}$ ) shows the primary yield results and the up take of sulphur in each case separately. In the first cultivation the sulphur fertilization produced the greatest decrease in a soil of sulphate-soil character (43a) and the greatest increase in a Carex peat soil (38a). The dosage of sulphur produced on average a yield increment of 22 per cent or $0.58 \mathrm{~g}$ per pot. In the pots in which the cultivation was repeated the total yield was mostly somewhat lower than it had been in the first cultivation, and the dependency on sulphur was usually unchanged.

The great differences in the produced plant material had the result that the yield of plant material and sulphur did not, as such, provide sufficient information about the sulphur situation in the sampled soils. Instead, the sulphur situation was assessed on the basis of the increase or the decrease in the yield of plant matter and sulphur that the fertilization with sulphur caused.

When the averages for the dry matter yield and the sulphur absorption were tested by t-test, it appeared that in 38 soils (1a, 6a, 6b, 7a, 7b, 9b, 11b, 14b, 15a, 20a, 20b, 21a, 25a, 25b, 26a, 26b, 27a, 30b, 33a, 33b, 35b, 37a, 37b, $38 \mathrm{a}, 39 \mathrm{a}, 41 \mathrm{~b}, 42 \mathrm{a}, 42 \mathrm{~b}, 47 \mathrm{a}, 49 \mathrm{a}, 50 \mathrm{a}, 51 \mathrm{a}, 52 \mathrm{a}, 54 \mathrm{a}, 55 \mathrm{a}, 56 \mathrm{a}, 61 \mathrm{a}$ and 62a) the fertilization with sulphur had caused a signicant increase either in the yield of plant material or in the uptake of sulphur.

1) Appendix 2 can be seen in the Department of Agricultural Chemistry, University of Helsinki. 
An evaluation of the statistical significance of the change in yield was made impossible in some cases, on account of the fact that the soil sample was insufficient for more than two pots and no replicate could thus be done, or on account of the yield being too small for analysis, or for other reasons. Of these instances, however, a few of the soil samples (8a, 15b, 46a and 48a) were thought to have given a positive result from fertilization with sulphur, in spite of the fact that this could not be statistically demonstrated although it appeared to be quite obvious.

A total of 42 of the 101 test soils, then, reacted positively to the sulphur fertilization in the pot experiment with the 0.5 litre pot. Distributed into classes of soil, these soils are brought together in Table 20 and the averages for the chemical extraction methods for this ssulphur-dependent" group calculated.

Table 20. Extractable sulphur in soils benefiting from sulphur application in pot experiments.

\begin{tabular}{|c|c|c|c|c|}
\hline & $\begin{array}{l}\text { Number of } \\
\text { samples }\end{array}$ & $\begin{array}{l}\text { NaCl-extract. } \\
\mathrm{mg} \mathrm{S} / \mathrm{kg} \text { soil }^{\mathbf{1}} \text { ) }\end{array}$ & $\begin{array}{c}\mathrm{NaH}_{2} \mathrm{PO}_{4}-\mathrm{CH}_{3} \mathrm{COOH} \text {-extr. } \\
\left.\mathrm{mg} \mathrm{S} / \mathrm{kg} \text { soil }{ }^{1}\right)\end{array}$ & $\begin{array}{c}\mathrm{CH}_{3} \mathrm{COONH}_{4} \text {-extr. } \\
\mathrm{mg} \mathrm{S} / 1 \text { soil }^{1} \text { ) }\end{array}$ \\
\hline Mould, peat ...... & 13 & $100 \pm 37$ & $150 \pm 42$ & $4 \pm 2$ \\
\hline Clay soils ......... & 13 & $26 \pm 5$ & $39 \pm 11$ & $6 \pm 3$ \\
\hline Silt, loam ......... & 5 & $41 \pm 7$ & $29 \pm 13$ & $6 \pm 3$ \\
\hline Finesand, sand . & 11 & $30 \pm 9$ & $63 \pm 26$ & $8 \pm 10$ \\
\hline
\end{tabular}

1) means $\pm s_{\vec{x}} \cdot t_{0.05}$.

When the averages given in Table 20 are compared with those in Table 18, which concern all the soil samples, it will be seen that the averages for the soils that gave a positive reaction to the fertilization with sulphur are in most cases lower than the average for the respective complete group of soil samples. The $\mathrm{NaCl}$ and $\mathrm{PA}$ methods, however, produced an increased or unchanged average for the organic and peat soils, and this must be regarded as an expression of the unsuitability of these methods for the analysis of such soils. The PA method moreover gave an implausible result for the finesand and sand soils.

In order to provide a closer study of the conformity between the results of analysis and those of yields, the results were distributed according to sulphur content and to type of soil. The results were converted into volume units by multiplying the original results by the bulk density given in Appendix 1, because the same volume of soil was employed in all cases in the pot experiment. For the extraction with $1 \% \mathrm{NaCl}$ the results of analysis, grouped according to size and soil and compared with the effect of the fertilization with sulphur in pot experiments, obtained the appearance: $\mathbf{1}=$ individual soil sample,/ $=$ significant increment in yield of dry matter and/or sulphur. 


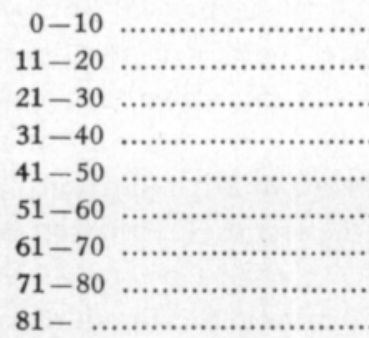

1111
1111111111111
111
111111
111
1111
111
1111

1
1111
1
1111
111

$\begin{array}{ll} & 111 \\ 11111111 & 1111 \\ 1111 & 1111 \\ 1 & 111111 \\ 1111111 & 11 \\ & i\end{array}$

1

$11111 \quad 1$

The conversion into units of volume was necessary for the results of the extraction with $\mathrm{NaCl}$ of the peat soils to be collated into the same classes of size as the mineral soils. The coarser mineral soils seem to be able largely to satisfy the needs of the plants also when they contain rather little sulphur according to the extraction with $\mathrm{NaCl}$.

Classified according to size and soil, the results of the extraction by PA compared with the effect of the fertilization with sulphur obtained the appearance (symbols as in the results of the extraction with $\mathrm{NaCl}$ ):

\begin{tabular}{|c|c|c|c|c|}
\hline $\mathrm{S} \mathrm{mg} / \mathrm{l}$ soil & sand, finesand & silt, loam & clay soils & mould, peat \\
\hline $0-15 \ldots \ldots \ldots \ldots \ldots \ldots \ldots \ldots$ & & & & \\
\hline $16-30 \ldots \ldots \ldots \ldots \ldots \ldots \ldots \ldots$ & 11 & 11 & 1111 & 111111 \\
\hline $31-45 \ldots \ldots \ldots \ldots \ldots \ldots \ldots \ldots \ldots$ & 11111111 & 111111 & 1111111111 & $111_{1}$ \\
\hline 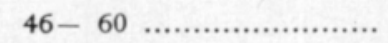 & 1A1111111111 & 11111 & 111 & 111 \\
\hline 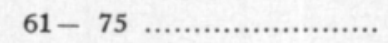 & 11111 & 11 & 1111 & 111 \\
\hline $76-90 \ldots \ldots \ldots \ldots \ldots \ldots \ldots \ldots$ & 11111 & & & 1 \\
\hline 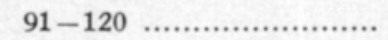 & 111 & & 1 & 111 \\
\hline 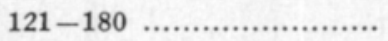 & 11111 & 1 & & \\
\hline $181-\ldots \ldots \ldots+\cdots \cdots+\cdots$ & 1 & 11 & & \\
\hline
\end{tabular}

The distribution of the results for the extraction with $0.03 \mathrm{M} \mathrm{NaH}_{2} \mathrm{PO}_{4}-$ $2 \mathrm{~N} \mathrm{CH}_{3} \mathrm{COOH}$ resembles the distribution for the extraction with $\mathrm{NaCl}$. In this case, too, the extraction seems to provide some information concerning the clay soils, but here, too, there are examples of dependency on sulphur despite relatively high results of analysis.

The analysis with acid ammonium acetate as solvent provides directly similar distributions of results for mineral soils and for organic soils, probably because of the extraction ratio based on volume (symbols as in previous tabulations):

\begin{tabular}{|c|c|c|c|c|}
\hline $\mathrm{S} \mathrm{mg} / \mathrm{l}$ soil & sand, finesand & silt, loam & clay soils & mould, peat \\
\hline 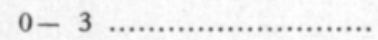 & 111111111111111 & 11111 & 11111111 & 11111111111 \\
\hline 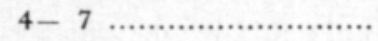 & 11111111111111 & 11 & 111 & 11 \\
\hline 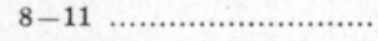 & 111 & 1111 & 11 & 111 \\
\hline 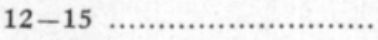 & 111 & 1 & 11111 & 1 \\
\hline 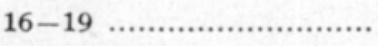 & 11 & 11 & & \\
\hline 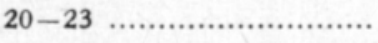 & 1 & 1 & 11 & 11 \\
\hline 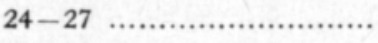 & & 1 & & 1 \\
\hline 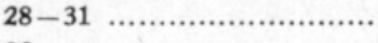 & & & & \\
\hline 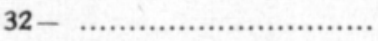 & 111 & 11 & 11 & \\
\hline
\end{tabular}


Few examples of effect of sulphur at high value of analysis give some hope that the method might be of some importance for the assessment of the sulphur situation of the soil. In 54 per cent of the mineral soils and 82 per cent of the organic soils of lowest class, of $0-3 \mathrm{mg}$ of $\mathrm{S}$ per litre of soil, the fertilization with sulphur had a positive effect. Especially where the coarse mineral soils are concerned, there seems to be a need to increase the selectivity of the analysis as the lowest class, too, contains many samples of finesand and sand in which the fertilization with sulphur caused no increase either in yield of plant material or in uptake of sulphur.

The visual assessment of the plants is compared in Table 21 with the results of the extraction with ammonium acetate.

Table 21. Ammonium-acetate extractable sulphur in soils compared with the visible sulphur deficiency symptoms in plants.

\begin{tabular}{|c|c|c|c|}
\hline \multirow{2}{*}{$\begin{array}{l}\text { Group } \\
\mathrm{mg} \mathrm{S} / 1 \text { soil }\end{array}$} & \multirow{2}{*}{$\begin{array}{c}\text { Number of } \\
\text { soils }\end{array}$} & \multicolumn{2}{|c|}{ Positive effect of S application } \\
\hline & & number & $\%$ \\
\hline $0-3$ & 40 & 26 & 65 \\
\hline $4-7$ & 21 & 12 & 57 \\
\hline $8-11$ & 11 & 5 & 45 \\
\hline $12-15$ & 10 & 3 & 30 \\
\hline $16-19$ & 4 & 1 & 25 \\
\hline 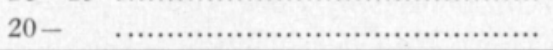 & 15 & 1 & 7 \\
\hline
\end{tabular}

When assessing the classification provided in Table 21, it must be borne in mind that the visual assessment was carried out in greenhouse conditions at a pot experiment with relatively small pots, and consequently with efficient nutrient uptake. The connection between the various classes and the effect of the fertilization with sulphur seems obvious nevertheless. Yet it is evident that the lowest class, too $(0-3 \mathrm{mg}$ of $\mathrm{S}$ per litre of soil), contains many soils in which no improvement of the amount or quality of yield can be obtained with sulphur fertilization.

On the basis of extensive field experiments ØDELIEN (1965) assumes that plants can utilize some of the sulphate sulphur that is not extracted by the ammonium acetate solution used by him. Unfortunately, the $\mathrm{pH}$ value of that solution is not given, but it was probably in the region of 5.8. The higher $\mathrm{pH}$ value (cf. ChANG and Thomas 1963) and the wider extraction ratio may have produced slightly higher quantities of sulphur than those obtained in the present study. It might be conceivable, on the other hand, that a lowering of the $\mathrm{pH}$ value of the extraction liquid may be justified in order that the propensity of the soil to fix sulphate may be raised and the extracted fraction thus confined to the most easily available part. In soils dominated by hydrous aluminium oxide in the anion-fixing colloidal fraction, a fixation maximum has been discovered at a $\mathrm{pH}$ of 4.0 (CHAO. et al. 1964). (How such a soil pH was measured is not stated, but the question is probably one of soil-water suspension.) There might be reason not to go under this value in the choice of 
acidity of extraction liquid. BYRne and HANLEY (1970) also obtained the most reliable results with an extraction liquid with a $\mathrm{pH}$ value of 4.8 ( $\mathrm{Na}$ acetate) when a comparison was made with some other common extraction liquids $\left(\mathrm{NH}_{4} \mathrm{Ac}, \mathrm{CaCl}_{2}, \mathrm{Na}_{2} \mathrm{CO}_{3}\right.$ and $\left.\mathrm{Ca}\left(\mathrm{H}_{2} \mathrm{PO}_{4}\right)_{2}\right)$.

\section{Sulphur supply in field experiments}

Without chemical soil analyses and pot experiments it is often difficult to forecast and explain various occurrences in field conditions. For commercial farming the results obtained in field experiments in natural conditions, however, are those of greatest interest. As the experiments arranged in connection with this investigation of sulphur made use of quite varied experimentation techniques for practical reasons, the technique employed will be described in the context of the respective series of experiments.

\section{Experimental results from North Finland}

In 1969 a few field experiments were arranged at Kuusamo, where a peculiar indifference to increased nitrogen and compound fertilization for ley had been observed during preceding years. These experiments were established by Typpi Oy, which had already received complaints in 1968 from fertilizer users at Taivalkoski and Posio, too, that the compound fertilizers of the manufacturer gave poor yields of hay with continued dressings on peat soils. As these types of compound fertilizer were practically free of sulphur at that time, it was natural that a deficiency in sulphur should be suspected as being the cause of the loss in yield.

With the experiments of 1969 there was determination to get an idea of the causes of the troubles with fertilization, and a very large number of treatments were consequently included (36 treatments in all), 14 of which had identical fertilization with nitrogen, phosphorus and potassium and could be used for comparison of the effect of sulphur. The experiments were in the nature of demonstrations and consequently lacked local replicates, but they were repeated at two separate localities (experimental sites 37 and 38), which are regarded as being replicates in the statistical calculations.

The field experiment was established on timothy leys on Carex peat where wintering had been as even as possible. The plots were manually fertilized on June 7. The harvest was movn on July 30 and during the first days in August. The weather conditions during the experimental period were fairly good, which can be seen from the results given for the observation station at Kuusamo in Table 22. The effect of the topdressing was obviously improved by a slight rain on June $12-13$.

In the experiments $216 \mathrm{~kg}$ of $\mathrm{N}$ per hectare was applied, in the form of nitrate and also partly in the form of ammonium. $90 \mathrm{~kg}$ of $\mathrm{P}$ per hectare was applied, partly in the form of superphosphate and partly in the form of nitrophosphate based compound fertilizer. $108 \mathrm{~kg}$ of $\mathrm{K}$ per hectare was applied, 
Table 22. Monthly averages of daily mean temperatures ${ }^{1}$ ) and precipitation at some meteorological stations situated in the vicinity of the experimental fields.

\begin{tabular}{|c|c|c|c|c|c|c|c|c|}
\hline & \multicolumn{2}{|c|}{ May } & \multicolumn{2}{|c|}{ June } & \multicolumn{2}{|c|}{ July } & \multicolumn{2}{|c|}{ Angust } \\
\hline & ${ }^{\circ} \mathrm{C}$ & $\mathrm{mm}$ & ${ }^{\circ} \mathrm{C}$ & $\mathrm{mm}$ & ${ }^{\circ} \mathrm{C}$ & $\mathrm{mm}$ & ${ }^{\circ} \mathrm{C}$ & $\mathrm{mm}$ \\
\hline \multicolumn{9}{|l|}{1969} \\
\hline \multirow{2}{*}{ Kuusamo ........................... } & 1.9 & & 10.3 & & 14.1 & & 13.3 & \\
\hline & & 9.7 & & 34.5 & & 44.3 & & 54.2 \\
\hline \multicolumn{9}{|l|}{1970} \\
\hline \multirow[t]{2}{*}{ Helsinki, Airport ............. } & 9.9 & & 17.2 & & 16.6 & & 15.8 & \\
\hline & & 25.1 & & 11.5 & & 136.1 & & 21.7 \\
\hline \multirow[t]{2}{*}{ Hyvinkää ........... } & 9.5 & & 16.5 & & 16.0 & & 14.7 & \\
\hline & & 30.1 & & 10.2 & & 100.8 & & 30.9 \\
\hline \multirow[t]{2}{*}{ 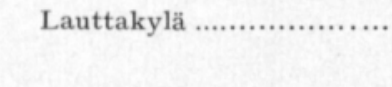 } & 9.7 & & 17.1 & & 15.9 & & 14.6 & \\
\hline & & 11.8 & & 2.7 & & 124.2 & & 25.8 \\
\hline \multirow[t]{2}{*}{ 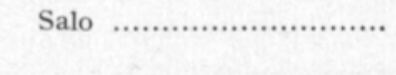 } & 9.9 & & 17.1 & & 16.4 & & 15.1 & \\
\hline & & 24.0 & & 9.8 & & 133.8 & & 41.9 \\
\hline
\end{tabular}

1) Mean temperature $=1 / 4\left(t_{02}+t_{03}+t_{14}+t_{20}\right)+k$, where the empirical correction term (k) has the following values in various months:

$$
\begin{array}{cccccccccccc}
\text { I } & \text { II } & \text { III } & \text { IV } & \text { V } & \text { VI } & \text { VII } & \text { VIII } & \text { IX } & \text { X } & \text { XI } & \text { XII } \\
-0.04 & +0.01 & +0.17 & 0.00 & -0.12 & -0.07 & -0.15 & -0.11 & +0.08 & +0.05 & -0.03 & -0.03
\end{array}
$$

either in the form of $60 \%$ potassium salt or as compound fertilizer. The sulphur was applied partly in the form of gypsum in simple form or in the superphosphate, and partly in the form of magnesium sulphate or copper sulphate. As the yield was not affected by magnesium, copper or boron, the plots in which the addition of any of these agents caused a changed situation in sulphur fertilization were included in Table 23 in such a way as if all the effect had derived from sulphur.

The amount and sulphur content of the timothy yield increased through fertilization with sulphur. $10 \mathrm{~kg}$ of $\mathrm{S} / \mathrm{ha}$ already seemed to have been enough to relieve the deficiency fairly well, but a larger dosage of sulphur produced a further increment in the sulphur content. It is a pity that there were no sulphur levels between 10 and $54 \mathrm{~kg}$ of S/ha, as it is conceivable that the optimum dosage of sulphur might lie within these limits, considering the intensity of the rest of the fertilization.

The relatively clear dependency of the yield upon the amount of sulphur in the fertilizer was expected, although the result is probably the first of its kind in field conditions in Finland. The surface layer of both experimental fields had a content of sulphur extractable with ammonium acetate of only $3 \mathrm{mg}$ per litre of soil. There were no local sources of emission of airborne sulphur, and the fairly intensive cultivation of leys had in the preceding years been carried out with the utilization of fertilizers completely free of sulphur. Other field experiments of the nature of demonstrations which were performed at 
Table 23. Yield of timothy grass and its sulphur content in field experiments carried out in Kuusamo in 1959 on Carex peat. ${ }^{1}$ )

\begin{tabular}{cccc}
\hline $\begin{array}{c}\text { Added sulphur } \\
\mathrm{kg} \mathrm{S} / \mathrm{ha}\end{array}$ & $\begin{array}{c}\text { Number of } \\
\text { crops }\end{array}$ & $\begin{array}{c}\text { Average yield } \\
\text { fresh matter } \\
\text { tons/ha }\end{array}$ & $\begin{array}{c}\text { Average sulphur } \\
\text { content \% of } \\
\text { dry matter }\end{array}$ \\
\hline 0 & 7 & $8.39^{\mathrm{a}}$ & $0.13^{\mathrm{a}}$ \\
10 & 2 & $16.60^{\mathrm{ab}}$ & $0.15^{\mathrm{ab}}$ \\
54 & 6 & $19.10^{\mathrm{b}}$ & $0.18^{\mathrm{ab}}$ \\
64 & 2 & $18.50^{\mathrm{b}}$ & $0.21^{\mathrm{abc}}$ \\
96 & 2 & $17.90^{\mathrm{b}}$ & $0.21^{\mathrm{abc}}$ \\
108 & 2 & $20.30^{\mathrm{b}}$ & $0.32^{\mathrm{d}}$ \\
150 & 4 & $16.50^{\mathrm{b}}$ & $0.25^{\mathrm{b}}$ \\
162 & 2 & $20.90^{\mathrm{b}}$ & $0.22^{\mathrm{bc}}$ \\
\hline
\end{tabular}

1) Means in each column followed by a common letter do not differ at $\mathrm{P}=0.05$.

a few other localities in the same region also seemed to show that the area of acute sulphur deficiency on peat soil extended over the districts of Posio, Kuusamo and Taivalkoski. The results of the analyses from experimental sites 39 and 46 also seem to speak in favour of this statement.

\section{Experimental results from South Finland}

During 1970 the experimental operations were transferred to South Finland and comprised ten experiments in which the fertilization with sulphur was combined with irrigation and three experiments in which the fertilization with sulphur was combined with supplementary fertilization with nitrogen. The experimental fields were located on farms with intensive cultivation of cereals, as it was assumed that any deficiency in sulphur would first reveal itself on farms where the use of other nutrients was great. On the other hand, no attempts were made to select the locations with a view to suspected or observed deficiency in sulphur.

The sulphur fertilizer consisted of industrial-grade sodium sulphate $\left(\mathrm{Na}_{2} \mathrm{SO}_{4}\right)$ with a sulphur content of a good 22 per cent. The solubility in water of the utilized salt was $378 \mathrm{~g} / \mathrm{l}$ at $20^{\circ} \mathrm{C}$ and $72 \mathrm{~g} / \mathrm{l}$ at $4^{\circ} \mathrm{C}$ according to performed investigations. The relatively high solubility in water was necessary in order that the surface-spread fertilizer might act in the soil with sufficient rapidity. In the experiments with irrigation the fertilizer was spread between May 21 and 28 i.e., little more than a week after sowing, the spreading being done with Juko-fertilizer placement drills of $2.5 \mathrm{~m}$ working width. The fertilizer coulters were kept close to the soil in order to prevent the wind from carrying off the powdery salt. In the three experiments comprising sulphur fertilization in combination with supplementary nitrogen, both the sodium sulphate and the ammonium nitrate limestone were spread by hand over the soil surface about one week after sowing, i.e. about May 20. 
The weather during summer 1970, expressed in quantity of rainfall and in averages for the daily mean temperatures at four locations in South Finland, is shown in Table 22. Helsinki Airport is the location closest to the experiment at Pakankylä (55), and Hyvinkää may represent the conditions at locations $52,54,58,59$ and 60 , Lauttakylä those at locations 49,50 and 61 , and Salo those at 51, 53, 56 and 62 . June was extremely dry in 1970 at all the locations, and the rainfall only amounted to $5-25$ per cent of the average for long-term observations. By contrast July was rather wet, the amounts of precipitation being 139-187 per cent of the mormaln. Under such conditions the surface spreading of the fertilizers was an unsatisfactory method. Observations out in the field, and the degree of ripeness of the harvested product, also indicated that the broadcast fertilizers were not washed down into the root zone and could not be taken up by the plants until July.

In the field experiments in which the fertilization with sulphur was combined with an increased dosage of nitrogen, the idea was that an intensified growth would speed up the emergence of symptoms of sulphur defiency on account of the nitrogen supplement. The basic fertilization consisted of $400 \mathrm{~kg}$ of compound fertilizer $(\mathbf{1 5}-\mathbf{8 . 8}-\mathbf{1 2 . 5})$ per hectare drilled in before sowing. This quantity of fertilizer contained less than $2 \mathrm{~kg}$ of $\mathrm{S}$ per hectare. Increments of nitrogen (54 kg of $\mathrm{N} / \mathrm{ha}$ in the form of ammonium nitrate limestone) or of sulphur (40 $\mathrm{kg}$ of $\mathrm{S} / \mathrm{ha}$ ) or of both were applied with four replicates at each experimental location. The experimental plots were $48 \mathrm{~m}^{2}$ at two of the locations and $28.8 \mathrm{~m}^{2}$ at one. The plant was Ruso spring wheat at location 52, Ingrid barley at location 55 and Sisu oats at location 56. The nitrogen produced a large number of green secondary shoots on account of the unfavourable weather conditions, as appears in Table 24, in the high moisture contents in the cereal from the plots fertilized with nitrogen. Perhaps it was this that resulted in the absence of effect of sulphur and interaction between sulphur and nitrogen. At location 56 in Perniö the oats grew so well without supplementary fertilization that the nitrogen caused a decrease in yield on account of the early lodging of the crop.

Table 24. Results from three field experiments on finesand (52a), silty clay (55a), and heavy clay (56a). Grain yields expressed in $\mathrm{kg} / \mathrm{ha}$ and grain moistures in per cent at harvesting.

\begin{tabular}{|c|c|c|c|c|c|c|c|}
\hline \multirow{4}{*}{$\begin{array}{l}\text { With basic fertilizing } \\
\text { Additional treatment }\end{array}$} & \multicolumn{2}{|c|}{$52 \mathrm{a}$} & \multicolumn{3}{|c|}{$55 a$} & \multicolumn{2}{|r|}{$56 \mathrm{a}$} \\
\hline & Yield & oisture & & Yield & Moisture & Yield & Moisture \\
\hline & 3240 & 26.2 & & 3520 & 24.7 & 4710 & 26.6 \\
\hline & & & e $f$ & $f$ e c & $\mathrm{t}$ & & \\
\hline S & -60 & -0.7 & & -10 & -0.1 & -160 & -0.5 \\
\hline $\mathrm{N}$ & $+310^{*}$ & $+4.0^{* * *}$ & & $+360^{* *}$ & $+7.9^{* * *}$ & $-580^{* *}$ & +1.4 \\
\hline $\mathrm{S} \times \mathrm{N} \ldots \ldots \ldots \ldots \ldots$ & +90 & -0.4 & & +20 & -0.7 & -40 & -0.9 \\
\hline
\end{tabular}

The sulphur content in the samples representatively taken at threshing did not clearly indicate that the fertilization with sulphur had any increasing effect. The sulphur concentration in the wheat (52) apparently varied independently of the fertilization from 1.07 to $2.14 \mathrm{~g}$ of $\mathrm{S}$ per $\mathrm{kg}$, and averaged 
1.6 of $\mathrm{S}$ per $\mathrm{kg}$. The respective values for the barley were $1.22-2.01 \mathrm{~g}$ of $\mathrm{S}$ per $\mathrm{kg}$, the average being $1.5 \mathrm{~g}$ of $\mathrm{S}$ per $\mathrm{kg}$, and for the oats $1.3-1.6$ with an average of $1.4 \mathrm{~g}$ of $\mathrm{S}$ per $\mathrm{kg}$.

In the experiments in which the fertilization with sulphur was combined with irrigation, the aim was to maximize the nutrient consumption of the plants by means of water increment. The experiments were established on the farms with the basic fertilization and crop demanded by the commercial farming. The original conditions appear in Table 25. The geographical position of the locations appears in Figure 5, and the characteristics of the soils in Appendix 1. The spreading of the supplementary sulphur (40 kg of S per hectare), the irrigation and the harvesting were carried out by the experimental personnel, while the basic fertilization, the sowing and the plant protection measures were performed by the farmers concerned.

Table 25. Experimental crop, basic fertilization and its sulphur content in the case of ten field experiments on sulphur application combined with irrigation.

\begin{tabular}{|c|c|c|c|}
\hline $\begin{array}{l}\text { Location } \\
\text { number }\end{array}$ & Crop & $\begin{array}{c}\text { Basic fertilization } \\
\text { kg/ha } \\
(\mathrm{N}-\mathrm{P}-\mathrm{K} \%)\end{array}$ & $\begin{array}{c}\text { Basic sulphur } \\
\text { amount } \\
\text { kg S/ha }\end{array}$ \\
\hline 49 & 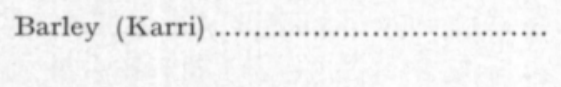 & $\begin{array}{c}750 \\
(15-8.8-12.5)\end{array}$ & 3 \\
\hline 50 & 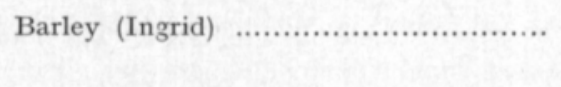 & $\begin{array}{c}700 \\
(15-11.0-8.3)\end{array}$ & 4 \\
\hline 51 & 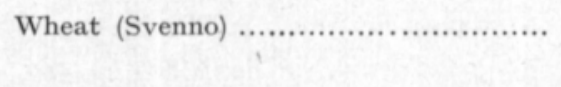 & $\begin{array}{c}600 \\
(20-4.4-8.3)\end{array}$ & 42 \\
\hline 53 & Wheat (Ruso) & $\begin{array}{c}700 \\
(20-8.8-0)\end{array}$ & 18 \\
\hline 54 & 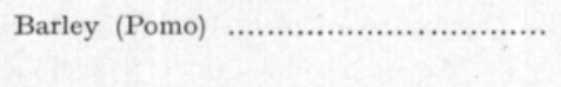 & $\begin{array}{c}500 \\
(15-8.8-12.5)\end{array}$ & 2 \\
\hline 58 & 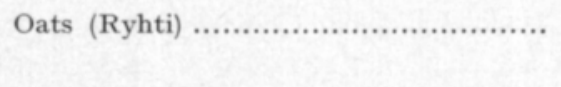 & $\begin{array}{l}500 \\
(13-10.1-16.6)\end{array}$ & 4 \\
\hline 59 & 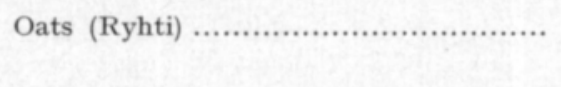 & $\begin{array}{c}500 \\
(13-10.1-16.6)\end{array}$ & 4 \\
\hline 60 & 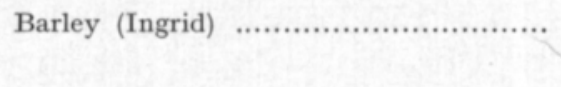 & $\begin{array}{c}600 \\
(15-8.8-12.5)\end{array}$ & 2 \\
\hline 61 & 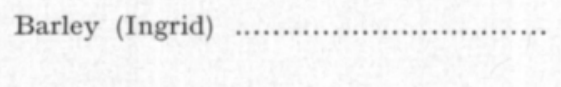 & $\begin{array}{c}750 \\
(15-8.8-12.5)\end{array}$ & 3 \\
\hline 62 & 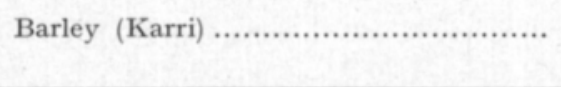 & $\begin{array}{c}500 \\
(20-8.8-0)\end{array}$ & 13 \\
\hline
\end{tabular}

In order that compaction of the tractor at plots fertilized with sulphur should not give rise to experimental error, the unfertilized plots were run over with the same tractor. The irrigation by sprinkler was performed at an intensity of 3-10 $\mathrm{mm}$ per hour. The first irrigation was done slightly more than 3 weeks (9-16 June) after the sowing, and on the twice-irrigated plots this treatment 
was repeated some 10 days later. As it was the intention to raise the moisture of the soil to field capacity, the total amount of water varied from case to case. The irrigation amounted to $39 \mathrm{~mm}$ per time on average.

The experimental locations individually would in no case have provided a statistically reliable effect for sulphur on the quantity or quality of yield, and Table 26 consequently shows the most important results as averages for all the experimental locations. The same index mark in one and the same column indicate that there is no significant difference.

Table 26. Average grain yield and its moisture, sulphur, and nitrogen contents. $I_{0}=$ without irrigation, $I_{1}=$ irrigated once, $I_{2}=$ irrigated twice. $S_{0}=$ without additional sulphur, $S_{1}=$ $\left.40 \mathrm{~kg} \mathrm{~S} / \mathrm{ha} \operatorname{added}^{\mathbf{1}}\right)$.

\begin{tabular}{|c|c|c|c|c|}
\hline & $\begin{array}{l}\text { Yield } \\
\mathrm{kg} / \mathrm{ha}\end{array}$ & $\begin{array}{c}\text { Moisture } \\
\%\end{array}$ & $\begin{array}{l}\text { Sulphur } \\
\text { g S/kg D.M. }\end{array}$ & $\begin{array}{c}\text { Nitrogen } \\
\text { g N/ kg D.M. }\end{array}$ \\
\hline $\mathrm{I}_{0} \mathrm{~S}_{0} \ldots \ldots \ldots \ldots \ldots \ldots \ldots \ldots \ldots \ldots \ldots$ & $3550^{\mathrm{a}}$ & $31.8^{\mathrm{a}}$ & $1.13^{\mathrm{c}}$ & $22.7^{\mathrm{a}}$ \\
\hline $\mathrm{I}_{0} \mathrm{~S}_{1} \ldots \ldots \ldots \ldots \ldots \ldots$ & $3540^{\mathrm{a}}$ & $31.5^{\mathrm{a}}$ & $1.10^{\mathrm{bc}}$ & $22.8^{\mathrm{a}}$ \\
\hline $\mathrm{I}_{1} \mathrm{~S}_{0} \ldots \ldots \ldots \ldots \ldots \ldots$ & $4340^{\mathrm{b}}$ & $27.7^{\mathrm{a}}$ & $1.01^{\mathrm{a}}$ & $21.6^{\mathrm{a}}$ \\
\hline $\mathrm{I}_{\mathbf{1}} \mathrm{S}_{1} \ldots \ldots \ldots \ldots \ldots \ldots \ldots$ & $4340^{\mathrm{b}}$ & $27.7^{\mathrm{a}}$ & $1.07^{\mathrm{b}}$ & $21.6^{\mathrm{a}}$ \\
\hline $\mathrm{I}_{2} \mathrm{~S}_{0} \ldots \ldots \ldots \ldots \ldots \ldots \ldots$ & $4600^{b}$ & $26.5^{\mathrm{a}}$ & $0.99^{\mathrm{a}}$ & $20.9^{\mathrm{a}}$ \\
\hline $\mathrm{I}_{2} \mathrm{~S}_{1} \ldots \ldots \ldots \ldots \ldots \ldots \ldots$ & $4600^{\mathrm{b}}$ & $26.1^{\mathrm{a}}$ & $1.08^{\mathrm{b}}$ & $20.9^{\mathrm{a}}$ \\
\hline
\end{tabular}

f) Means in each column followed by a common letter do not differ at $\mathrm{P}=0.05$.

The increment of sulphur did not affect the amount of yield or the moisture content of the cereal on these experimental fields. Small but noticable changes, however, could be discerned in the sulphur content of the grains. Without sulphur fertilization the irrigation produced a slightly decreased content of sulphur, but this decrease could be counteracted through the fertilization. This circumstance could be taken as indicating that although the supply of sulphur may have been sufficient for a good yield, it was nevertheless not unlimited and some shortage may have arisen during heavy absorption.

That the fertilization with sulphur did not produce an increased concentration of sulphur without irrigation is surprising, considering that July was very rainy and that the sodium sulphate should have become dissolved by that month at the latest. Whether this was due to a lowered absorption of sulphur towards the end of the growing season or to other factors could not be discovered.

The experiments with the various types of spring cereal on mineral soils in South Finland showed that under the prevailing conditions the increment in sulphur had an insignificant effect on the development of the plants. The sulphur content of the basic fertilization was so high in some cases that no effect was to be expected. Even a small amount of sulphur in the fertilization can be of importance, especially as local increments in the sulphur fallout from the atmosphere can be counted upon in the densely settled parts of South Finland. The cereal plants are, too, among those that require least sulphur. 


\section{Comparison between field and pot experiments}

A circumstance that often throws doubt upon the use of the technique of the pot experiment is the unclear relationship between such experiments and the natural conditions in the field. In order to clarify this question a comparison was made between the results of the field experiments and those of the pot experiments with the same soils in pots of $\mathbf{5}$ and 0.5 litres. The basic fertilization in the experimental fields had been performed by the time at which the soils for the pot experiments were taken. The sample soils represented the cultivated soil layer from the surface to a depth of $25 \mathrm{~cm}$. In the pots the fertilization was applied according to Table 19. There were two treatments, one with sulphur and one without, while the other nutrients were added to all the pots.

The experiment with the 5-litre pots was carried out partly indoors, in a greenhouse with the temperature set at $20^{\circ} \mathrm{C}$, and partly in a pot shed in which the temperature corresponded rather closely with outdoor conditions. These experiments were sown on June 26, 1970 and were harvested at the end of August. Every treatment had three replicates, and the plant was the same as in the respective field experiment. This comparison was performed for 12 of the experimental locations in South Finland, where the field experiments did not give any positive result for sulphur fertilization. Location 56a was excluded in this connection, as it had been the subject of detailed study in another connection $\left.^{1}\right)$.

In the pot experiments with 5-litre pots two of the soils (55a and 61a) provided a positive result for fertilization with sulphur in respect of the grain and the straw yield. The other soils $(49 a, 50 a, 51 a, 52 a, 53 a, 58 a, 59 a, 60 a$ and $62 a)$ by contrast provided no signs that the fertilization with sulphur had affected the growth of the sulphur uptake in any way. In the material there was no connection between the fertilization with sulphur and the temperature conditions where the grain yield is concerned. In one of the soils, however (61a), the sulphur in combination with the lower temperature produced the biggest yield of straw, there being an interaction between the sulphur and the temperature (cf. Herath and Ormrod 1971). It is conceivable that the rather low temperature in field conditions in Finland may cause a greater need for sulphur than is the case in warmer places or in greenhouse environment.

In the smaller pots the plants seemed to be more dependent upon the added nutrients. In six clay soils $(49 \mathrm{a}, 50 \mathrm{a}, 51 \mathrm{a}, 55 \mathrm{a}, 61 \mathrm{a}$ and $62 \mathrm{a})$, one finesand soil (52a) and one silt soil (54a) the fertilization with sulphur caused an increase in the uptake of sulphur in the barley plants cut when coming into ear. The silty clay soil rich in organic matter (53a) in which the fertilization with sulphur seems to have had a negative effect was also the soil with the highest content of sulphur extractable with $\mathrm{NH}_{4}$-Ac. Sulphur thus had an effect in none of the twelve cases in the field, in two cases out of the twelve in the 5-litre pots and in eight cases out of the twelve in the 0.5 litre pots. As the active volume of soil in the field is calculated at 2.5 million litres per hectare, the production

1) ErJALA, M. 1971. Liejusavien rikkivaroista. Graduate work 90 pp. 
of dry matter in the respective conditions was about 4,8 and $12 \mathrm{~g}$ per litre of soil. The differences in the production of dry matter appears to be smaller than the differences in the dependency on sulphur. The optimum conditions of humidity and, often, of temperature in pot experiments, however, usually make the plants develop more quickly than they do in the field. According to the experience provided by the present study of sulphur, this time factor should also be taken into account when comparative experiments are being performed. The average period of growth was 105 days in the field experiments, 65 days in the 5 -litre pots and 45 days in the small pots, and the dry matter production per day is consequently $0.04,0.12$ and $0.27 \mathrm{~g}$ per litre of soil in these three growing conditions respectively. This gives an intensity ratio of $1: 3: 7$, which resembles the results of the experiments with sulphur.

It is obvious that a comparison of this kind between conditions of cultivation has many weaknesses. Firstly, the crop of the small pots was not cut when ripe, which was the case with the field experiments and the 5-litre pots. It might be said that a constant and even production of dry matter up to the time of ripeness would be necessary, but this is not quite realistic. Secondly, a supply of sulphur in the rainwater could not be prevented in the field. The calculation nevertheless provides a picture of how different the situation may be between field conditions and pot conditions. Such a difference is well reflected in the effect of sulphur fertilization on the various soils. 


\section{Dependence of the availability of sulphur to the plants upon the supply of certain other nutrients}

If it is assumed that the information provided by chemical analysis on the sulphur situation of the soil is really relevant in view of the opportunities of plants to satisfy their need for sulphur (cf. section on mobilization of sulphur), the differences in growth observed in pot and field experiments must have their origin in some other factor. The differences may be due to variations in the sulphur fallout from the atmosphere on account of the geographical location, or due to variations in leaching propensity of incremental sulphur in field conditions, or due to other differences caused by the climate.

In this chapter an analysis is made of the differences that may be due to variations in the supply of some other nutrients. The experimental technique employed ensured that no leaching occurred, and any effect that one nutrient has upon the leaching propensity of another may consequently be disregarded. In field conditions, however, this is a factor that must be taken into account. In the experiments carried out with sand cultures the substrate probably had no nutrient-absorbing features worth mentioning. The relationships ascertained in these cases are consequently held to have originated in processes of plant physiology alone. In samples of natural soil, however, it is necessary to take account, too, of the propensity of the soil to fix various nutrient ions.

\section{A. Relationship between sulphur and nitrogen}

Probably on account of the central role of sulphur and nitrogen in the structure of proteins, the supplies of sulphur and nitrogen in plants are highly integrated. O'CONNOR and VARTHA (1969) were consequently able to demonstrate that a large dosage of gypsum gave a reduced yield of ley when the nitrogen situation of the soil was unsatisfactory. EPPENDORFER (1969), on the other hand, was able to induce symptoms of sulphur deficiency by means of large dosages of nitrogen.

Three pot experiments were established in this study in an attempt to clarify the relationship between sulphur and nitrogen.

\section{Physiological effect of ammonium nitrogen and nitrate nitrogen on the sulphur supply}

A pot experiment with Otra barley in a 0.5-litre pot was performed from July 10 to August 4, 1969 with washed quartz sand as substrate. 1 per cent by weight of undecayed Sphagnum peat was mixed into the sand to give it 
solidity and better water-retentiveness. Both the peat and the sand had been treated with hydrochloric acid $(\mathrm{HCl})$ prior to use, and were thereafter rinsed with water until the leached water no longer showed any acid reaction.

In this pot experiment the fertilization was identical with that shown in Table 19 except in respect of sulphur and nitrogen. There were three levels of sulphur: no addition $\left(\mathrm{S}_{0}\right), 2.5 \mathrm{mg}$ of $\mathrm{S}$ per litre of soil $\left(\mathrm{S}_{1}\right)$ and $5 \mathrm{mg}$ of S per litre of soil $\left(\mathrm{S}_{2}\right) .107 \mathrm{mg}$ of $\mathrm{N}$ per litre of soil was given, partly in the form of $\mathrm{Ca}\left(\mathrm{NO}_{3}\right)_{2}$ and partly in the form of $\mathrm{NH}_{4} \mathrm{Cl}$. The pots were sown with 12 grains of barley each, and were watered so that the nutrient solutions and the water would together amount to $120 \mathrm{ml}$ per pot, which amply corresponded with the field capacity determined in laboratory. 25 days after the sowing and immedialely before coming into ear, the crop was harvested by cutting the barley stalks at the surface of the soil. The roots were washed clean of soil with a jet of water. The total sulphur was determined in the ordinary way in both stalk and leaf samples and in root matter (Table 27).

Table 27. Shoot and root yields at various sulphur levels with ammonium and nitrate nitrogen application, sulphur content of the plant material and sulphur uptake by the plants. ${ }^{\mathbf{1}}$ )

\begin{tabular}{|c|c|c|c|c|c|c|c|}
\hline & & \multicolumn{3}{|c|}{ Shoot material } & \multicolumn{3}{|c|}{ Root material } \\
\hline & & $\begin{array}{c}\text { Yield } \\
\text { D.M. g/pot }\end{array}$ & $\begin{array}{l}\text { S content } \\
\mathrm{mg} / \mathrm{g}\end{array}$ & $\begin{array}{l}\text { S yield } \\
\mathrm{mg} / \text { pot }\end{array}$ & $\begin{array}{c}\text { Yield } \\
\text { D.M. g/pot }\end{array}$ & $\begin{array}{c}\text { S content } \\
\mathrm{mg} / \mathrm{g}\end{array}$ & $\begin{array}{c}\text { S yield } \\
\text { g/pot }\end{array}$ \\
\hline \multirow{3}{*}{$\mathrm{NO}_{3}-\mathrm{N}$} & $\mathrm{S}_{0} \ldots \ldots \ldots \ldots \ldots \ldots \ldots \ldots \ldots \ldots$ & $0.99^{\mathrm{b}}$ & $0.80^{\mathrm{a}}$ & $0.79^{\mathrm{a}}$ & $0.80^{\mathrm{c}}$ & $0.63^{\mathrm{a}}$ & $0.49^{\mathrm{a}}$ \\
\hline & $\mathrm{s}_{1} \ldots \ldots \ldots \ldots \ldots \ldots$ & $1.33^{\mathrm{c}}$ & $1.10^{\mathrm{ab}}$ & $1.48^{\mathrm{ab}}$ & $0.86^{\mathrm{c}}$ & $0.68^{\mathrm{ab}}$ & $0.59^{\mathrm{ab}}$ \\
\hline & $\mathrm{S}_{2} \ldots \ldots \ldots \ldots \ldots \ldots$ & $1.92^{\mathrm{c}}$ & $1.60^{\mathrm{b}}$ & $2.85^{\mathrm{c}}$ & $1.08^{\mathrm{d}}$ & $0.74^{\mathrm{abc}}$ & $0.80^{\mathrm{ab}}$ \\
\hline \multirow[t]{3}{*}{$\mathrm{NH}_{4}-\mathrm{N}$} & $\mathrm{S}_{0} \ldots \ldots \ldots \ldots \ldots \ldots$ & $0.73^{\mathrm{a}}$ & $1.07^{\mathrm{ab}}$ & $0.78^{\mathrm{a}}$ & $0.61^{\mathrm{a}}$ & $0.99^{\text {bed }}$ & $0.60^{\mathrm{ab}}$ \\
\hline & $\mathrm{s}_{1} \ldots \ldots \ldots \ldots \ldots \ldots$ & $1.12^{\mathrm{bc}}$ & $0.96^{\mathrm{ab}}$ & $1.09^{\mathrm{a}}$ & $0.63^{\mathrm{ab}}$ & $1.05^{\mathrm{cd}}$ & $0.66^{\mathrm{ab}}$ \\
\hline & $\mathrm{S}_{2} \ldots \ldots \ldots \ldots \ldots \ldots$ & $1.65^{\mathrm{d}}$ & $1.23^{\mathrm{ab}}$ & $2.05^{\mathrm{bc}}$ & $0.75^{\mathrm{bc}}$ & $1.15^{\mathrm{d}}$ & $0.88^{b}$ \\
\hline
\end{tabular}

1) Means in each column followed by a common letter do not differ at $\mathrm{P}=0.05$.

In these extreme conditions of substrate the nitrate nitrogen seemed to be a trifle more favourable to growth than was the ammonium nitrogen. The root mass especially proved to be smaller with $\mathrm{NH}_{4}-\mathrm{N}$ than with $\mathrm{NO}_{3}-\mathrm{N}$, while the difference in stalk and leaf mass was smaller relatively. A slight tendency to higher sulphur content in the root mass at fertilization with ammonia is due to a sulphur concentration that is higher throughout than it is in the nitrate treatment. A certain competition between nitrate and sulphate ions in the root tissue may be conceived of in the treatment with nitrate. The $\mathrm{pH}$ value of the substrate probably had no effect, as it was 6.0 before the sowing whether the fertilizer was nitrate or ammonium, and 6.9 to 7.1 at harvest irrespective of the fertilization.

The sulphur taken up in the $\mathrm{S}_{0}$ treatment may come from various sources such as sulphur remaining in the substrate despite the treatment, impurities in other added chemicals and in the irrigation water and impurities in the atmosphere or from sulphur in the seed. It is impossible, however, to distinguish among these factors on the basis of this experiment or of any of the experiments 
to be reported on later. Considering the precision at the rinsing of the soil samples and taken account of the ion exchange of the irrigating water, the author estimates that quite a large proportion of the sulphur originates in the atmosphere while a smaller proportion may have been mineralized out of the Sphagnum peat.

The absorption of the added sulphur seems to have been just about complete in one of the cases $\left(\mathrm{NO}_{3}-\mathrm{N}, \mathrm{S}_{2}\right)$. It seems that the uptake of sulphur in the case of the smaller sulphur dosage was also weaker in relative terms, too, than it was from the larger dosage, which might suggest that despite its particularity of character the substrate competes with the plants for a certain quantity of the added nutrient.

\section{Dependence of yield upon the $N / S$ ratio of the substrate}

In a pot experiment with 0.5-litre pots performed during July and August 1969 with washed quartz sand as substrate, the N/S ratio was varied between 5 and 430 , while other nutrients were applied according to the basic fertilization schedule in Table 19. By varying both the nitrogen and the sulphur dosages, the following N/S values were achieved at the various levels of nitrogen (the index numbers refer to the ratio to the basic amounts stated in Table 19, which are ascribed the value of 1 :

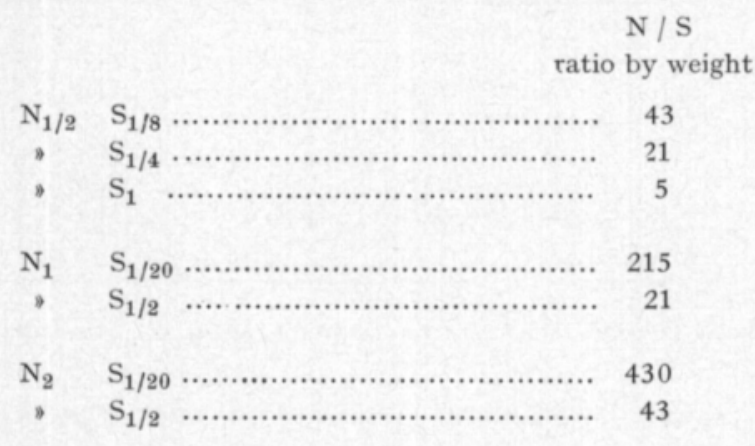

In Figure 8 the yield is related to the N/S ratio on a semilogarithmic scale. Points for the nitrogen levels 107,215 and $430 \mathrm{mg}$ per litre of soil are indicated with various signs. The yield pertains to the stalk and leaf of Otra barley immediately prior to coming into ear.

The result shows that despite large variations in the amounts of added nitrogen and sulphur, the N/S ratio is an acceptable indicator of yield. What the N/S ratio should optimally have been under the prevailing conditions of absorption of atmospheric sulphur and the prevailing mobilization rate for the sulphur and nitrogen reserves in the soil, in this case minimal, remains an open question. Clarification would have necessitated a number of experimental harvests for an N/S ratio between 0 and 20 and perhaps especially for an N/S ratio of between 5 and 20 .

The relationship between the sulphur and the nitrogen was studied in a second pot experiment with five cultivated surface soils, three Carex peat soils 


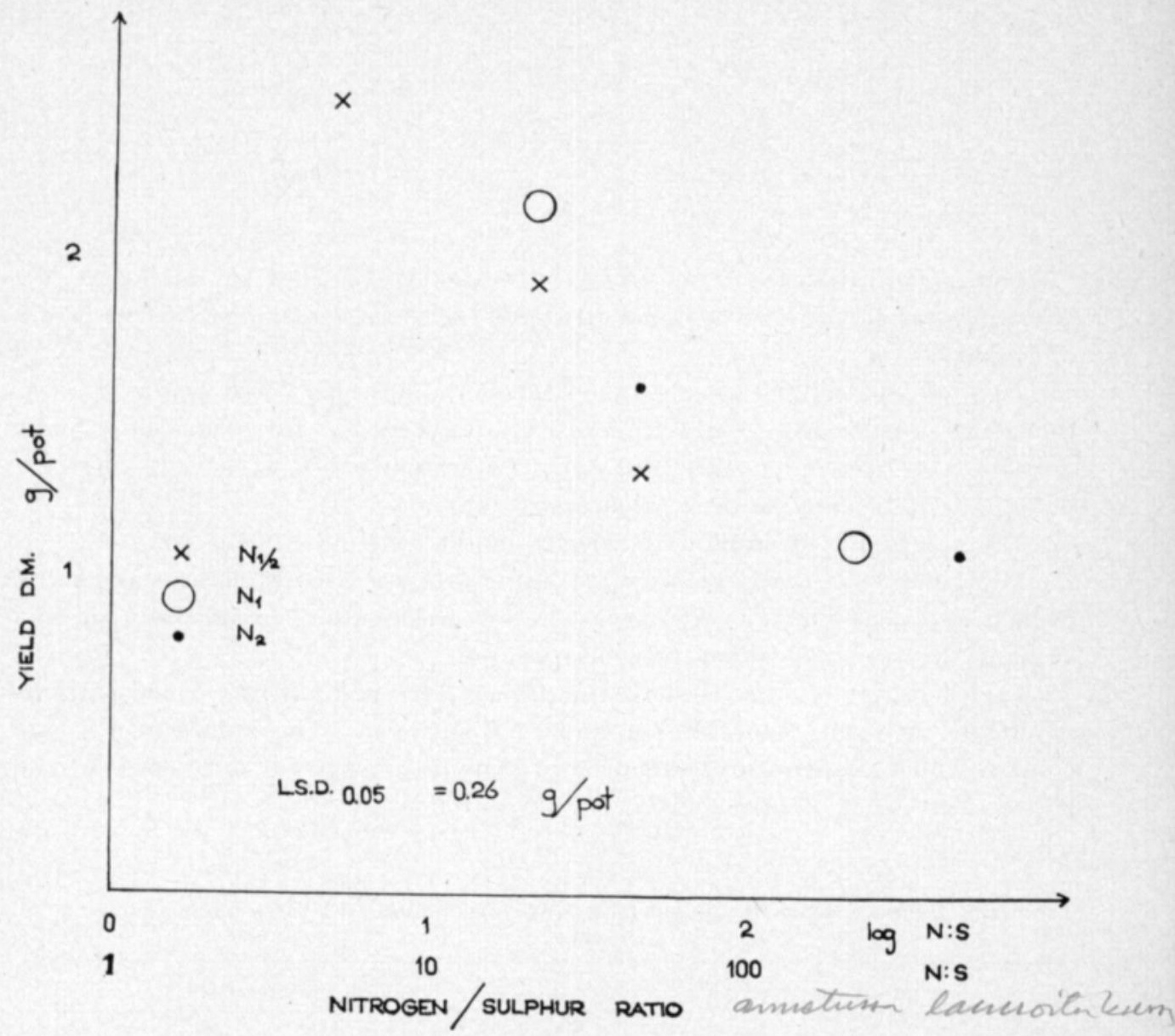

Figure 8. Yield of plant material in sand cultures with Otra barley compared with the NS ratio.

(38a, 39a and 45a), one loamy clay soil (47a) and one finesand soil (48a). In this experiment there were two levels of nitrogen, i.e. $\mathrm{N}_{1}=43$ and $\mathrm{N}_{2}=215 \mathrm{mg}$ of $\mathrm{N}$ per litre of soil, and sulphur at the levels $\mathrm{S}_{0}$ and $\mathrm{S}_{1}(20 \mathrm{mg}$ of $\mathrm{S}$ per litre). The $\mathrm{N}_{0}$ factor was held to be superfluous, for a small dosage of nitrogen was expected to give a greater return of information. All the other nutrients were applied according to the basic level (Table 19).

Liming was omitted, however. All the treatments had three replicates and there were consequently twelve pots of each soil. These 5-litre plastic pots were sown with 40 Otra grains each on July 30,1969 and thinned out to 25 specimens on August 5, 1969 and harvested on September 25, 1969, by which time all the treatments had come into ear. The thinning-out was probably unnecessary, as a vigorous formation of secondary shoots in the heavily fertilized treatments in any case made the density of shoots very different in the various treatments. The original content of $0.5 \mathrm{~N} \mathrm{~K}_{2} \mathrm{SO}_{4}$ extractable ammonium and nitrate nitrogen and of ammonium-acetate extractable sulphur in the various experimental soils were: 


\begin{tabular}{|c|c|c|}
\hline & & $\begin{array}{c}\mathrm{N} \\
\mathrm{mg} / \mathrm{l}\end{array}$ \\
\hline $38 \mathrm{a}$ & & 29 \\
\hline $39 \mathrm{a}$ & 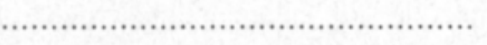 & 37 \\
\hline $45 \mathrm{a}$ & 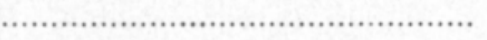 & 39 \\
\hline & (.). & 14 \\
\hline & , & 41 \\
\hline
\end{tabular}

This meant that the molar ratio between nitrogen and sulphur after fertilization varied between 4.4 and 610 and the weight ratio N/S between 1.9 and 260 .

Two weeks after the sowing the effect of the nitrogen could be observed in four soils out of five. Only three days later were the first signs of sulphur deficiency registered, on two peat soils. After four more days the symptoms of sulphur deficiency were at their most distinct.

The symptoms of sulphur deficiency in this pot experiment were at their most distinct $1-2$ weeks before the coming into ear, the differences becoming evened out subsequently. At harvest a few weeks after coming into ear, the sulphur shortage had apparently disappeared.

Tables 28, 29, 30 and 31 show the dry matter yield and the concentrations of nitrate nitrogen, total sulphur and total nitrogen. The values in any one column which possess an identical letter show no significant differences at the 95 per cent level of probability.

Table 28. Yield of shoots (D.M. g/pot) in a pot experiment with Otra barley. ${ }^{1}$ )

\begin{tabular}{|c|c|c|c|c|c|}
\hline \multirow{2}{*}{ Treatment } & \multicolumn{5}{|c|}{ Sample number } \\
\hline & $38 \mathrm{a}$ & $39 a$ & $45 a$ & $47 \mathrm{a}$ & $48 \mathrm{a}$ \\
\hline 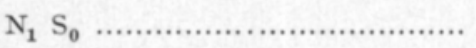 & $22.0^{\mathrm{a}}$ & $32.1^{\mathrm{a}}$ & $11.9^{\mathrm{ab}}$ & $8.4^{\mathrm{a}}$ & $17.1^{\mathrm{a}}$ \\
\hline 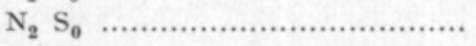 & $26.2^{\mathrm{b}}$ & $30.6^{\mathrm{a}}$ & $10.5^{\mathrm{a}}$ & $18.2^{\mathrm{b}}$ & $23.5^{\mathrm{b}}$ \\
\hline 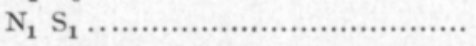 & $27.1^{\mathrm{b}}$ & $36.4^{\mathrm{b}}$ & $12.9^{\mathrm{b}}$ & $10.3^{\mathrm{a}}$ & $16.1^{\mathrm{a}}$ \\
\hline 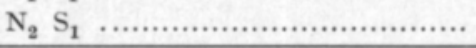 & $33.2^{\mathrm{c}}$ & $35.1^{\mathrm{b}}$ & $13.8^{\mathrm{b}}$ & $19.8^{b}$ & $21.9^{\mathrm{b}}$ \\
\hline
\end{tabular}

1) Means in each column followed by a common letter do not differ at $\mathrm{P}=0.05$.

Table 29. Concentration of nitrate nitrogen in shoots (g/kg D.M.) of Otra barley. ${ }^{1}$ )

\begin{tabular}{|c|c|c|c|c|c|c|}
\hline & \multirow{2}{*}{ Treatment } & \multicolumn{5}{|c|}{ Sample number } \\
\hline & & $38 \mathrm{a}$ & $39 a$ & $45 a$ & $47 \mathrm{a}$ & $48 \mathrm{a}$ \\
\hline $\mathrm{N}_{1} \mathrm{~S}_{0}$ & .... & $0.5^{\mathrm{a}}$ & $0.4^{\mathrm{a}}$ & $1.6^{\mathrm{a}}$ & $0.1^{\mathrm{a}}$ & $0.5^{\mathrm{a}}$ \\
\hline $\mathrm{N}_{2} \mathrm{~S}_{0}$ & 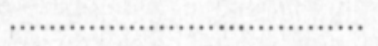 & $0.8^{b}$ & $3.6^{c}$ & $5.5^{\mathrm{b}}$ & $3.5^{\mathrm{b}}$ & $2.5^{\mathrm{b}}$ \\
\hline $\mathrm{N}_{1} \mathrm{~S}_{1}$ & (.................................... & $0.3^{\mathrm{a}}$ & $0.3^{\mathrm{a}}$ & $1.3^{\mathrm{a}}$ & $0.1^{\mathrm{a}}$ & $0.5^{\mathrm{a}}$ \\
\hline $\mathrm{N}_{2} \mathrm{~S}_{1}$ & …............................. & $0.5^{\mathrm{a}}$ & $1.9^{\mathrm{b}}$ & $2.4^{\mathrm{a}}$ & $3.5^{\mathrm{b}}$ & $2.7^{\mathrm{b}}$ \\
\hline
\end{tabular}

1) Means in each columnn followed by a common letter do not differ at $\mathrm{P}=0.05$. 
In two Carex peat soils, 38a and 39a, both of which had been obtained from the area of Kuusamo in North Finland, the fertilization with sulphur produced a significant increment of yield at the lower as well as the higher level of nitrogen. The yields for the other soils showed an indistinct or nil effect of sulphur, but in mineral soils $47 \mathrm{a}$ and $48 \mathrm{a}$ the fertilization with nitrogen produced a significant increment of yield, as it also did in soil 38a. Heavy fertilization with nitrogen without the addition of sulphur produced the highest concentration of nitrate nitrogen in all the peat soils $(38 \mathrm{a}, 39 \mathrm{a}$ and $45 \mathrm{a})$. This is an expression of the close affinity between sulphur and nitrogen in the metabolism of the plant (cf. O'CONNOR and VARTHA 1969). Instead of the formation of protein there occurs under sulphur deficiency an accumulation of nitrate nitrogen, amino-acids and amides.

Table 30. Concentration of sulphur in shoots (g/kg D.M.) of Otra barley. ${ }^{1}$ )

\begin{tabular}{|c|c|c|c|c|c|c|}
\hline \multirow{2}{*}{\multicolumn{2}{|c|}{ Treatment }} & \multicolumn{5}{|c|}{ Sample number } \\
\hline & & $38 \mathrm{a}$ & $39 a$ & $45 a$ & $47 \mathrm{a}$ & $48 \mathrm{a}$ \\
\hline $\mathrm{N}_{1} \mathrm{~S}_{0}$ & (n................................... & $1.7^{\mathrm{a}}$ & $1.5^{\mathrm{a}}$ & $3.4^{\mathrm{a}}$ & $1.7^{\mathrm{a}}$ & $1.8^{\mathrm{a}}$ \\
\hline $\mathrm{N}_{2} \mathrm{~S}_{0}$ & ..... & $1.7^{3}$ & $1.9^{\mathrm{a}}$ & $3.5^{\mathrm{a}}$ & $1.7^{\mathrm{a}}$ & $1.6^{\mathrm{a}}$ \\
\hline $\mathrm{N}_{1} \mathrm{~S}_{1}$ & …............................... & $1.9^{\mathrm{b}}$ & $1.7^{\mathrm{a}}$ & $3.8^{\mathrm{b}}$ & $1.8^{\mathrm{a}}$ & $1.9^{\mathrm{a}}$ \\
\hline $\mathrm{N}_{2} \mathrm{~S}_{1}$ & 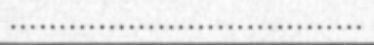 & $1.9^{\mathrm{b}}$ & $2.4^{\mathrm{b}}$ & $3.5^{\mathrm{a}}$ & $2.4^{\mathrm{b}}$ & $1.9^{\mathrm{a}}$ \\
\hline
\end{tabular}

1) Means in each column followed by a common letter do not differ at $\mathrm{P}=0.05$.

Table 31. Concentration of nitrogen in shoots (g/kg D.M.) of Otra barley. ${ }^{1}$ )

\begin{tabular}{|c|c|c|c|c|c|}
\hline & \multirow{2}{*}{ Treatment } & \multicolumn{4}{|c|}{ Sample number } \\
\hline & & $38 \mathrm{a}$ & $39 a$ & $45 a$ & $47 \mathrm{a}$ \\
\hline $\mathrm{N}_{1} \mathrm{~S}_{0}$ & …................ & $15.5^{\mathrm{a}}$ & $13.3^{\mathrm{a}}$ & $23.5^{\mathrm{ab}}$ & $15.7^{a}$ \\
\hline $\mathrm{N}_{2} \mathrm{~S}_{0}$ & & $18.0^{\mathrm{a}}$ & $24.9^{\mathrm{c}}$ & $30.4^{c}$ & $34.8^{\mathrm{b}}$ \\
\hline $\mathrm{N}_{1} \mathrm{~S}_{1}$ & n............. & $16.9^{\mathrm{a}}$ & $12.8^{a}$ & $20.4^{\mathrm{a}}$ & $17.9^{\mathrm{a}}$ \\
\hline $\mathrm{N}_{2} \mathrm{~S}_{1}$ & 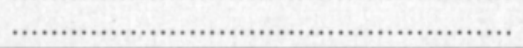 & $18.4^{\mathrm{a}}$ & $22.3^{\mathrm{b}}$ & $27.0^{\mathrm{bc}}$ & $39.4^{\mathrm{c}}$ \\
\hline
\end{tabular}

1) Means in each column followed by a common letter do not differ at $\mathrm{P}=0.05$.

Table 30 does not provide a clear picture of the sulphur uptake. In soil $39 \mathrm{a}$ an increment of nitrogen in addition to that of sulphur was necessary for the concentration of total sulphur to rise. Fertilization with sulphur in conditions of nitrogen deficiency in this experiment did not produce any consistent increase in the concentration of total sulphur. This status may be due to metabolistic inactivity in plants when there is a deficiency of nitrogen, but also due to the nutrient fixing conditions in the soil.

The concentration of total nitrogen in all the analyzed cases was raised through increased dosage of nitrogen (Table 31). It seems that the nitrogen uptake was rather independent of the sulphur situation. 
As the results of these pot experiments only provided an opportunity for modest conclusions, the experiment was repeated the following spring with the same soils and the same experimental scheme but with spring rape as the experimental plant. The experimental soils, stored in dry conditions, were homogenized pot by pot and were fertilized in such a manner that every pot received the same dosage of nutrients as that for the first experimental harvest. For instance, the pots that had received $S_{0}$ treatments in the first round were once again left without sulphur fertilizer. A certain impoverishment of the sulphur reserves was expected to occur in consequence.

20 seeds of spring rape were sown on February 20, 1970. As the early development of rape is rather slow, thinning out to tenspecimens was not performed until one month after sowing. Two weeks later another four plants per pot were culled. The removed plants were dried and weighed and were analyzed for total sulphur. The final yield of seeds and stalks was harvested 4.5 months after sowing.

The poor growth of the rape during the first month had the result that no real differences could be discovered between the various treatments until a good month subsequent to sowing. At the time of the second thinning, however, the differences were very obvious. The growth-inhibiting effects of nitrogen in conditions of sulphur shortage could already be observed at that stage. Symptoms of sulphur deficiency could be discerned on two peat soils, on the loamy clay and on the finesand soil, while one Carex peat (45a) produced a weak growth throughout and showed slow development.

The analyses of the removed material showed that the sulphur concentration in the youngest shoots of rape may rise to $10 \mathrm{~g}$ per $\mathrm{kg}$. At the same time, when there was a shortage of sulphur the concentration only amounted to about $2 \mathrm{~g}$ per $\mathrm{kg}$. Two weeks later the sulphur contents had fallen to 4 and $0.8 \mathrm{~g}$ per $\mathrm{kg}$ respectively. The most important results of this pot experiment are shown in Tables 32 and 33 .

All the soils except for 45 a reacted to the fertilization with sulphur. The seed yield of these other soils was poorest in those cases in which the increased dosage of nitrogen was combined with a lack of sulphur $\left(\mathrm{N}_{2} ; \mathrm{S}_{0}\right)$. It is clear that the need for additional sulphur increases with increased input of nitrogen, as an increase of nitrogen from $\mathrm{N}_{1}$ to $\mathrm{N}_{2}$ in the $\mathrm{S}_{0}$ treatment in these soils pro-

Table 32. Spring rape yield (g/pot) in a pot experiment with two nitrogen and sulphur levels and five soils. ${ }^{1}$ )

\begin{tabular}{|c|c|c|c|c|c|c|}
\hline \multirow{2}{*}{\multicolumn{2}{|c|}{ Treatment }} & \multicolumn{5}{|c|}{ Sample number } \\
\hline & & $38 \mathrm{a}$ & $39 a$ & $45 \mathrm{a}$ & $47 a$ & $48 \mathrm{a}$ \\
\hline $\mathrm{N}_{1} \mathrm{~S}_{0}$ & ...................... & $0.03^{\mathrm{a}}$ & $3.10^{\mathrm{b}}$ & $7.32^{\mathrm{a}}$ & $4.25^{\mathrm{b}}$ & $3.74^{\mathrm{b}}$ \\
\hline $\mathrm{N}_{2} \mathrm{~S}_{0}$ & ………….... & $0.00^{\mathrm{a}}$ & $0.00^{\mathrm{a}}$ & $11.08^{\mathrm{c}}$ & $0.77^{\mathrm{a}}$ & $0.06^{\mathrm{a}}$ \\
\hline $\mathrm{N}_{1} \mathrm{~S}_{1}$ & ........................ & $8.15^{b}$ & $5.53^{\mathrm{c}}$ & $7.38^{\mathrm{ab}}$ & $4.20^{\mathrm{b}}$ & $3.89^{b}$ \\
\hline $\mathrm{N}_{2} \mathrm{~S}_{1}$ & ………....... & $16.74^{\mathrm{c}}$ & $15.86^{\mathrm{d}}$ & $9.26^{\mathrm{bc}}$ & $17.00^{\circ}$ & $21.25^{\mathrm{c}}$ \\
\hline
\end{tabular}

1) Means in each column followed by a common letter do not differ at $\mathrm{P}=0.05$. 


\begin{tabular}{|c|c|c|c|c|c|c|}
\hline \multirow{2}{*}{\multicolumn{2}{|c|}{ Treatment }} & \multicolumn{5}{|c|}{ Sample number } \\
\hline & & $38 \mathrm{a}$ & $39 a$ & $45 \mathrm{a}$ & $47 a$ & $48 \mathrm{a}$ \\
\hline$N_{1} S_{0}$ & 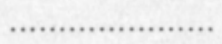 & $18.7^{\mathrm{c}}$ & $17.2^{\mathrm{c}}$ & $10.9^{\mathrm{ab}}$ & $8.5^{\mathrm{a}}$ & $7.3^{\mathrm{a}}$ \\
\hline $\mathrm{N}_{2} \mathrm{~S}_{0}$ & ...................... & $1.1^{\mathrm{a}}$ & $1.4^{\mathrm{a}}$ & $17.1^{\mathrm{c}}$ & $28.7^{\mathrm{b}}$ & $25.7^{\mathrm{b}}$ \\
\hline $\mathrm{N}_{1} \mathrm{~S}_{1}$ & ....................... & $12.4^{\mathrm{b}}$ & $10.1^{\mathrm{b}}$ & $8.2^{\mathrm{a}}$ & $8.7^{\mathrm{a}}$ & $6.9^{\mathrm{a}}$ \\
\hline $\mathrm{N}_{2} \mathrm{~S}_{1}$ & ...................... & $31.3^{\mathrm{d}}$ & $34.4^{\mathrm{d}}$ & $14.9^{\mathrm{bc}}$ & $39.4^{\mathrm{e}}$ & $35.1^{\mathrm{c}}$ \\
\hline
\end{tabular}

1) Means in each column followed by a common letter do not differ at $\mathrm{P}=0.05$.

duced a marked decrease in the seed yield. It is interesting to note how the situation is a rather different one where the stalk yield is concerned. In two cases on Carex peat $(38 \mathrm{a}, 39 \mathrm{a})$ stalk yield and seed yield go together, but on both the loamy clay (47a) and on the finesand soil (48a) a relatively high yield of stalk was obtained despite a total failure in seed yield. It seems that a balance between sulphur and nitrogen was primarily needed for a good seed formation, which is evidently induced through an effective protein synthesis, while the vegetative part of the crop is less susceptible to an unsuitable N/S ratio.

At the lower level of nitrogen the fertilization with sulphur had no effect on the yield of either seed or stalk on the mineral soils, in which a definite shortage of nitrogen excluded an increase in yield. The effect of sulphur is significant on the Carex peat soils $(38 \mathrm{a}, 39 \mathrm{a})$, which have a sulphur shortage. The interesting thing, however, is that while the seed yield was positively affected, the sulphur had a reducing effect upon the yield of stalk. This redisposition of the very scarce nitrogen reserves may be seen as an expression of the capability of the plant to translocate nitrogen from the oldest leaves, which wither and fall away, to the growing point. In the treatment $\mathrm{N}_{1} ; \mathrm{S}_{0}$ there is a concurrent shortage of sulphur and nitrogen. The nitrogen caused a restriction in the total yield of plant matter while the shortage of sulphur made the seed formation impossible. This is the reason why the seed yield brought on by the dosage of sulphur in treatment $\mathrm{N}_{1} ; \mathrm{S}_{1}$ could only be achieved through a reduction in the stalk yield. The growth was good in treatment $\mathrm{N}_{2} ; \mathrm{S}_{1}$ with an applied N/S ratio of about 11, but an even higher yield might have been obtained with additional nitrogen.

\section{B. Pot experiment with sulphur and phosphorus as variables.}

Sulphur and phosphorus are evidently more loosely bound to each other in physiological terms than are sulphur and nitrogen. The stimulation of the uptake of phosphorus which has been accomplished in some cases by means of sulphur fertilization is chiefly due to a change in the propensity of the soil to phosphorus, caused by the fertilization. The total phosphorus fixation in some soils of high $\mathrm{pH}$ value may be directly influenced by means of sulphur fertilizers possessing an acid effect (KACAR and AKGÜL 1967), such as elemental 
sulphur and ammonium sulphate. Without any change in the fixation capacity it is possible to imagine a limited exchange of phosphorus ions for sulphur ions when there is a substantial addition of sulphur (MENary and Hughes 1967). In a pot experiment with a mixture of quartz sand and peat JoHANsson (1959) recorded a reduced yield with sulphur fertilization when the supply of phosphorus was scanty.

In order to investigate the physiological interaction between sulphur and phosphorus, a pot experiment with a 0.5 -litre plastic pot with washed quartz sand as substrate was carried out between July 11 and August 4, 1969. The plant was Otra barley, and was cut immediately before coming into ear. The fertilization is shown in Table 19 except that there were three different levels of sulphur, i.e., $\mathrm{S}_{0}, \mathrm{~S}_{1}(2.5 \mathrm{mg}$ of $\mathrm{S}$ per 1$)$ and $\mathrm{S}_{2}(5 \mathrm{mg}$ of $\mathrm{S}$ per 1$)$ and two levels of phosphorus, i.e., $\mathrm{P}_{1}(4 \mathrm{mg}$ of $\mathrm{P}$ per 1$)$ and $\mathrm{P}_{2}(20 \mathrm{mg}$ of $\mathrm{P}$ per 1). Nitrogen equivalent to $107 \mathrm{mg}$ of $\mathrm{N}$ per litre was applied in the form of $\mathrm{Ca}\left(\mathrm{NO}_{3}\right)_{2} \cdot 4 \mathrm{H}_{2} \mathrm{O}$. Sowing, moistening and reaping were performed as in the experiment with the fertilization with nitrate and ammonium nitrogen. The yields from this pot experiment are shown in Table 34 .

Table 34. Shoot and root yields (D.M. g/pot) in a pot experiment with twophosphorus and three sulphur levels in quartz sand. ${ }^{1}$ )

\begin{tabular}{|c|c|c|c|c|c|c|c|}
\hline \multirow{3}{*}{$\mathrm{S}_{0}$} & \multirow{4}{*}{$\begin{array}{l}\text { Shoot } \\
\text { Root } \ldots \ldots \ldots \ldots \ldots \ldots \ldots \ldots \\
\text { Total } \ldots \ldots \ldots \ldots \ldots \ldots \ldots \ldots \ldots \ldots \ldots \ldots \ldots \ldots \ldots \ldots\end{array}$} & \multicolumn{3}{|c|}{$\mathrm{P}_{1}$} & \multicolumn{3}{|c|}{$\mathrm{P}_{2}$} \\
\hline & & $0.87^{a}$ & & & $1.59^{\mathrm{bc}}$ & & \\
\hline & & & $0.86^{\mathrm{m}}$ & & & $1.12^{\mathrm{mn}}$ & \\
\hline & & & & $1.73^{\mathrm{s}}$ & & & $2.71^{\text {tu }}$ \\
\hline \multirow[t]{3}{*}{$\mathrm{S}_{1}$} & Shoot …................. & $1.21^{\mathrm{ab}}$ & & & $1.89^{c}$ & & \\
\hline & Root ................... & & $0.98^{\mathrm{mn}}$ & & & $1.19^{\mathrm{n}}$ & \\
\hline & Total $\ldots \ldots \ldots \ldots \ldots \ldots$ & & & $2.19^{\mathrm{st}}$ & & & $3.08^{u v}$ \\
\hline \multirow[t]{3}{*}{$\mathrm{S}_{2}$} & Shoot …................. & $1.37^{\mathrm{b}}$ & & & $2.37^{\mathrm{d}}$ & & \\
\hline & Root ................... & & $1.06^{\mathrm{mn}}$ & & & $1.24^{\mathrm{n}}$ & \\
\hline & Total …................ & & & $2.47^{\text {stu }}$ & & & $3.61^{\mathrm{v}}$ \\
\hline
\end{tabular}

1) Means for shoot, root, and total yields, respectively, followed by a common letter do not differ at $\mathrm{P}=0.05$.

In Table 34 the stalk and leaf material was statistically processed separately from the root material. The indices for the former values are a, b, c and d, for the root material $\mathrm{m}$ and $\mathrm{n}$, and for the sum $\mathrm{s}, \mathrm{t}, \mathrm{u}$ and $\mathrm{v}$.

The interaction effect between the sulphur and the phosphorus was calculated on the basis of the total stalk, leaf and root material yields. The interaction effects of $\mathrm{S}_{1} \times \mathrm{P}$ and $\mathrm{S}_{2} \times \mathrm{P}$ were lacking. The factor analysis also showed that the effect of the sulphur was not statistically reliable at the lower level of sulphur but was at the higher.

Statistically the factor analysis shows that the same absolute increase in yield is obtained with the phosphorus fertilization at the different levels of sulphur. This interesting but somewhat surprising circumstance is due in the 
present material to the fact that the fertilization with phosphorus at the higher levels of sulphur produced a smaller increase in the root material both absolutely and relatively than it did at the nil level of sulphur fertilization. The factor analysis for the yield of root material, however, does not show a statistically reliable antagonism.

Table 35. Uptake of phosphorus in shoot and root material (mg P/pot). ${ }^{1}$ )

\begin{tabular}{|c|c|c|c|c|c|c|c|}
\hline \multirow{3}{*}{$\mathrm{S}_{\mathbf{0}}$} & \multirow{4}{*}{$\begin{array}{l}\text { Shoot } \\
\text { Root } \\
\text { Total }\end{array}$} & \multicolumn{3}{|c|}{$\mathrm{P}_{1}$} & \multicolumn{3}{|c|}{$\mathrm{P}_{2}$} \\
\hline & & $2.17^{\mathrm{a}}$ & & & $4.92^{\mathrm{c}}$ & & \\
\hline & & & $0.98^{\mathrm{n}}$ & & & $1.95^{\mathrm{q}}$ & \\
\hline & & & & $3.15^{\text {st }}$ & & & $6.87^{\mathrm{u}}$ \\
\hline \multirow[t]{3}{*}{$\mathrm{S}_{1}$} & Shoot …….............. & $2.47^{\mathrm{b}}$ & & & $5.32^{\mathrm{d}}$ & & \\
\hline & Root $\ldots \ldots \ldots \ldots \ldots \ldots$ & & $0.88^{\mathrm{n}}$ & & & $1.72^{\mathrm{q}}$ & \\
\hline & Total …................... & & & $3.35^{t}$ & & & $7.04^{\mathrm{u}}$ \\
\hline \multirow[t]{3}{*}{$\mathrm{S}_{2}$} & Shoot ….................. & $2.24^{\mathrm{a}}$ & & & $5.44^{\mathrm{d}}$ & & \\
\hline & Root & & $0.75^{\mathrm{m}}$ & & & $1.60^{\circ}$ & \\
\hline & Total $\ldots \ldots \ldots \ldots \ldots \ldots$ & & & $2.99^{\mathrm{s}}$ & & & $7.04^{u}$ \\
\hline
\end{tabular}

1) Means for shoot, root, and total yields, respectively, followed by a common letter do not differ at $\mathrm{P}=0.05$.

The indices for the phosphorus content of the stalk and leaf material (Table 35) start with "an and the indices for the phosphorus yield of the root material run from "m" and those for the sum from "ss. The phosphorus content of the root material decreases with increased sulphur input, primarily on account of severely reduced phosphorus concentration in the root tissue at increased fertilization with sulphur. In this experiment the sulphur prompted a distinct redisposition of the total quantity of phosphorus taken up, especially at the higher level of phosphorus. With decreasing supply of sulphur an increasing proportion of the phosphorus is to be found in the root tissue. Thus at level $\mathrm{P}_{1}$ the root matter contained 45 per cent of the phosphorus in the $\mathrm{S}_{0}$ treatment and 34 per cent in the $\mathrm{S}_{2}$ treatment, while at level $\mathrm{P}_{2}$ the figures were 40 per cent and 30 per cent respectively.

As the lack of interaction between sulphur and phosphorus reveals, it is impossible to set an optimum ratio between $\mathrm{P}$ and $\mathrm{S}$ in fertilizer on the basis of the experiment outlined here. There were no critical points within the limits tested therein $(\mathrm{P} / \mathrm{S}=0.8-8.0)$.

The sulphur concentration both in the stalk and leaf material and in the root material was nowise affected by the fertilization with phosphorus.

\section{Pot experiment with sulphur and molybdenum as variables}

It seems to be a generally accepted fact that sulphur fertilization results in reduced uptake of molybdenum (GUPTA 1969, ReISENAUER 1963). Fertilization with superphosphate, for instance, has an inhibiting effect in this re- 
spect upon the uptake of molybdenum because of its content of sulphur, in spite of the fact that it is known that phosphorus has a stimulating effect on the absorption of Mo (Gupta and Cutcliffe 1968, JAAKkola 1972). Likewise, a shortage of sulphur may induce abnormally high, toxic contents of molybdenum ( $>10$ ppm of Mo) (Gupta 1969).

A pot experiment with quartz sand from July 11 to August 4, 1969 with the variables $\mathrm{S}_{0}, \mathrm{~S}_{1}\left(5 \mathrm{mg}\right.$ of $\mathrm{S}$ per litre) and $\mathrm{S}_{2}(20 \mathrm{mg} \mathrm{S} / \mathrm{l})$ and $\mathrm{Mo}_{0}$ and $\mathrm{Mo}_{1}$ ( $3 \mathrm{mg} \mathrm{Mo/1)}$ and three replicates of each treatment produced a total of $36 \mathrm{ex}-$ perimental yields when the young Otra barley was reaped immediately before coming into ear. The dosage of nitrogen was the equivalent of $107 \mathrm{mg}$ of $\mathrm{N}$ per litre and was given in the form of calcium nitrate. The rest of the fertilization was done in accordance with Table 19. The yields of this pot experiment are shown in Table 36 .

Table 36. Shoot and root yields (D.M. g/pot) in a pot experiment with two molybdenum and three sulphur levels in quartz sand. ${ }^{1}$ )

\begin{tabular}{|c|c|c|c|c|c|c|c|}
\hline \multirow{4}{*}{$\mathrm{S}_{0}$} & & \multicolumn{3}{|c|}{$\mathrm{Mo}_{0}$} & \multicolumn{3}{|c|}{$\mathrm{Mo}_{1}$} \\
\hline & Shoot ...................... & $0.85^{\mathrm{a}}$ & & & $0.99^{\mathrm{a}}$ & & \\
\hline & Root $\ldots \ldots \ldots \ldots \ldots \ldots \ldots \ldots$ & & $0.70^{\mathrm{m}}$ & & & $0.80^{\mathrm{m}}$ & \\
\hline & Total …................. & & & $1.55^{\mathrm{a}}$ & & & $1.79^{\mathrm{s}}$ \\
\hline \multirow[t]{3}{*}{$\mathrm{S}_{1}$} & Shoot ….................. & $1.92^{\mathrm{b}}$ & & & $1.92^{\mathrm{b}}$ & & \\
\hline & Root $\ldots \ldots \ldots \ldots \ldots \ldots . . . . . . .$. & & $1.22^{\mathrm{n}}$ & & & $1.08^{\mathrm{n}}$ & \\
\hline & Total & & & $3.14^{t}$ & & & $3.00^{t}$ \\
\hline \multirow[t]{3}{*}{$\mathrm{S}_{2}$} & Shoot ..................... & $2.57^{\mathrm{c}}$ & & & $2.39^{c}$ & & \\
\hline & Root $\ldots \ldots \ldots \ldots \ldots \ldots \ldots$ & & $1.46^{\circ}$ & & & $1.46^{\circ}$ & \\
\hline & Total …................. & & & $4.03^{\mathrm{u}}$ & & & $3.85^{\mathrm{u}}$ \\
\hline
\end{tabular}

f) Means for shoot, root, and total yields, respectively, followed by a common letter do not differ at $\mathrm{P}=0.05$.

The indices for the yield of stalk and leaf run from san, those for the yield of root from "m" and those for the sum from "s", and as Table 36 shows, the exclusion of fertilization with molybdenum did not affect the yield in this experiment. Table 37 shows the concentrations of total sulphur in the same experimental yields.

Here, too, the stalk and leaf matter was processed separately from the root matter. The values with the indices na", b" and "cn are thus comparable, and so, on the other hand, are the values for the root material with the indices "m» and "ns.

The sulphur content rises slightly with raised dosage of sulphur, while the molybdenum dosage has no significant effect.

The molybdenum content in the yields appears in Table 38. Here, too, the stalk and leaf yield was tested separately from the root yield, the indices in the former case running from na" and in the latter from "m».

Table 38 shows how easily molybdenum is translocated into the plant when 
Table 37. Concentration of sulphur (g S/kg D.M.) in shoot and root material. ${ }^{1}$ )

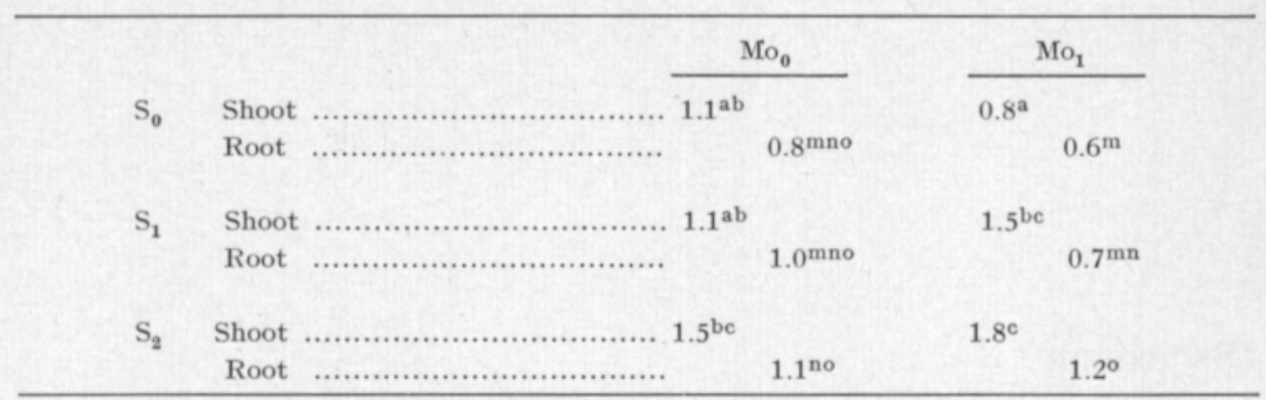

1) Means for shoots and roots, respectively, followed by a common letter do not differ at $\mathrm{P}=0.05$.

Table 38. Concentration of molybdenum (mg Mo/kg D.M.) in shoot and root material. ${ }^{1}$ )

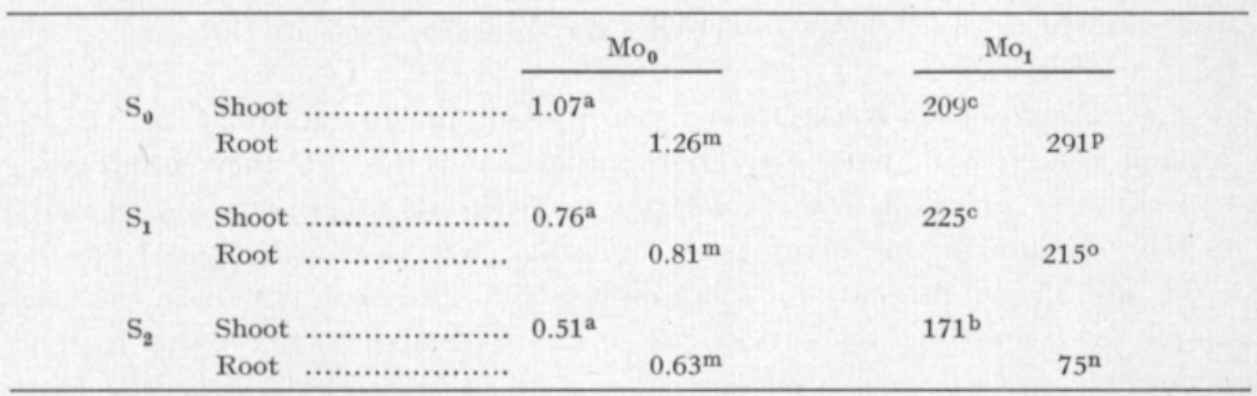

1) Means for shoots and roots, respectively, followed by a common letter do not differ at $\mathbf{P}=0.05$.

there are no fixing features in the substrate. Although the crops fertilized with molybdenum all have a high content of molybdenum, a certain decrease in the content can be registered with increased dosages of sulphur. It is also interesting to note that the very large dosages of molybdenum in this experiment and the very high content of molybdenum produced thereby seem to have no kind of toxic effect upon the plants. 


\section{Discussion}

The chemical determination of sulphur in samples of soil and plants and in extracts thereof proved to be surprisingly laborious and susceptible to interference. An efficient study of the problems of sulphur on a large scale necessitates a simplification and an improvement in the methods of analysis. The difficulty consists in the fact that the quantities of sulphur to be analyzed are relatively small, while the interfering materials, especially in the soil extracts, occur in abundance.

The determination of the total amount of sulphur in plant and soil samples through combustion in an induction furnace and through the turbidimetric determination of sulphate gives a rather great variation between parallel analyses on account of the many phases of work (cf. TABAtabai and Bremner 1970), and a small proportion of the sulphur will apparently remain in the fused sample, and consequently outside the analysis. Employment of this method, in any event, may be justified on account of its low requirement of labour.

It is difficult to develop methods for the analysis of soil extracts which would be totally insensitive to all the other materials that may occur in such extracts in highly varying quantities. In the present work it was possible, more or less by chance, to demonstrate how a concentration of phosphate has a very great influence upon the chromate determination of sulphate, but there may certainly be a number of other impurities with similar effect. It might be said that the determination will ultimately express the relationship between the sulphur and the materials which interfere in various ways. Whether the determined factor under such circumstances is called sulphur or is given some other name and numerical value is probably a matter of indifference.

The most difficult thing in the discussion on the sulphur balance of the soil is, without doubt, the assessment of the magnitude of leaching. The calculations are only based on four annual samplings with simultaneous flow measurements. Moreover, a few sampling sites not loaded with waste were in some cases used to represent large areas where other sampling sites were excluded on account of sulphur contamination from industry and human settlement. The included samples were often taken from rather remote locations, and the calculated values for leaching consequently constituted only a natural basic level that is locally exceeded in parts with large-scale industrial industry or intensive agriculture.

It was clear that there would be a relationship between the added and the leached quantities of sulphur (ØDELIEN 1965), but it was surprising that the calculations should show the same numerical value for the fallout with pre- 
cipitation as for the leaching. How this situation changes on account of fertilizer application on cultivated soils regrettably remains outside the scope of the present work. There is probably a certain risk of leaching of all the unutilized added sulphur during the autumn and spring under Finnish conditions.

It is clear that if fertilization with sulphur merely causes an increase of leaching, such fertilization should be avoided. Where the sulphur content in the atmosphere and in precipitation and the spontaneous mobilization of sulphur in the soil are not sufficient to produce a qualitatively and quantitatively acceptable yield, fertilization with sulphur should, by contrast, be carried out. In the present study experiments were made with little success to predict by chemical analysis those cases in which fertilization with sulphur may be warranted. The risk of erroneous conclusions was great even when the most suitable method was employed, i.e. the method of extraction with acid ammonium acetate. Mineral soil in particular probably contains sulphur that is not extracted by this method but is nevertheless available to plants. A high value of analysis in extraction with ammonium acetate in any event makes it possible to assume with rather high reliability that an increment of sulphur is superfluous. It is more difficult to interpret the significance of low values.

A clue to why this should be so was provided by extraction with more effective solvents. In a comparison with results obtained elsewhere by the same methods (KESSEN et al. 1962, COOPER 1968) it proved that cultivated soils in Finland contain somewhat more firmly bound sulphur over a relatively large extent. This state of things was assumed to be the result of the generally rather high content of organic matter in Finnish soils.

To indicate the ratio in which various nutrients should be added in each separate case in order that optimum biological results might be achieved with minimum input would require a very thorough study of the needs of the respective plant and the characteristics of the soil. Special attention was paid to the ratio between added sulphur and added nitrogen. In artificial substrates the proper ratio between these two nutrients can be determined to some extent with the aid of the analysis of a well-developed plant material, but in natural conditions, account must also be taken of differences in the rate of mobilization, the propensity of fixation, the evaporation and the leaching of sulphur and nitrogen.

Although symptoms of sulphur deficiency in greenhouse conditions may easily emerge when fertilization is unsatisfactory, the field experiments showed that the supply of sulphur on cultivated soils in southern Finland is probably satisfactory in general. The sulphur effect recorded on the Carex peat soils in the region of Kuusamo in North Finland was, by contrast, probably one of the most distinct ever observed in field conditions. The great need for sulphur is explicable in the sense that the region lacks sources of emission of sulphur dioxide, and that there have been many years of heavy application of NPK fertilizers perfectly free of sulphur. 


\section{Summary}

A number of chemical methods for the analysis of the sulphur content of plant and soil samples and of extracts thereof were examined in the present study. A method for the determination of the total sulphur of plant and soil material was worked out, being based upon the combustion of the samples in a Leco induction furnace and upon turbidimetric analysis of the quantity of sulphate sulphur in the combustion gas. The great difficulties with the analysis of soil extracts were demonstrated, and the value of the information obtained through such determination was shown to be questionable in respect of one of the methods (precipitation with barium chromate). A new procedure of analysis was proposed for sulphur determination in ammonium acetate extract ( $\mathrm{pH} 4.65)$, the interference of the organic matter being reduced by oxidation of the extract with $\mathrm{H}_{2} \mathrm{O}_{2}$.

The sulphur balance of the cultivated soils in Finland was investigated on the basis of the increment in sulphur received by the soil through the atmosphere and through measures of cultivation, and of the loss in sulphur occurring through leaching and through overflow into the watercourses and the uptake by plants. The amount of sulphur falling out with precipitation, as well as the amount of sulphur washed off into the watercourses, seemed to average about $8 \mathrm{~kg}$ per hectare per annum. During the $1970-71$ fertilization period the sulphur of the fertilizers distributed over the field acreage is reckoned to have amounted to $12 \mathrm{~kg}$ per hectare, which is adequate for a cereal crop but not for crops possessing higher sulphur requirements than those of cereals.

A preliminary survey of the sulphur reserves of the cultivated soils in Finland and of the availability of the soil sulphur to the plants was carried out through the analysis of a set of soil samples and plant experiments on those soils. The series composes a sparse network covering the land south of the line running from Qulu to Kuusamo, there being 104 samples including 62 of surface soil and 42 of subsoil.

The 21 mould and peat soils of the series of samples contained an average of $1180 \pm 220 \mathrm{mg}$ of $\mathrm{S}$ per $\mathrm{kg}$ of air-dried soil $\left(\mathrm{t}_{0.05}\right)$, the 22 clay soils $450 \pm$ 94 , the 18 silt and loam soils $410 \pm 100$, and the 42 finesand and sand soils $310 \pm 43$. The subsoil samples of the mineral soils contained some 30 per cent less sulphur than the surface soils on average.

The total sulphur content of the sample soils correlated rather closely with the content of organic carbon $\left(\mathrm{r}=0.83^{* * *}\right)$. For sulphur extracted through treatment with $1 \% \mathrm{NaCl}, 0.03 \mathrm{M} \mathrm{NaH}_{2} \mathrm{PO}_{4}-2 \mathrm{~N} \mathrm{CH}_{3} \mathrm{COOH}$ and a solution 
of $\mathrm{CH}_{3} \mathrm{COONH}_{4}-\mathrm{CH}_{3} \mathrm{COOH}$ with a $\mathrm{pH}$ of 4.65 there were no close correlations with the criteria determined for the general characteristics of the soil $\left(\mathrm{pH}_{\mathrm{CaCl}_{2}}\right.$, org. C and texture).

Of the various methods of extraction, that with acid ammonium acetate gave the lowest values also when the bulk density is taken into account, while the two other methods gave results of a roughly equal order of magnitude. None of the methods of extraction could provide a satisfactory explanation of the effect of fertilization with sulphur in the pot experiments. The determination of sulphur soluble in $\mathrm{NH}_{4}$-acetate, however, did provide some information about the sulphur situation of the soil samples. An important advantage with this method seems to consist in the use of a volume-based extraction ratio, which gives comparable values for mineral and for mould and peat soils.

In field experiments with ley dominated by timothy on peat soil in the Kuusamo region of North Finland, fertilization with sulphur in the summer of 1969 produced a relatively distinct positive result in respect both of ley yield and of sulphur content of yield. A dosage of sulphur of $10 \mathrm{~kg}$ of S per hectare was enough to raise the yield of ley to a relatively high level, and further increment of the dosage had an effect almost exclusively upon the sulphur content of the crop alone. In South Finland field experiments with spring cereal in 1970 showed that the amount of yield was not affected by supplementary fertilization with sulphur.

With a view to the planning of the composition of fertilizers, an investigation by means of pot experiments was made of the relationships between sulphur on the one hand and nitrogen, phosphorus and molybdenum on the other. In order to produce an optimum yield it seems that sulphur and nitrogen had to be available in a certain ratio which would apparently lie between the limits $\mathrm{N} / \mathrm{S}=5-20$ for barley. With a concurrent shortage of these two nutrients in rape, nitrogen primarily restricted the vegetative development and sulphur the seed formation. No definite relationship could be demonstrated between phosphorus and sulphur in these experiments, while fertilization with molybdenum under conditions of sulphur shortage led to a sharp increase in the molybdenum content of the plant material. 


\section{REFERENCES}

Alway, F, J. 1940. A nutrient element slighted in agricultural research. J. Amer. Soc.Agron. 32: $913-921$.

Alway, F. J., Marsh, A. W. \& Methley, W. J. 1937. Sufficiency of atmospheric sulfur for maximum crop yields. Soil Sci. Soc. Amer. Proc. 2: 229-238.

Ames, J. W. \& Boltz, G. E. 1919. Effect of sulfofication and nitrification on potassium and other soil constituents. Soil Sci. 7: 183-195.

Aylmore, L. A. G., Karim, M. \& QUirk, J. P. 1967. Adsorption and desorption of sulfate ions by soil constituents. Soil Sci. 103: 10-15.

Bardsley, C. E. \& Lancaster, J. D. 1960. Determination of reserve sulfur and soluble sulfates in soils. Soil Sci. Soc. Amer. Proc. 24: 265-268.

Barrow, N. J. 1968. Determination of elemental sulphur in soils. J. Sci. Fd Agr. 19: 454-456.

- 1970 a. Comparison of the adsorption of molybdate, sulfate and phosphate by soils. Soil Sci. 109: 282-288.

- 1970 b. Note on incomplete extraction of elemental sulphur from wet soil by chloroform. J. Sci. Fd Agr. 21: 439.

BEATon, J. D. 1966. Sulfur requirements of cereals, tree fruits, vegetables, and other crops. Soil Sci. 101: 267-282.

Beaton, J. D., Burns, G. R. \& Platou, J. 1968. Determination of sulphur in soils and plant material. Sulphur Inst. Techn. Bull. 14: 1-56.

Bogdanov, S. 1899. On the sulphur in plants. Zhur. Russ. Fiz. Khim. Obshch. 31: 471. Abs. Bibliography of the literature on the minor elements and their relation to plant and animal nutrition. 4th ed. 1948. New York 1037 p. Vol. 1: 871-872.

Bremner, J. M. \& Shaw, K. 1958. Denitrification in soil: I. Methods of investigation. J. Agric. Sci. 51: 22-39.

Buchner, A. 1958. Die Schwefelversorgung der westdeutschen Landwirtschaft. Landw. Forsch. 11: $79-92$.

Byrne, E. \& HANLEY, P. K. 1970. A comparison of methods for predicting sulphur deficiencies and uptake from Irish soils. pp. 88-106 in Sulphur. in agriculture. Dublin 226 p.

Cantino, E. C. 1946. Titrimetric determination of sulfate in natural waters and soil extracts. Soil Sci. $61: 361-368$.

Chang, M. L. \& Тномas, G. W. 1963. A suggested mechanism for sulfate adsorption by soils. Soil Sci. Soc. Amer. Proc. 27: 281-283.

Chao, T. T., HARWARD, M. E. \& FANG, S. C. 1964. Iron and aluminum coatings in relation to sulfate adsorption characteristics of soils. Soil Sci. Soc. Amer. Proc. 28: 632-635.

Chapman, H. D. 1936. Effect of nitrogenous fertilizers, organic matter, sulfur, and colloidal silica on the availability of phosphorus in calcareous soils. J. Amer. Soc. Agron. 28: $135-145$.

Chesnin, L. \& Yien, C. H. 1951. Turbidimetric determination of available sulfates. Soil Sci. Soc. Amer. Proc. 15: 149-151.

Coleman, R. 1966. The importance of sulfur as a plant nutrient in world crop production. Soil Sci. 101: $230-239$.

COOPER, M. 1968. A comparison of five methods for determining the sulphur status of New Zealand soils. 9th Int. Congr. Soil Sci. Trans. 2: 263-271. 
Cormis, L. DE, 1968. Ann. Physiol. Veg. Paris 10: 99-112. Abs. Sulphur adsorption by plants in an atmosphere containing sulphur dioxide. Soils \& Fert. 32: 3019.

Daiкuнara, G. 1907. Are soils containing less than $0.02 \% \mathrm{SO}_{3}$ benefited by special manuring with sulphates? Bull. Imp. Cent. Agr. Exp. Sta. Japan 1, 2: 135-143.

Dodgson, K. S. 1961. Determination of inorganic sulphate in studies on the enzymic and nonenzymic hydrolysis of carbohydrate and other sulphate esters. Biochem. J. 78: 312-319.

Duley, F. L. 1916. The relation of sulphur to soil productivity. J. Amer. Soc. Agron. 8: 154160. Abs. Bibliography of the literature on the minor elements and their relation to plant and animal nutrition. 4th ed. 1948. New York 1037 p. Vol 1: 879.

Duncan, D. B. 1955. Multiple range and multiple F tests. Biometrics 11: 1-42.

Elonen, P. 1971. Particle-size analysis of soil. Acta Agr. Fenn. 122: 1-122.

Ensminger, L. E. 1954. Some factors affecting the adsorption of sulfate by Alabama soils. Soil Sci. Soc. Amer. Proc. 18: 259-264.

EPPENDORFER, W. 1969. The effects of nitrogen and sulphur on dry matter yields of barley plants, on total-N and -S concentrations in grain and straw, and on cystine and methionine contents of grain. Roy. Vet. Agric. Univ. Yearbook 1969: 100-116.

Erdman, L. W. 1922. The sulfur content of rainwater. Soil Sci. 14: 363-367.

ERviö, R. 1971. Volymviktens inverkan på markkarteringsvärden. Nord. Jordbr. Forskn. 53: 216-218.

FAller, N. 1971 a. Effects of atmospheric $\mathrm{SO}_{2}$ on plants. Sulphur Inst. J. 6, 4: 5-7.

- 1971 b. Plant nutrient sulphur $-\mathrm{SO}_{2}$ vs. $\mathrm{SO}_{4}$. Sulphur Inst. J. 7, 2: 5-6.

Finnnetro, F. 1912. Bol. Quind. Sox. Agr. Ital. 17: 425-429. Abs. Study of sulphur as a fertilizer. Bibliography of the literature on minor elements and their relation to plant and animal nutrition. 4th ed. 1948. New York 1037 p. Vol 1: 882-883.

Freney, J. R. 1958. Determination of water-soluble sulfate in soils. Soil Sci. 86: 241-244.

- 1961. Some observations on the nature of organic sulphur compounds in soil. Austr. J. Agric. Res. 12: 424-432.

- Barrow, N. J. \& Spencer, K. 1962. A review of certain aspects of sulphur as a soil constituent and plant nutrient. Plant \& Soil 17: 295-308.

- Melville, G. E. \& Williams, C. H. 1970. The determination of carbon bonded sulfur in soil. Soil Sci. 109: 310-318.

Graham, E. R. 1948. Determination of soil organic matter by means of a photoelectric colorimeter. Soil Sci. 65: $181-183$.

GuptA, U. C. 1969. $\mathrm{S} \times$ Mo interaction in plant nutrition. Sulphur Inst. J. 5, 1: 4-6.

- \& CutCliffe, J. A. 1968. Influence of phosphorus on molybdenum content of Brussels sprouts under field and greenhouse conditions and on recovery of added molybdenum in soil. Can. J. Soil Sci. 48: 117-123.

Harward, M. E. \& Reisenauer, H. M. 1966. Reactions and movement of inorganic soil sulfur. Soil Sci. 101: $326-335$.

Herath, H. M. W. \& Ormrod, D. P. 1971. Temperature effects on the response to sulphur of barley, peas and rape. Plant. \& Soil 35: 635-646.

Hirst, C. T. \& Greaves, J. E. 1922. Factors influencing the determination of sulfates in soil. Soil Sci. 13: $231-249$.

HoGg, D. E. 1966. Studies on leaching losses of sulphur from pumice soils, yellow brown sands and loams. Proc. N. Z. Grassl. Ass, 1965: 123-128. Abs. Soils \& Fert. 29: 3403.

Honcamp, F. 1931. Düngung und Düngemittel. pp. 1-44 in Handbuch der Pflanzenernährung und Düngerlehre. II. Düngemittel und Düngung. Berlin 919 p.

ЈалккоцA, A. 1972. Availability to plants of molybdenum in Finnish mineral soils. Acta Agr. Fenn. 126: $1-92$.

JAckson, M. L. 1956. Soil chemical analysis - advanced course. Madison 991 p.

JENSEN, J. 1963. Some investigations on plant uptake of sulfur. Soil Sci. 95: 63-68.

- 1964. Investigations concerning sulfur in Danish soils. 8th Int. Congr. Soil Sci. Trans. 4: $411-417$.

JонаNsson, O. 1959. On sulfur problems in Swedish agriculture. Ann. Agr. Coll. Sweden 25: $57-169$.

- 1969. Aktuellt om svavel som växtnäringsämne. Rapp. Avd. Växtnäringslära 8. 
Johnson, E. M. 1925. Analyses of rainfall from a protected and an exposed gage for sulfur, nitrate nitrogen, and ammonia. J. Amer. Soc. Agron. 17: 589-591.

Johnson, C. M. \& ARKLEY, T. H. 1954. Determination of molybdenum in plant tissue. Anal. Chem. 26: 572-574.

Johnson, C. M. \& Nishita, H. 1952. Microestimation of sulfur in plant materials, soils, and irrigation waters. Anal. Chem. 24: 736-742.

Jones, L. H. P., Cowling, D. W. \& Lockyer, D. R. 1972. Plant-available and extractable sulfur in some soils of England and Wales. Soil Sci. 114: 104-114.

KACAR, B. \& AKGÜL, M. E. 1967. Influence of heavy dressing of sulfur on the availability of soil phosphorus in an alkaline calcareous soil. Yb. Fac. Agric. Univ. Ankara 1966: 33-41. Abs. Soils \& Fert. 31: 840.

KanlA, A. 1963. Phosphorus conditions at various depths in some mineral soils. J. Scient. Agric. Soc. Finl. 35: 69-79.

Kilmer, V. J. \& NeArpass, D. C. 1960. The determination of available sulfur in soils. Soil Sci. Soc. Amer. Proc. 24: $337-340$.

KolthofF, I. M. \& SANDELl, E. B. 1950. Textbook of quantitative inorganic analysis. London $794 \mathrm{p}$.

Koyama, T. \& Tomino, T. 1970. Influence of sea salts on the soil metabolism (I). On the behaviour of iron, manganese, ammonium, and carbohydrates in waterlogged soils. Soil Sci. \& Plant Nutr. 16: 69-80.

LAAKSONEN, R. 1969. Vesistöjen veden laadusta vuosina 1962-1968. Vesiensuojelutoimiston tiedonantoja 47: 1-512 + Appendixes.

- 1970. Vesistöjen veden laatu. Summary: Water quality in the water systems. Soil and Hydrotechn. Inv, 17: 1-132.

Lavkulich, L. M., Dairon, P. A. \& Spindler, B. von, 1970. Determination of carbon and sulfur in soil extracts by dry combustion using a high temperature induction furnace. Can. J. Soil Sci. 50: 95-96.

LIEBIG, J. von, 1862. Die Chemie in ihrer Anwendung auf Agricultur und Physiologie. 7th ed. Braunschweig I part 469 p.

Lipman, J. G., McLean, H. C. \& Lint, H. C. 1916. The oxidation of sulfur in soils as a means of increasing the availability of mineral phosphates. Soil Sci. 1: 533-539.

LowE, L. E. 1964. An approach to the study of the sulphur status of soils and its application to selected Quebec soils. Can. J. Soil Sci. 44: 176-179.

- 1965. Sulphur fractions of selected Alberta soil profiles of the chernozemic and podzolic orders. Can. J. Soil Sci. 45: 297-303.

Lyon, T. L. \& Bizzell, J. A. 1918. Records for tanks 1 to 12 during the years 1910 to 1914, inclusive. Cornell Univ. Agric. Exp. Sta. Mem. 12: 1-115.

- 1936. Lysimeter experiments. - IV, Records for tanks 17 to 20 during the years 1922 to 1933 and for tanks 13 to 16 during the years 1913 to 1928. Cornell Univ. Agric. Exp. Sta. Mem. 194: 1-59.

MACK, A. R. \& SAnderson, R. B. 1971. Sensitivity of the nitrate-ion membrane electrode in various soil extracts. Can. J. Soil Sci. 51: 95-104.

Mahendrappa, M. K. 1969. Determination of nitrate nitrogen in soil extracts using a specific ion activity electrode. Soi Sci. 108: 132-136.

McClung, A. C., DeFreitas, L. M. M. \& Lotr, W. L. 1959. Analyses of several Brazilian soils in relation to plant responses to sulfur. Soil Sci. Soc. Amer. Proc. 23: 221-224.

Menary, R. C. \& Hughes, J. D. 1967. The effect of sulphate on phosphorus availability on a krasnozem soil. Austr. J. Exp. Agr. Anim. Husb. 7: 168-173.

Milton, R. F. \& Waters, W. A. 1949. Methods of quantitative micro-analysis. London 599 p.

Myers, R. J. K. \& PAUL, E. A. 1968. Nitrate ion electrode method for soil nitrate nitrogen determination. Can. J. Soil Sci. 48: 369-371.

Neller, J. R. 1959. Extractable sulfate-sulfur in soils of Florida in relation to amount of clay in the profile. Soil Sci. Soc. Amer. Proc. 23: 346-348.

Nelson, L. E. 1964. Status and transformation of sulfur in Mississippi soils. Soil Sci. 97: 300306. 
Nydahl, F. \& Gustafsson, L. A. 1953. Separation of sulphate and hydrogen sulphate ions from interfering substances by adsorption on aluminium oxide, prior to sulphate determination. Acta Chem. Scand. 7: 143-153.

O'Connor, K. F. \& VArthA, E. W. 1969. Responses of grasses to sulphur fertilisers. N. Z. J. Agric. Res. 12: 97-118.

ØDELIEN, M. 1957. Kulturvekstenes svovelforsyning. Summary: The sulphur supply of cultivated plants. Res. Norwegian Agr. 8: 377-387.

- 1965. Undersøkelser over utvaskingen av sulfat fra jorda. Summary: Investigations on the leaching of sulphate from soil. Res. Norwegian Agr. 16: 39-76.

- 1970. Kulturvekstenes svovelforsyning. En oversikt. Summary: The sulphur supply of cultivated plants. A review. Res. Norwegian Agr. 21: 1-21.

ODÉN, S. 1968. Nederbördens och luftens försurning - dess orsaker, förlopp och verkan i olika miljöer. Summary: The acidification of air and precipitation and its consequenses on the natural environment. Ecolog. Res. Comm. Bull. 1: 1-86.

ØIEN, A. \& Selmer-Olsen, A. R. 1969. Nitrate determination in soil extracts with the nitrate electrode. Analyst 94: 888-894.

OLSEN, R. A. 1957. Absorption of sulfur dioxide from the atmosphere by cotton plants. Soil Sci. 84: 107-111.

PAUl, J. L. \& CARLson, R. M. 1968. Nitrate determination in plant extracts by the nitrate electrode. J. Agr. Food Chem. 16: 766-768.

Purokosкi, P. 1958. Die schwefelhaltigen Tonsedimente in dem Flachlandgebiet von Liminka im Lichte chemischer Forschung. Agrogeol. Publ. 70: 1-88.

- 1959. Rannikkoseudun rikkipitoisista maista. Referat: Über die schwefelhaltigen Böden an der Küste Finnlands. Agrogeol. Publ. 74: 1-27.

Quinlan, K. P. \& DESEsA, M. A. 1955. Spectrophotometric determination of phosphorus as molybdovanadophosphoric acid. Anal. Chem. 27: 1626-1629.

Rankama, K. \& Sahama, T. G. 1964. Geochemistry. 5th ed. Chicago 912 p.

REHM, G. W. \& CALDwell, A. C. 1968. Sulfur supplying capacity of soils and the relationship to soil type. Soil Sci. 105: 355-361.

Reisenauer, H. M. 1963. The effect of sulfur on the absorption and utilization of molybdenum by peas. Soil Sci. Soc. Amer. Proc. 27: 553-555.

RoBerts, S. \& KoEHLER, F. E. 1968. Extractable and plant-available sulfur in representative soils of Washington. Soil Sci. 106: 53-59.

SaAlbach, E., Kessen, G. \& Judel, G. K. 1962. Untersuchungen über die Bestimmung des Gehaltes an pflanzenverfügbarem Schwefel im Boden. Landw. Forsch. 15: 6-15.

Salonen, M., Tähtinen, H., Tainio, A., Keränen, T., Barkoff, E. \& Jokinen, R. 1965. Rikkipitoisten ja rikittömien moniravinteisten lannoitteiden käyttöarvoa selvitteleviä tutkimuksia. Summary: Comparative studies on the effect of sulphur-containing and sulphur-free multi-nutrient fertilizers. Ann. Agric. Fenn. 4: 155-177.

Scotr, P. R. \& Robertson, W. C. 1926. Gypsum or copi. J. Dept. Agr. Victoria 24, 2: 6574. Abs. Bibliography of literature on the minor elements and their relation to plant and animal nutrition. 4th ed. 1948. New York 1037 p. Vol 1: 913.

SEARLE, P. L. 1968. Determination of total sulphur in soil by using high-frequency induction furnace equipment. Analyst 93: 540-545.

Serm, E. C., Caldwell, A. C. \& Rehm, G. W. 1969. Sulfur response by alfalfa (Medicago sativa L.) on a sulfur-deficient soil. Agron. J. 61: 368-371.

SHEDD, O. M. 1926. Influence of sulfur and gypsum on the solubility of potassium in soils and on the quantity of this element removed by certain plants. Soil Sci. 22: $335-354$.

SteINBergs, A. 1953. A rapid turbidimetric method for the determination of small amounts of sulphur in plant material. Analyst 78: 47-53.

SöDerbaum, H. G. 1919. Kan svavel betecknas som ett gödselmedel? K. Lantbr. Akad. Handl. Tidskr. 58: $357-363$.

Tabatabai, M. A. \& Bremner, J. M. 1970. Comparison of somé methods for determination of total sulfur in soils. Soil Sci. Soc. Amer. Proc. 34: 417-420.

TAKaI, Y. \& Asami, T. 1962. Formation of methyl mercaptan in paddy soils. I. Soil Sci. \& Plant Nutr. 8: 132-136. 
Takijima, Y., Shiojrma, M. \& Konno, K. 1962. J. Sci. Soil Tokyo 33: 331-334. Abs. Growthinhibiting substances found in poorly drained peaty paddy soils. 1. Inhibition of plant growth and soil metabolism. Soils \& Fert. 26: 2755.

TikKanen, M. H. \& YläSAARI, S. 1972. Ilman saastuminen ja atmosfäảrinen korroosio. Finnish J. Chem. Ind. 29: 118-122.

Totringham, W. E. \& Hart, E. B. 1921. Sulfur and sulfur composts in relation to plant nutrition. Soil Sci. 11: 49-73.

Vermorel, V. \& DAnthony, E. 1913. Engrais 28: 1304-1306. Abs. Sulfur and iron pyrites as fertilizers. Chem. Abs. 8 (1914): 545-546.

WiKLANDER, L. 1957. Om svavlets förekomst i marken. Nord. Jordbr. Forskn. 39: 399-406

Williams, C. H. \& Steinrergs, A. 1959. Soil sulphur fractions as chemical indices of available sulphur in some Australian soils. Austr. J. Agric. Res. 10: 340-352.

- 1964. The evaluation of plant-available sulphur in soils. II. The availability of adsorbed and insoluble sulphates. Plant \& Soil 21: 50-62.

Wrisson, B. D. 1926. Nitrogen and sulfur in rainwater in New York. J. Amer. Soc. Agron. 18: 1108-1112.

Vincent, Sarazin \& Herviaux, 1935. Le soufre dans les goémons, les vases marines et les eaux de pluie en Bretagne. Compt. Rend. Acad. Agr. France 21: 1032-1034.

VRIES, T. DE, 1968. Potentials of electrochemical reactions at $25^{\circ} \mathrm{C}$. Section D.86 in Handbook of chemistry and physics. 49th ed. 1968-1969. Ohio.

Vuorinen, J. \& MÄкıтı́, O. 1955. The method of soil testing in use in Finland. Agrogeol. Publ. 63: 1-44. 
Appendix 1. Some characteristics of the soil samples. $a=0-25 \mathrm{~cm}, \mathrm{~b}=25-50 \mathrm{~cm}$

\begin{tabular}{|c|c|c|c|c|c|c|c|}
\hline $\begin{array}{c}\text { Sample } \\
\qquad \mathrm{Nr}\end{array}$ & Soil type & $\begin{array}{c}\text { Clay } \\
\%\end{array}$ & $\begin{array}{c}\text { Organic C } \\
\%\end{array}$ & $\begin{array}{c}\text { Bulk } \\
\text { density } \\
\mathrm{kg} / \mathrm{l}\end{array}$ & $\mathrm{pH}_{\mathrm{CaCl}_{2}}$ & $\begin{array}{l}\text { Total } \\
\text { sulphur } \\
\text { mg S/kg }\end{array}$ & $\begin{array}{r}\text { Amm. ace } \\
\text { extractabl } \\
\text { sulphur } \\
\text { mg } \mathrm{S} / 1\end{array}$ \\
\hline $1 \mathrm{a}$ & finesand ............ & 4 & 2.8 & 1.02 & 5.3 & 450 & 3 \\
\hline $1 b$ & finesand .............. & 3 & 0.4 & 1.29 & 5.1 & 400 & 5 \\
\hline $2 a$ & loam ................. & 13 & 4.5 & 0.85 & 5.2 & 690 & 3 \\
\hline $2 b$ & loam ................. & 11 & 1.5 & 1.00 & 4.9 & 400 & 3 \\
\hline $3 a$ & Carex peat .......... & - & 29.1 & 0.47 & 4.5 & 1190 & 3 \\
\hline $3 b$ & Carex peat ......... & - & 36.3 & 0.51 & 3.5 & 2160 & 3 \\
\hline $4 a$ & finesand ............. & 3 & 2.0 & 1.02 & 5.0 & 180 & 2 \\
\hline $4 b$ & finesand ............. & 2 & 0.2 & 1.34 & 5.1 & 210 & 7 \\
\hline $5 a$ & finer finesand ...... & 8 & 2.3 & 0.97 & 6.4 & 320 & 3 \\
\hline $5 b$ & finer finesand ...... & 7 & 0.4 & 1.13 & 5.4 & 230 & 9 \\
\hline $6 a$ & finer finesand ..... & 13 & 2.6 & 0.85 & 5.1 & 420 & 2 \\
\hline $6 b$ & finesand ............. & 7 & 0.6 & 1.10 & 4.9 & 220 & 3 \\
\hline $7 \mathrm{a}$ & silt $\ldots \ldots \ldots \ldots \ldots \ldots$ & 28 & 3.2 & 0.98 & 4.8 & 580 & 3 \\
\hline $7 b$ & silty clay ............ & 33 & 0.6 & 1.13 & 5.4 & 120 & 2 \\
\hline $8 \mathrm{a}$ & Carex peat .......... & - & 32.6 & 0.39 & 4.5 & 530 & 2 \\
\hline $8 \mathrm{~b}$ & Carex peat ......... & - & 33.5 & 0.40 & 3.8 & 960 & 2 \\
\hline $9 \mathrm{a}$ & mould ................ & 33 & 14.2 & 0.57 & 4.5 & 700 & 20 \\
\hline $9 b$ & loam $\ldots \ldots \ldots \ldots \ldots$ & 17 & 0.5 & 1.24 & 4.7 & 120 & 7 \\
\hline $10 \mathrm{a}$ & loam .................. & 18 & 7.5 & 0.70 & 5.5 & 590 & 8 \\
\hline $10 \mathrm{~b}$ & loam …............... & 9 & 1.0 & 1.13 & 5.0 & 130 & 0 \\
\hline $11 \mathrm{a}$ & loam ................. & 14 & 3.1 & 1.14 & 4.7 & 340 & 27 \\
\hline $11 b$ & silt $\ldots \ldots \ldots \ldots \ldots \ldots . \cdots$ & 18 & 1.2 & 1.20 & 5.2 & 230 & 9 \\
\hline $12 \mathrm{a}$ & loamy clay ......... & 33 & 2.8 & 0.96 & 4.7 & 500 & 10 \\
\hline $12 \mathrm{~b}$ & loamy clay ......... & 36 & 1.7 & 0.97 & 4.7 & 460 & 23 \\
\hline $13 \mathrm{a}$ & mould ................. & 6 & 13.5 & 0.69 & 4.0 & 710 & 24 \\
\hline $13 b$ & finesand ............. & 9 & 2.1 & 1.00 & 3.8 & 700 & 57 \\
\hline $14 \mathrm{a}$ & silt $\ldots \ldots \ldots \ldots \ldots \ldots$ & 23 & 4.6 & 0.90 & 4.5 & 430 & 16 \\
\hline $14 \mathrm{~b}$ & silt $\ldots \ldots \ldots \ldots \ldots \ldots$ & 15 & 0.6 & 1.08 & 5.0 & 180 & 8 \\
\hline $15 a$ & Carex peat .......... & - & 40.3 & 0.18 & 3.5 & 850 & 3 \\
\hline $15 b$ & Carex peat ......... & - & 48.0 & 0.28 & 3.8 & 740 & 9 \\
\hline $16 \mathrm{a}$ & finer finesand ...... & 5 & 3.0 & 1.02 & 5.2 & 450 & 13 \\
\hline $16 \mathrm{~b}$ & finer finesand ..... & 3 & 0.6 & 1.30 & 5.0 & 210 & 23 \\
\hline $17 \mathrm{a}$ & finesand ............ & 6 & 4.0 & 1.02 & 4.5 & 420 & 13 \\
\hline $17 \mathrm{~b}$ & finesand .............. & 3 & 0.8 & 1.31 & 4.9 & 200 & 14 \\
\hline $18 \mathrm{a}$ & finesand ............. & 4 & 2.0 & 1.05 & 5.4 & 260 & 3 \\
\hline $18 b$ & finesand ............. & 5 & 1.3 & 1.17 & 5.4 & 140 & 6 \\
\hline $19 \mathrm{a}$ & moraine ............. & 2 & 0.8 & 1.44 & 4.9 & 140 & 41 \\
\hline $19 b$ & moraine .............. & 2 & 0.9 & 1.50 & 4.3 & 200 & 26 \\
\hline $20 \mathrm{a}$ & finesand ............. & 3 & 2.3 & 1.10 & 4.3 & 130 & 9 \\
\hline $20 \mathrm{~b}$ & finesand .............. & 2 & 1.4 & 1.34 & 4.5 & 190 & 49 \\
\hline $21 \mathrm{a}$ & silty clay $\ldots \ldots \ldots$ & 49 & 4.2 & 0.90 & 4.9 & 480 & 4 \\
\hline $21 b$ & heavy clay ........ & 67 & 2.0 & 1.04 & 5.2 & 270 & 3 \\
\hline $22 \mathrm{a}$ & finer finesand ..... & 12 & 2.6 & 1.13 & 5.1 & 380 & 3 \\
\hline $22 b$ & finer finesand & 7 & 0.5 & 1.41 & 5.4 & 160 & 1 \\
\hline $23 a$ & loamy clay ......... & 39 & 4.3 & 0.90 & 4.4 & 530 & 22 \\
\hline
\end{tabular}


Appendix 1. Some characteristics of the soil samples (continued).

\begin{tabular}{|c|c|c|c|c|c|c|c|}
\hline $\begin{array}{c}\text { Sample } \\
\mathrm{Nr}\end{array}$ & Soil type & $\begin{array}{c}\text { Clay } \\
\%\end{array}$ & $\begin{array}{c}\text { Organic C } \\
\%\end{array}$ & $\begin{array}{c}\text { Bulk } \\
\text { density } \\
\mathrm{kg} / \mathrm{l}\end{array}$ & $\mathrm{pH}_{\mathrm{CaCl}_{2}}$ & $\begin{array}{l}\text { Total } \\
\text { sulphur } \\
\text { mg S/kg }\end{array}$ & $\begin{array}{c}\text { Amm. acet. } \\
\text { extractable } \\
\text { sulphur } \\
\text { mg S/1 }\end{array}$ \\
\hline $23 b$ & loamy clay ........ & 39 & 1.8 & 1.04 & 4.1 & 790 & 180 \\
\hline $24 \mathrm{a}$ & loamy clay ........ & 50 & 3.0 & 0.96 & 5.2 & 580 & 14 \\
\hline $24 b$ & heavy clay ........ & 64 & 1.2 & 0.99 & 4.9 & 480 & 40 \\
\hline $25 a$ & loamy clay ........ & 37 & 5.0 & 0.84 & 4.5 & 410 & 13 \\
\hline $25 b$ & loamy clay ......... & 34 & 0.7 & 1.08 & 4.7 & 160 & 15 \\
\hline $26 a$ & finesand ............. & 19 & 1.9 & 1.26 & 4.8 & 320 & 4 \\
\hline $26 b$ & loamy clay ........ & 48 & 0.8 & 1.20 & 5.0 & 320 & 9 \\
\hline $27 \mathrm{a}$ & finesand ............ & 10 & 2.5 & 1.12 & 5.7 & 310 & 3 \\
\hline $27 b$ & sand $. . . . \ldots \ldots \ldots . . . . .$. & 7 & 0.5 & 1.43 & 5.4 & 270 & 5 \\
\hline $28 \mathrm{a}$ & moraine........... & 4 & 3.7 & 1.25 & 4.6 & 660 & 6 \\
\hline $28 \mathrm{~b}$ & moraine ............. & 3 & 1.2 & 1.51 & 5.0 & 460 & 19 \\
\hline $29 a$ & finesand ............ & 6 & 6.3 & 0.90 & 4.7 & 650 & 5 \\
\hline $29 b$ & finesand ............. & 3 & 0.8 & 1.52 & 5.2 & 340 & 16 \\
\hline $30 \mathrm{a}$ & mould ................ & 45 & 13.8 & 0.52 & 4.7 & 1120 & 9 \\
\hline $30 \mathrm{~b}$ & mould ................. & 59 & 12.0 & 0.53 & 5.1 & 900 & 12 \\
\hline $31 \mathrm{a}$ & finesand ............ & 8 & 3.1 & 1.02 & 5.1 & 460 & 7 \\
\hline $31 b$ & finer finesand ..... & 5 & 0.6 & 1.35 & 5.1 & 220 & 5 \\
\hline $32 \mathrm{a}$ & sand $. . . \ldots \ldots \ldots . . . . .$. & 3 & 2.0 & 1.16 & 4.6 & 280 & 3 \\
\hline $32 \mathrm{~b}$ & finesand ............ & 2 & 0.6 & 1.44 & 4.7 & 170 & 2 \\
\hline $33 \mathrm{a}$ & Carex peat .......... & - & 46.8 & 0.27 & 4.6 & 980 & 3 \\
\hline $33 b$ & Carex peat ......... & - & 44.3 & 0.20 & 3.5 & 760 & 5 \\
\hline $34 \mathrm{a}$ & loam .................. & 7 & 2.6 & 0.99 & 4.7 & 350 & 15 \\
\hline $34 \mathrm{~b}$ & loam .................. & 8 & 1.6 & 1.16 & 4.6 & 270 & 17 \\
\hline $35 \mathrm{a}$ & finesand ............. & 3 & 2.5 & 1.09 & 4.6 & 320 & 9 \\
\hline $35 b$ & finesand.......... & 2 & 1.1 & 1.54 & 5.5 & 260 & 4 \\
\hline $36 \mathrm{a}$ & silt $\ldots \ldots \ldots \ldots \ldots \ldots$ & 8 & 5.2 & 0.67 & 4.9 & 760 & 21 \\
\hline $36 \mathrm{~b}$ & 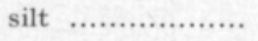 & 8 & 1.0 & 1.06 & 4.7 & 400 & 11 \\
\hline $37 a$ & Carex peat ......... & - & 39.6 & 0.38 & 5.1 & 1500 & 3 \\
\hline $37 \mathrm{~b}$ & Carex peat .......... & - & 47.1 & 0.35 & 4.3 & 1580 & 2 \\
\hline $38 \mathrm{a}$ & Carex peat ......... & - & 45.7 & 0.19 & 4.3 & 1530 & 3 \\
\hline $39 a$ & Carex peat ......... & - & 46.8 & 0.20 & 4.3 & 1620 & 3 \\
\hline $40 a$ & finer finesand ...... & 6 & 2.3 & 1.04 & 4.6 & 360 & 4 \\
\hline $40 \mathrm{~b}$ & finer finesand ..... & 6 & 1.4 & 1.16 & 4.6 & 260 & 4 \\
\hline $41 \mathrm{a}$ & finesand ............. & 3 & 2.9 & 1.14 & 4.2 & 340 & 5 \\
\hline $41 b$ & sand $\ldots \ldots \ldots \ldots . . . \cdots$ & 3 & 2.9 & 1.10 & 3.9 & 280 & 2 \\
\hline $42 \mathrm{a}$ & Carex peat ......... & - & 38.9 & 0.38 & 4.4 & 1810 & 6 \\
\hline $42 b$ & Carex peat ......... & - & 50.4 & 0.28 & 4.4 & 1960 & 2 \\
\hline $43 a$ & loam ................... & 19 & 6.1 & 0.91 & 4.9 & 750 & 250 \\
\hline $43 b$ & silt $\ldots \ldots \ldots \ldots \ldots \ldots \ldots$ & 26 & 0.7 & 1.25 & 4.1 & 500 & 210 \\
\hline $44 a$ & mould ................ & 22 & 12.8 & 0.78 & 4.7 & 580 & 11 \\
\hline $44 b$ & finesand ............. & 11 & 1.4 & 1.40 & 4.8 & 250 & 5 \\
\hline $45 a$ & Carex peat ......... & - & 39.6 & 0.34 & 4.0 & 1520 & 23 \\
\hline $46 a$ & Carex peat .......... & - & 41.1 & 0.33 & 4.5 & 1130 & 2 \\
\hline $47 a$ & loamy clay ......... & 47 & 2.0 & 1.00 & 5.7 & 320 & 3 \\
\hline $48 \mathrm{a}$ & finesand ............. & 4 & 1.5 & 1.36 & 4.9 & 230 & 1 \\
\hline
\end{tabular}


Appendix 1. Some characteristics of the soil samples (continued).

\begin{tabular}{|c|c|c|c|c|c|c|c|}
\hline $\begin{array}{c}\text { Sample } \\
\qquad \mathrm{Nr}\end{array}$ & Soil type & $\begin{array}{c}\text { Clay } \\
\%\end{array}$ & $\begin{array}{c}\text { Organic C } \\
\%\end{array}$ & $\begin{array}{c}\text { Bulk } \\
\text { density } \\
\mathrm{kg} / \mathrm{l}\end{array}$ & $\mathrm{pH}_{\mathrm{CaCl}_{2}}$ & $\begin{array}{l}\text { Total } \\
\text { sulphur } \\
\text { mg S/kg }\end{array}$ & $\begin{array}{c}\text { Amm, acet. } \\
\text { extractable } \\
\text { sulphur } \\
\text { mg } \mathrm{S} / \mathrm{l}\end{array}$ \\
\hline $49 \mathrm{a}$ & loamy clay ......... & 30 & 2.9 & 0.91 & 4.5 & 400 & 6 \\
\hline $50 \mathrm{a}$ & silty clay .......... & 41 & 2.6 & 0.90 & 4.7 & 330 & 3 \\
\hline $51 \mathrm{a}$ & loamy clay ......... & 47 & 1.9 & 1.00 & 5.7 & 310 & 5 \\
\hline $52 a$ & finesand ............. & 6 & 2.1 & 0.91 & 5.8 & 310 & 3 \\
\hline $53 a$ & silty clay ........... & 59 & 3.9 & 0.81 & 4.6 & 540 & 14 \\
\hline $54 a$ & 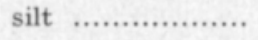 & 23 & 2.8 & 0.86 & 4.7 & 380 & 1 \\
\hline $55 \mathrm{a}$ & silty clay ........... & 50 & 3.0 & 0.98 & 5.4 & 450 & 0 \\
\hline $56 a$ & heavy clay ......... & 62 & 4.3 & 0.85 & 5.1 & 480 & 12 \\
\hline $57 a$ & silty clay .......... & 56 & 4.5 & 0.72 & 3.3 & 8200 & - \\
\hline $58 \mathrm{a}$ & loam $\ldots . . . \ldots \ldots . . . . .$. & 22 & 2.8 & 0.89 & 5.9 & 330 & 4 \\
\hline $59 a$ & finer finesand ...... & 11 & 3.1 & 0.84 & 5.7 & 360 & 3 \\
\hline $60 \mathrm{a}$ & silty clay ........... & 34 & 3.2 & 0.81 & 5.3 & 1140 & 3 \\
\hline $61 \mathrm{a}$ & loamy clay ......... & 48 & 3.4 & 0.93 & 6.0 & 430 & 3 \\
\hline $62 \mathrm{a}$ & loamy clay ......... & 34 & 3.1 & 0.96 & 5.6 & 360 & 3 \\
\hline
\end{tabular}




\title{
SELOSTUS
}

\section{Suomen viljelysmaiden rikkitila}

\author{
JOHAN KORKMAN
}

\section{Helsingin Yliopiston maanviljelyskemian laitos}

Tässä tutkimuksessa jouduttiin aluksi rikin määritystapojen joukosta valitsemaan laboratorion varustuksen ja maanäytteiden laadun mukaiset menetelmät. Kokonaisrikin määrittămiseen kehitettiin menetelmä, joka perustuu näytteen polttamiseen induktiouunissa ja sulfaattirikin turbidimetriseen mittaukseen vetyperoksidiin imeytetystä polttokaasusta. Maauutteiden analysoinnissa esille tulevat vaikeudet voitiin selvästi osoittaa. Analyysitulosten arvo näytti yleisesti käytetyn bariumkromaattimenetelmän kohdalla jopa kyseenalaiselta. Rikin määrittämiseksi ammoniumasetaattiuutteesta ( $\mathrm{pH} \mathrm{4.65)} \mathrm{on} \mathrm{esitetty} \mathrm{uusi} \mathrm{menetelmä,} \mathrm{jossa}$ eloperäisen aineksen määritystä häiritsevää vaikutusta on vähennetty käsittelemällä uutteita vetyperoksidilla.

Suomen viljelysmaitten rikkitase arvioitiin ottamalla huomioon maahan ilmakehästä ja viljelytoimenpiteiden seurauksena tuleva rikki sekä huuhtoutumisesta ja kasvien otosta aiheutuva rikin kulutus. Sateen mukana tulevan ja vesistöihin huuhtoutuvan rikin määrät näyttivät olevan samaa suuruusluokkaa eli noin $8 \mathrm{~kg} / \mathrm{ha}$ vuodessa. Lannoitusvuonna $1970-71$ levitettiin rikkiä lannoitteissa noin $12 \mathrm{~kg}$ viljeltyä hehtaaria kohti. Tämä viljasadolle riittävä määrä on ilmeisesti liian niukka paljon rikkiä vaativille kasveille.

Alustava tutkimus Suomen viljelysmaiden rikkivaroista ja niiden käyttökelpoisuudesta kasveille suoritettiin analysoimalla joukko maanäytteitä ja järjestämällä näissä maissa astia- ja kenttäkokeita. Näytteet olivat 62 kohteesta linjan Oulu-Kuusamo eteläpuolella. Näytteiden kokonaismäärä oli 104 , joista 62 pinta- ja 42 jankkonäytettä.

Näytesarjan multa- ja turvemaat $(21 \mathrm{kpl})$ sisälsivät keskimäärin $1180 \pm 220 \mathrm{mg}$ rikkiä ilmakuivaa maakiloa kohti, savimaat $(22 \mathrm{kpl}$, koska eräs sulfaattimaan näyte jätettiin tarkastelun ulkopuolelle) $450 \pm 94$, hiesu- ja hiuemaat (18 kpl) $410 \pm 100$ ja hieta- ja hiekkamaat (42 kpl) $310 \pm 43 \mathrm{mg} / \mathrm{kg}$ (vaihtelurajat ilmoitettu $95 \%$ luotettavuudella). Kivennäismaiden jankko sisälsi keskimäärin $30 \%$ vähemmän rikki kuin pintamaa.

Maanäytteiden kokonaisrikin pitoisuus oli melko hyvin korreloitunut eloperäisen aineksen pitoisuuden kanssa $\left(\mathrm{r}=0.83^{* * *}\right)$. Tutkittuihin reagensseihin $\left(1 \% \mathrm{NaCl}, 0.03 \quad \mathrm{M} \mathrm{NaH}_{2} \mathrm{PO}_{4}-2\right.$ $\mathrm{N} \mathrm{CH}_{3} \mathrm{COOH}$ ja $\mathrm{CH}_{3} \mathrm{COONH}_{4}-\mathrm{CH}_{3} \mathrm{COOH}$, pH 4.65) uuttuva rikki sen sijaan ei juuri riippunut määritetyistä maan yleisistä ominaisuuksista $\left(\mathrm{pH}_{\mathrm{CaCl}_{2}}\right.$, org.C ja tekstuuri).

Tutkituista uuttoliuoksista hapan ammoniumasetaatti uutti vähiten rikkiä myôs kun tilavuuspaino otettiin huomioon. Muut kaksi menetelmää antoivat keskenään samaa suuruusluokkaa olevia tuloksia. Mikään uuttomenetelmistä ei pystynyt antamaan selvää kuvaa siitä, miten lannoiterikki vaikuttaa kasvien kehitykseen. Ammoniumasetaattiin uuttuvan rikin määrä kuvasi kuitenkin jotenkin maan rikkitilaa. Tämän menetelmän tärkeä etu näytti olevan tilavuusyksikköön perustuva uuttosuhde, joka antoi vertailukelpoisia tuloksia niin kivennäis- kuin multa- ja turvemaistakin.

Timoteivaltaisen nurmen rikkilannoitus saraturvemailla Kuusamossa lisäsi suhteellisen 
selvästi nurmisatoa ja sen rikinottoa kesällä 1969. 10 kg rikkiä hehtaarille oli tarpeeksi nurmisadon kohottamiseksi tyydyttävälle tasolle. Vielä runsaampi rikkilannoitus aiheutti melkein yksinomaan sadon rikin pitoisuuden lisääntymisen. Etelä-Suomessa vuonna 1970 järjestetyissä kenttäkokeissa rikkilannoitus ei vaikuttanut kevätviljojen satoihin.

Lähinnä lannoitteiden koostumuksen suunnittelua ajatellen tutkittiin astiakokein toisaalta rikin toisaalta typen, fosforin ja molybdeenin vuorosuhteita. Tuntui ilmeiseltä, että määrältään ja laadultaan optimaalisen sadon saavuttamiseksi rikkiä ja typpeä täytyy olla kasvien käytettävissä tietyssä suhteessa, joka todennäköisesti on rajojen $\mathrm{N} / \mathrm{S}=5-20$ puitteissa. Kun rapsi kärsi samanaikaisesti näiden kahden ravinteen puutetta, typpi rajoitti ensisijaisesti kasvin vegetatiivista kehitystä ja rikki siementen muodostusta. Rikki ja fosfori tuntuivat vaikuttavan kasvissa toisistaan riippumatta, kun taas molybdeenilannoitus rikin niukkuuden vallitessa kohotti voimakkaasti kasviaineksen molybdeeninpitoisuutta. 